TITLE:

\title{
HARPACTICOID COPEPODS FROM THE PACIFIC ABYSSAL OFF MINDANAO. II. CERVINIIDAE (CONT.), THALESTRIDAE, AND AMEIRIDAE
}

$\operatorname{AUTHOR}(S)$ :

Ito, Tatsunori

\section{CITATION:}

Ito, Tatsunori. HARPACTICOID COPEPODS FROM THE PACIFIC ABYSSAL OFF MINDANAO. II. CERVINIIDAE (CONT.), THALESTRIDAE, AND AMEIRIDAE. PUBLICATIONS OF THE SETO MARINE BIOLOGICAL LABORATORY 1983, 28(1-4): 151-254

\section{ISSUE DATE:}

1983-03-30

URL:

http://hdl.handle.net/2433/176059

RIGHT: 


\title{
HARPACTICOID COPEPODS FROM THE PACIFIG ABYSSAL OFF MINDANAO. II. GERVINIIDAE (CONT.), THALESTRIDAE, AND AMEIRIDAE ${ }^{122}$
}

\author{
TATSUNORI ITÔ
}

Seto Marine Biological Laboratory, Kyoto University

With Text-figures $1-65$

As the second report on the abyssal harpacticoids collected in the Pacific Ocean off Mindanao, the present paper deals with the following seven genera of three families: Cervinia Norman, Eucanuella T. Scott, and Cerviniopsis Sars (Fam. Cerviniidae), Pseudotachidius T. Scott (Fam. Thalestridae), Malacopsyllus Sars, Parameiropsis Becker, and a previously unknown genus (Fam. Ameiridae).

Although the specimens reported in the previous paper (Itô, 1982) have been deposited in the Zoological Museum, Faculty of Science, Hokkaido University, specimens which are reported in the present paper are deposited tentatively in the Seto Marine Biological Laboratory, Kyoto University, until this serial taxonomic work is finished. After the completion of this work, they will be deposited permanently in the Zoological Museum of Hokkaido University. Before going further, I would like to express my sincere thanks to Dr. P.A. Montagna, University of South Carolina, for his kind comments on some relevant species.

\section{Cervinia plumosa n. sp.}

(Figs. 1-4)

Material. An adult male dissected was designated as the holotype. Type-locality: Southeast off Mindanao, the Pacific Ocean. The specimen was collected with Murano's net (6-II-1979).

Male (holotype). Body (Figs. 1-1, 1-2) $1.12 \mathrm{~mm}$ long, colorless and semitransparent. Cephalon longer than wide, tapering toward apical in dorsal aspect, forming a very prominent rostrum (Fig. 1-3) which is represented by an arched plate (see Fig. 1-4) with a pair of short sensory hairs on about mediodorsal surface and another pair of short sensory hairs near its apex (Fig. 1-5); integument with fine mesh-like texture (Fig. 1-6); posterior hyaline membrane extending over first thoracic somite (Figs. 1-3, 1-4). Pleurotergite of first thoracic somite well defined (Fig. 1-6). Second, third, and fourth thoracic somites combined shorter than cephalon, a little tapering posteriorly. Hind body somites (Figs. 1-7, 1-8, 1-9)

1) Contributions from the Seto Marine Biological Laboratory, No. 690 .

2) This study is supported in part by a Grant-in-Aid for Scientific Research from the Ministry of Education of Japan.

Publ. Seto Mar. Biol. Lab., XXVIII (1/4), 151-254, 1983. 


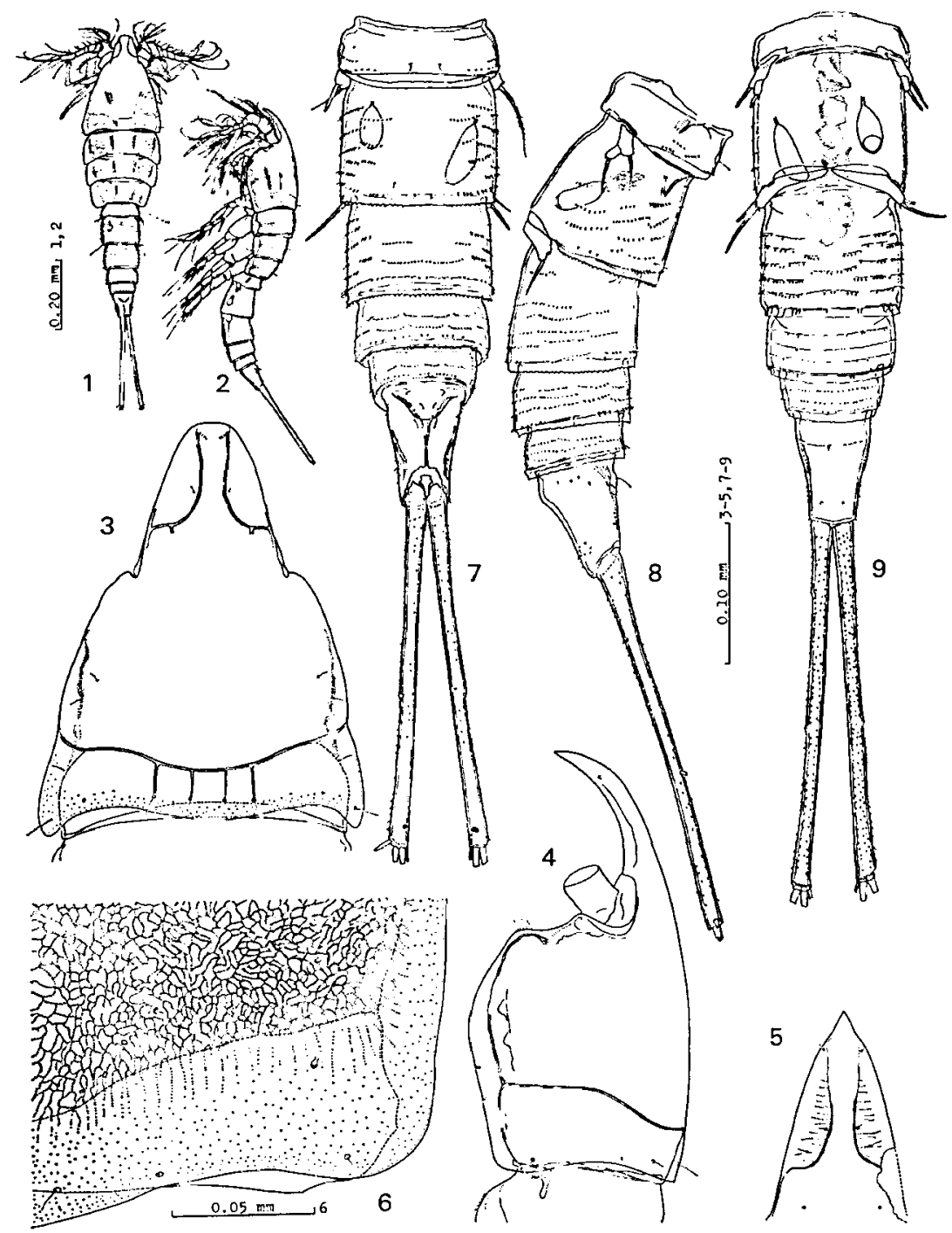

Fig. 1. Cervinia plumosa n. sp. Male (holotype): 1. habitus, dorsal; 2. habitus, lateral; 3. cephalon and first thoracic somite, dorsal; 4. cephalon and first thoracic somite, lateral; 5. rostrum; 6. cephalic integument and pleurotergite of first thoracic somite; $7 . \operatorname{leg} 5$ and abdomen, dorsal; 8. leg 5 and abdomen, lateral; 9 . leg 5 and abdomen, ventral.

narrower than fore body, tapering toward posterior especially through antepenultimate, penultimate, and anal somites, furnished with rows of very short spinules. Antepenultimate and penultimate somites short. Anal somite as long as preceding two somites combined, with a prominent anal operculum whose edge is smooth. Furcal rami basally close to each other (not fused), divergent, very much elongated; each ramus longer than the last four abdominal somites combined, furnished with numerous short spinules; all setae broken or missing. 
A n t e n n le (Fig. 2-1) eight-segmented, first four segments thicker than other segments; first segment thickening apically, somewhat protruded posteriorly, armed with a seta anteriorly; second segment furnished with long hairs on its rounded posterior edge, with many anterior and dorsal setae of different lengths; third and fourth segments protruded anteriorly, armed with two long anterior setae and one very thick anterior seta, together with small setae; fifth segment shortest, armed

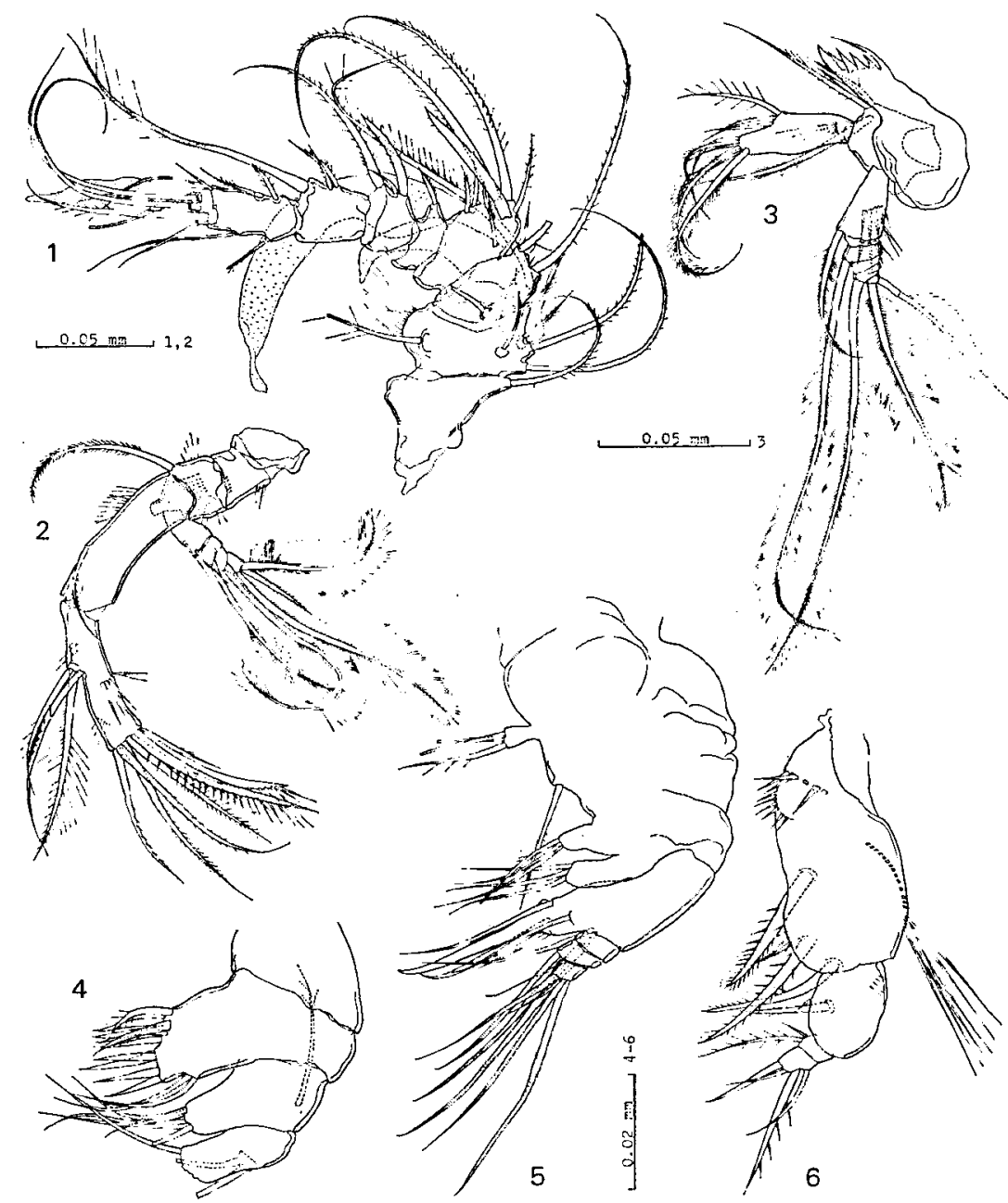

Fig. 2. Cervinia plumosa n. sp. Male (holotype): 1. antennule; 2. antenna; 3. mandible; 4. maxillula (broken); 5. maxilla; 6. maxillipede.

with a short seta on a short anterior protuberance; sixth and seventh segments armed with setae anteriorly; eighth segment with setae anteriorly, posteriorly, and apically; a prominent wide aesthetasc attached onto each of second, third, and fourth segments; most setae furnished with short spinules. A n t e n n a (Fig. 2-2). Precoxa very short, bare. Coxa as long as thick, with fine spinules posteriorly and 
inwards. Basis as long as coxa, armed with a spinulose seta on its anterior face close to apical end; a longitudinal row of hairlike spinules occurring on anterior face, and a transverse row of hairlike spinules on outer face. Exopodite foursegmented; first segment as long as three apical segments combined, armed with two setulae anteriorly; each of second an dthird segments armed with one well-developed plumose seta on anterior distal end; fourth segment armed apically with two plumose setae and one spinulose short seta. First endopodite segment clearly demarcated from basis by a suture, about 1.5 times as long as coxa and basis combined, with a longitudinal row of fine spinules on anterior face, armed with one spinulose small seta on a point at two-thirds the length of anterior face from the base. Second endopodite segment as long as first endopodite segment, with a transverse row of long spinules on about the middle of posterior face, armed with three, closely set, spinulose setae on a stepped edge at about the middle of anterior face, and seven spinulose setae, two of which are spiniform, on apical end. $\mathrm{M}$ a $\mathrm{n} \mathrm{di-}$ b le (Fig. 2-3). Inner half of precoxa slim; pars incisiva simple; four (? five) spines and a short seta attached onto oblique cutting edge. Coxa-basis as long as wide, much widening apically, armed with three closely set setae on inner distal angle and one long hairy seta near inner distal angle. Exopodite four-segmented; first segment longer than three apical segments combined, with two transverse rows of prominent spinules each on about the middle and near distal end of anterior face, armed with one hairy seta on inner distal angle; second and third segments armed with one long plumose seta on each inner distal angle; fourth segment very small, armed apically with two long plumose setae. Endopodite represented by a segment about twice as long as its greatest width, with a few hairlike spinules on anterior face near its base, armed with three closely set setae on a stepped edge located near the middle of inner edge, six hairy setae of different lengths on and near distal end. Maxillula (Fig. 2-4). The maxillula illustrated was damaged, and the counterpart was missing. Arthrite of precoxa armed with ten spines and setae along inner edge, two closely set setae on dorsal edge. Coxa armed with five setae on inner process. Epipodite represented by one slender seta. Most setae of basis were broken. Endopodite represented by a very short segment with two setae (broken). Maxilla (Fig. 2-5). Syncoxa furnished with four endites, first three widely spaced; first endite represented by a short process terminating in three setae; second endite represented by one seta; third endite represented by a short process terminating in three setae; fourth endite close to third endite, cylindrical, armed apically with three setae. Basis forming a strong claw which is accompanied with one slender spine and four setae in all; two (? three) fine setae arising from distal edge close to endopodite. Endopodite consisting of three short segments; first segment armed with one geniculate spiniform seta on anterior distal edge; second segment armed with one seta on inner distal angle, one geniculate spiniform seta on anterior distal edge; third segment armed apically with three simple setae and one geniculate spiniform seta. Maxillipede (Fig. 2-6). Coxa about twice as long as wide, furnished with two arched rows of prominent spinules near 
inner proximal edge, an almost longitudinal row of very long cirri (most of them broken) along outer margin, armed with three spinulose stout setae near inner edge, one spinulose setula occurring between the first two setae. Basis about half as long as coxa, armed with one stout short seta near the middle of inner edge, accompanied with a setula (? spinule) near its base. Endopodite represented by two small segments; first segment armed with one setula and one sparsely spinulose setae on inner edge; second segment armed with one smooth spine and one short seta terminally, one thick seta, which bears spinules sparsely, and one smooth seta on outer edge.

L e g 1 (Fig. 3). Intercoxal plate simple, with no spinule or hair. Coxa

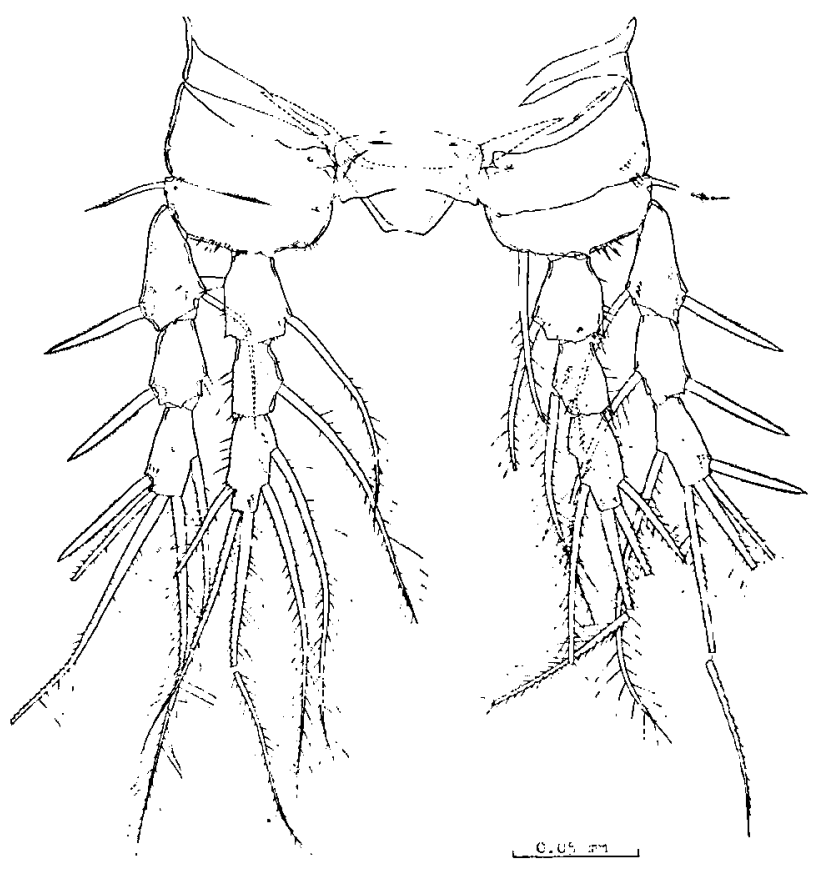

Fig. 3. Cervinia plumosa n. sp. Male (holotype): A pair of leg 1.

furnished with minute spinules near outer edge and along distal extremity of anterior face. Basis low, with several spinules near distal edge, armed with one, sparsely spinulose, stout seta, which arises from inner distal angle and reaches distal end of second endopodite segment, and one short outer seta, which bears a few spinules. Both rami subequal in length, three-segmented. Exopodite: first segment about 1.5 times as long as second segment, with a few spinules on anterior and posterior faces; each of first two segments armed with one finely spinulose outer spine and one inner seta with sparse hairs, not forming prominent projections near the base of outer spine; third segment as long as second segment, armed with one finely spinulose outer spine on a subapical stepped edge, three apical setae which bear spinules and hairs, and one hairy inner seta which arises medially. Endopodite: 
first and third segments subequal in length, a little longer than second segment; first segment a little wider than other segments, pointed at outer distal angle, armed with one inner seta on a point at two-thirds the length from the base; third segment armed with one spinulose outer spine on a stepped edge on a point at threequarters the length from the base, two setae terminally, and two spaced inner setae; all setae more or less spinulose or hairy; all segments furnished with a few slender spinules along each outer edge. L e g 2 (Fig. 4-1). Free edge of intercoxal plate slightly concaved, furnished with hairs near each lateral end. Coxa furnished with several transverse rows of short spinules on anterior face. Basis forming a small spinous projection on its distal edge between exopodite and endopodite, furnished

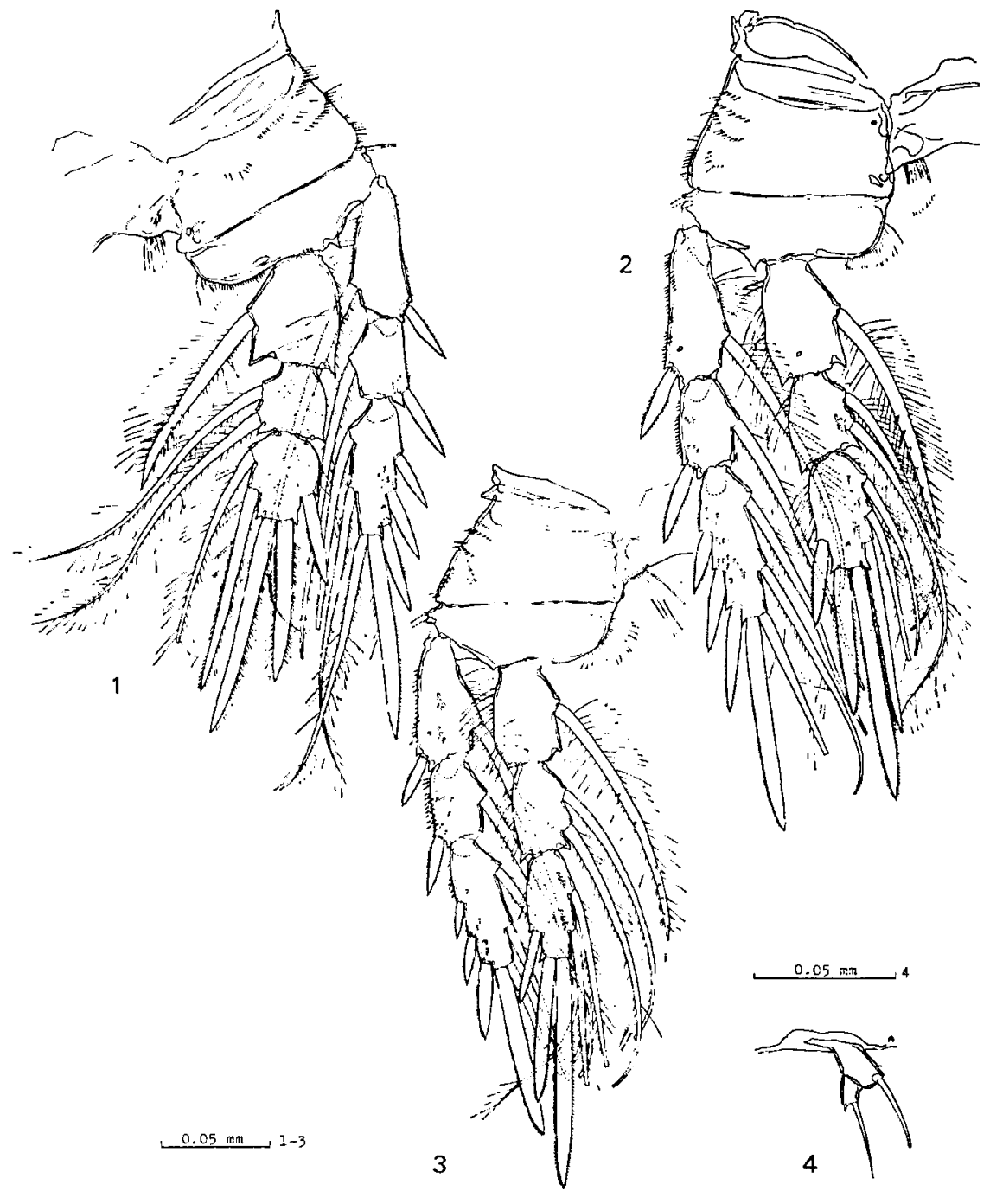

Fig. 4. Cervinia plumosa n. sp. Male (holotype): 1. $\operatorname{leg} 2$; leg 3; $3 . \operatorname{leg} 4$; 4. leg 5 . 
with hairs around inner distal angle, armed with one slender outer seta (broken). Both rami three-segmented, exopodite longer than endopodite. Exopodite: first and third segments subequal in length, about 1.5 times as long as second segment; first segment with hairs along inner edge, armed with one outer spine and one inner seta, which arises from subapical edge; second segment armed with one outer spine and one inner seta, which arises from about the middle of inner edge; third segment armed with three outer spines, two inner setae, and terminally one stout rod-shaped spine and one plumose seta; all outer spines bearing fine spinules; all inner setae long and plumose. Endopodite: first segment about 1.5 times as wide as other segments, pointed at both distal angles, armed with one strong spiniform inner seta which bears hairs and spinules; second segment shorter than first segment, a little pointed at both distal angles, armed with two plumose inner setae; third segment about 1.5 times as long as wide, armed with one outer spine which arises from a clearly stepped edge located on a point at two-thirds the length from the base, two rod-shaped spinulose spines terminally, and two inner setae, the first (proximal) plumose, the second (distal) spiniform and plumose; the second inner seta and the outer spine located at the same level; all segments bearing hairs along each outer edge. L e g 3 (Fig. 4-2). Free edge of intercoxal plate scarcely concaved, furnished with hairs. Shape and armature of coxa, basis, and exopodite as in leg 2. Endopodite: first segment scarcely wider than other segments; setal and spinal armature of first two segments as in leg 2; third segment about twice as long as wide, armed with one outer spine, which arises from a stepped edge on a point at about two-thirds the length from the base, two rod-shaped strong spines terminally, and three inner setae, of which the third (distalmost) is spiniform; the outer spine located at a level between the second and third inner setac. L eg 4 (Fig. 4-3). Intercoxal plate, coxa, basis, and exopodite almost as in leg 3. Endopodite: first two segments armed as in leg 3; third segment 2.2 times as long as wide, armed with one outer spine on a point at about two-thirds the length from the base, two rod-shaped spines terminally, and two plumose inner setae (neither rod-shaped nor spiniform). L e g 5 (Fig. 4-4). Both legs widely separated from each other, small. Baseoendopodite without inner expansion, armed with one simple outer seta. Exopodite represented by a small segment with one bare seta on outer distal edge and one rudimentary spine on inner distal edge. L e g 6 (Fig. 1-9) represented by a wide plate armed apically with two slender setae together with a spinule (? rudimentary seta).

Remarks. There is no doubt that the present new species belongs to the 'bradyi' group in the sense of Montagna (1981, p. 1212). Although the prominent rostrum of the male specimen described is very impressive, a similar feature has already been known in the males of C. bradyi Norman reported by Sars (1910) and Por (1967). It is possible that the rostrum of the present new species does exhibit a sexual dimorphism, though the rostrum of the male of C. magna Smirnov, 1946, is not particularly big (see Montagna, 1981). The present new species resembles $C$. tenuicauda 
Brotzkaja, 1963, and C. tenuiseta Brotzkaja, 1963, in having extremely elongate furcal rami which are about as long as the last four abdominal somites combined. The new species, however, differs from the latters as well as other congeneric species in the shape and armature of the mandible. In the new species, the inner half of the mandibular precoxa is clearly slenderized, and setae of the mandibular endopodite are markedly plumose (The specific name denotes this.). On the other hand, the new species has some rod-shaped spines on the exopodite and endopodite of leg 2 , leg 3 , and leg 4 . Other congeneric species so far known have not such highly developed spines on their legs, though $C$. tenuicauda seems to have at least three rodshaped spines on the endopodite of leg 2 (Brotzkaja, 1963, fig. 2).

\section{Cervinia langi Montagna}

(Figs. 5 -9)

Cervinia langi: Montagna, 1979, p. 79, figs. 2-4.

Material. An adult female was dissected. The specimen was collected with Murano's net (Southeast off Mindanao, the Pacific Ocean; 6--II-1979).

Female. Body (Figs. 5-1, 5-2) about $1.7 \mathrm{~mm}$ long, colorless and semitransparent, tapering toward posterior. Cephalon a little wider than long, forming a triangular rostrum (Fig. 5-3) which is not defined at base; posteriolateral edge of cephalic integument, in lateral view, cutting obliquely (see Fig. 5-2). Labrum (Fig. 5-4) trapezoid. First thoracic somite clearly defined from cephalon, covered with a pleurotergite which reduces in length dorsally (Fig. 5-3). Each pleurotergite of second, third, and fourth thoracic somites densely covered with very small punctures (not illustrated in Fig. 5-5: Transverse lines illustrated represent interruptions of puncture arrangement.); well-developed secretory pores present. Genital double-somite (Figs. 6-1, 6-2, 6-3) as long as succeeding three abdominal somites combined, subdivided by a suture dorsally and laterally; genital area forming a protruded part (see Fig. 6-2), furnished with a pair of widely separated leg 6, each represented by a small cylindrical segment with three apical setulae (Fig. 6-3); spinules occurring along base of posterior hyaline membrane ventrally and laterally. Antepenultimate and penultimate somites furnished with circumambient spinular rows. Anal somite almost pyriform in outline, furnished with some transverse rows of conspicuous spinules ventrally; anal operculum defined at base, its free edge semicircular. Furcal rami proximally close to each other and divergent toward distal; each ramus cylindrical, as long as last two abdominal somites combined, about eight times as long as its median diameter, ornamented with a longitudinal row of roughly arranged spinules dorsally; a setula attached onto a point at a proximal quarter of outer face; two closely set setulae on about the middle of outer dorsal face; a basally geniculate setula arising from inner dorsal face near posterior end; two principal terminal setae (broken) accompanied by a short seta on both lateral sides.

Antennule (Fig. 6-4; right antennule broken off) seven-segmented; first 


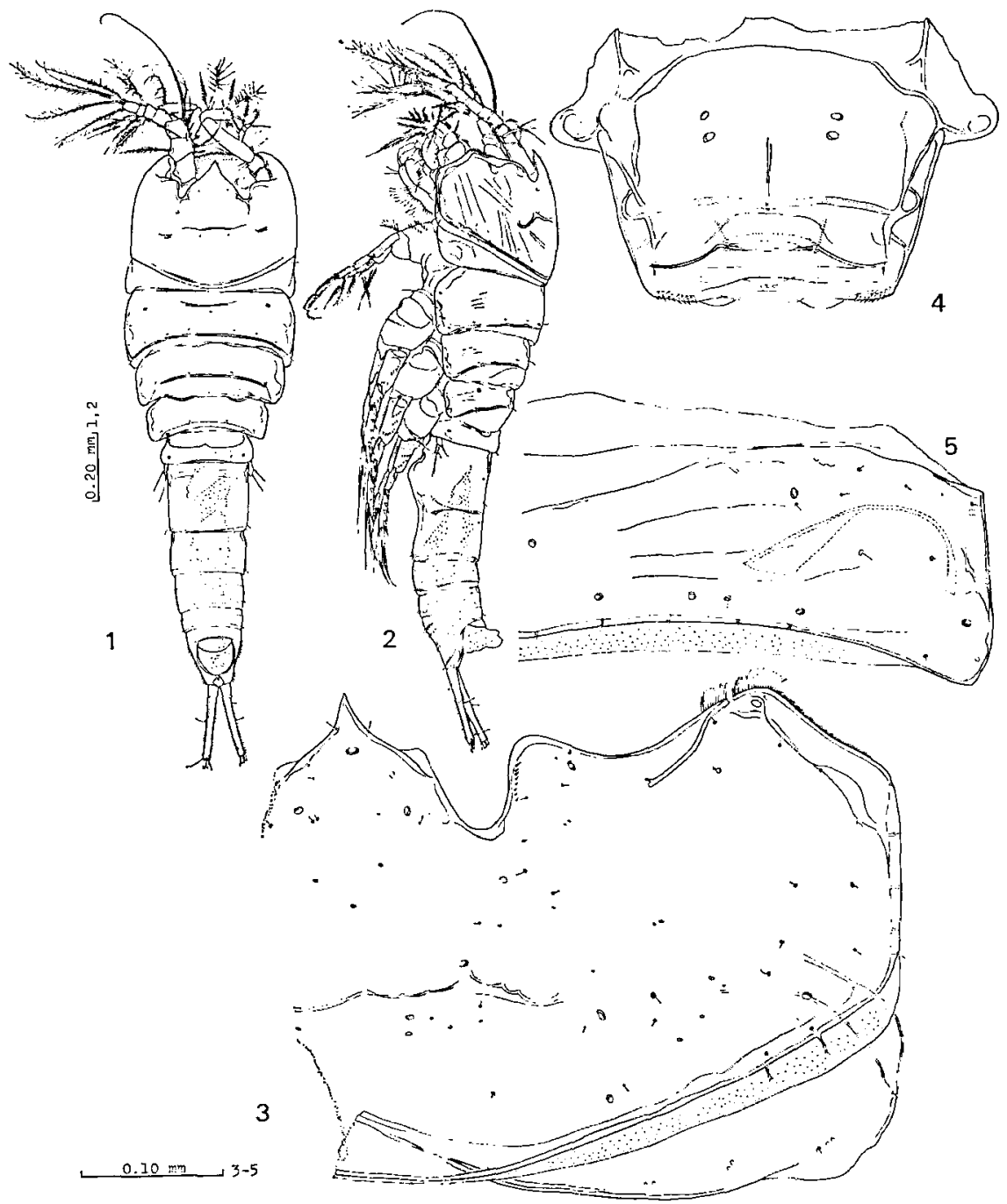

Fig. 5. Cervinia langi Montagna. Female: 1. habitus, dorsal; 2. habitus, lateral; 3. cephalic integument and pleurotergite of first thoracic somite; 4. labrum; 5. pleurotergite of second thoracic somite.

three segments thicker than other segments; first segment with a clear protuberance posteriorly; two long aesthetascs attached onto third segment; apical four segments combined as long as first two segments combined; most of anterior and apical setae long and markedly spinulose. A n t e n n a (Fig. 6-5). Precoxa defined from coxa, very short. Coxa furnished with a few spinules. Allobasis about four times as long as median diameter, armed with two very widely separate setae anteriorly; a few prominent spinules attached onto subproximal inner face (and hairlike spinules on subproximal outer face; cf. Figs. 6-5 and 6-6). Exopodite arising from a point at a proximal third of allobasis, four-segmented; first segment as long as other 


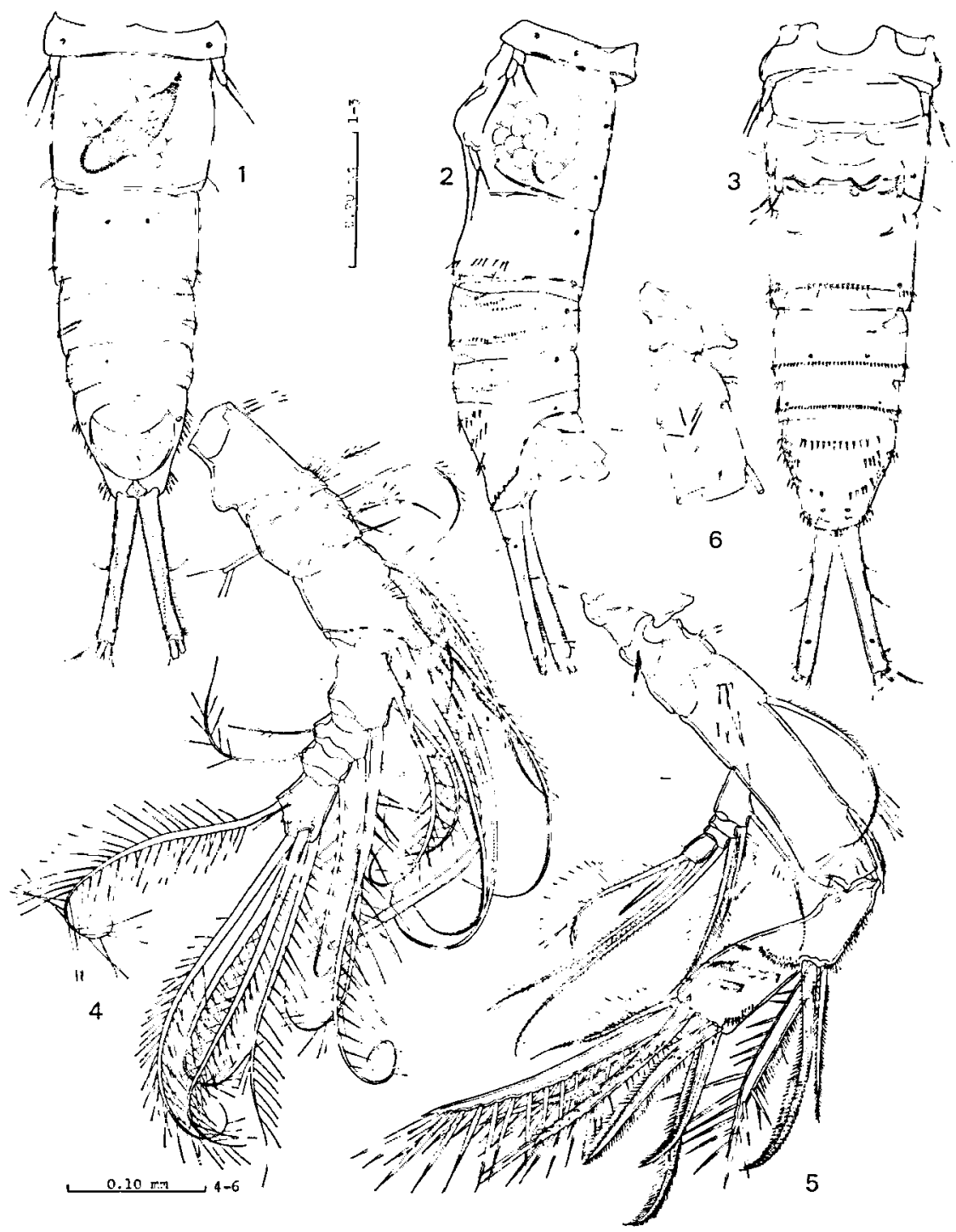

Fig. 6. Cervinia langi Montagna. Female: $1 . \operatorname{leg} 5$ and abdomen, dorsal; 2. leg 5 and abdomen, lateral; 3 . leg 5 and abdomen, ventral; 4. antennule; 5. antenna; 6. proximal part of right antenna.

three segments combined, thickening apically, armed with two bilaterally hairy setae; second and third segments short and subequal in length, each armed with a hairy long seta; third segment as long as preceding two segments combined, apically armed with two hairy long setae and a finely spinulose short seta; a transverse row of delicate spinules attached onto outer face of fourth segment near its apical end. Endopodite about 1.2 times as long as allobasis, thickening apically, with a few oblique rows of fine spinules on its distal half; three closely set setae arising from anteromedial edge, which bear spinules either sparsely or densely; apical 
end with three thick and densely spinulose setae, two spiniform setae with long spinules, and one strong spiniform seta with long spinules, which has a small basal branch with many roughly arranged hairs. Mandible (Figs. 7-1, 7-2). Precoxa well developed, sclerotized. Coxa-basis as long as wide, armed with four

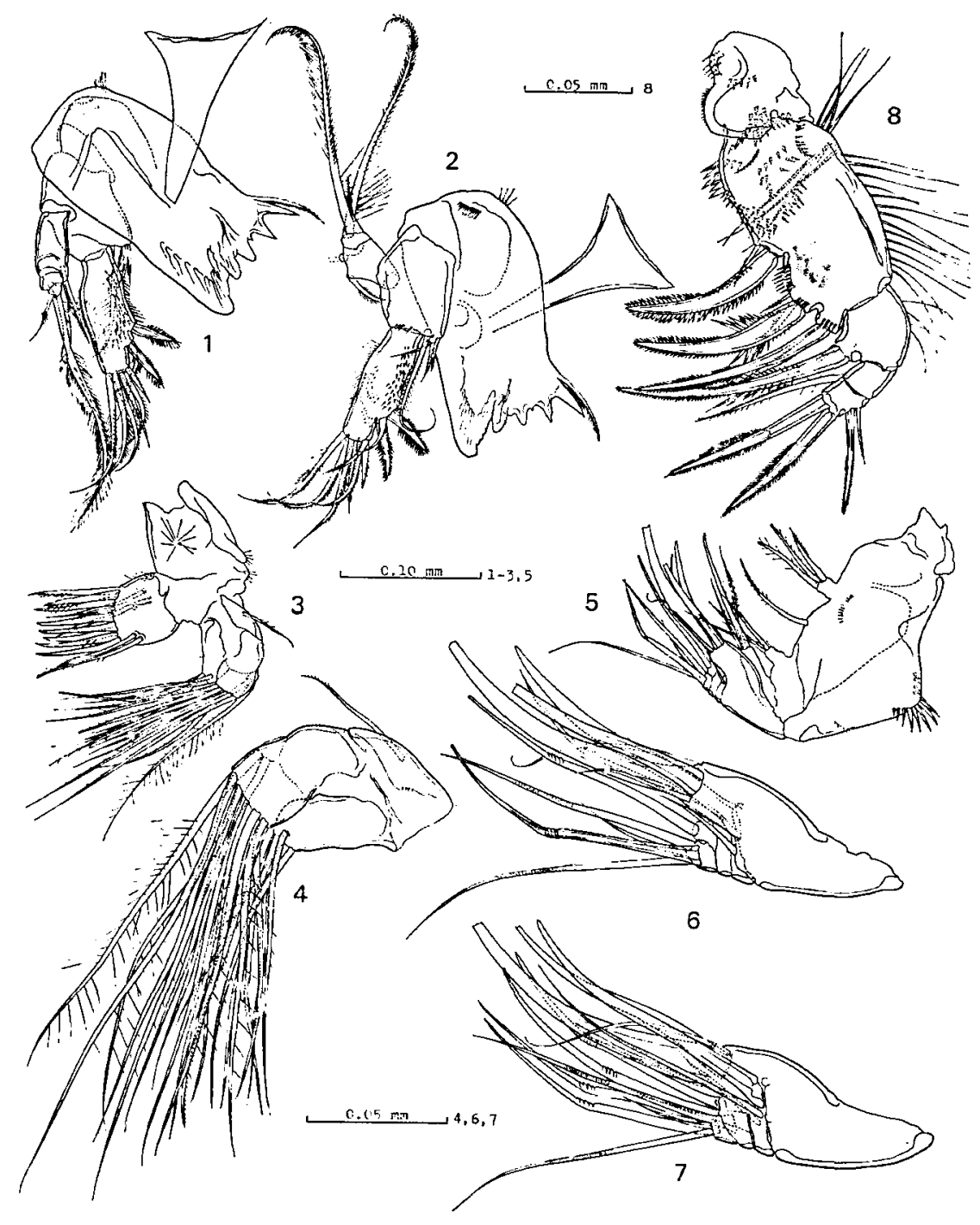

Fig. 7. Cervinia langi Montagna. Female: 1, mandible; 2. mandible; 3. maxillula; 4. maxillula (precoxa omitted); 5. maxilla; 6. left maxilla (syncoxa omitted); 7. right maxilla (syncoxa omitted); 8. maxillipede.

apical setae, three of which are small. Exopodite cylindrical, three-segmented; first segment with a transverse (not circumambient) suture near distal end, armed with two setae on inner edge; second segment short, armed with one inner seta 
which is long and spinulose; third segment small, armed with two closely set apical setae, one of which is long, about three times as long as three exopodite segments combined, and the other is very small. Endopodite composed of one segment, a little longer than exopodite segments combined, about three times as long as wide, armed with one spinulose spine on a stepped inner edge on a point at two-thirds the length from the base, one spinulose spine and one short seta on a stepped inner edge located subapically, and seven more or less spinulose setae on apical edge. Maxillula (Figs. 7-3, 7-4). Arthrite of precoxa as long as wide, armed with nine (?) spines and setae along inner edge, two parallel slender setae on anterior face near ventral inner corner, and two setae on posterior face of its dorsal half. Epipodite represented by a seta which arises from the middle of outer edge of coxa. Coxal inner process short, directed toward rather ventral (not toward inner), armed with six (?) apical setae. Basis armed with 12 (?) apical setae. Endopodite represented by a small segment, armed apically with two sparsely plumose setae. $\mathrm{Maxilla}$ (Figs. 7-5, 7-6, 7-7). Syncoxa furnished with a row of prominent spinules on its protruded outer edge, armed with four endites, the first three spaced widely; first endite represented by a short process with three apical setae, one of which is rather spiniform and densely spinulose, the other two bear spinules sparsely; second endite represented by a single seta; third endite represented by a short process with three apical setae; fourth endite represented by a well-developed process, apically armed with one spine and two setae. Basis forming a thick inner process terminating in a strong claw, which is accompanied by a spine and a seta close to its anterior base and a slender seta near its dorsal base; a strong spine and a slender seta attached onto posterior face of inner process near base of endopodite; a small seta arising from anterior distal edge. Endopodite (Endopodal armature of the left maxilla seems incomplete: see Fig. 7-7) consisting of three short segments; first segment armed with a geniculate spiniform seta on inner edge; second segment a little protruded inwards, armed with two geniculate spiniform setae, one located anteriorly, the other located on inner distal edge; third segment very small, armed with two simple apical setae, one of which is fine and short, and a geniculate spiniform seta on subapical anterior face. Maxillipede (Fig. 7-8). Precoxa as long as wide, with short spinules on posterior face and inner edge. Coxa twice as long as wide, furnished with many spinules on posterior face and inner edge, and long hairs along outer edge; three sets of appendices attached onto inner edge of its distal half, the first consisting of one strong bilaterally spinulose spine and one small seta, the second consisting of one strong spine, which resembles the former, and two small setae, and the third arising from a short process, consisting of one long bilaterally spinulose spine and one seta. Basis curving toward inner, as long as wide, armed with one long bilaterally spinulose spine and a small seta on inner distal angle; a few long hairs along outer edge. Endopodite markedly narrower than basis, consisting of two short segments; first segment armed with one finely spinulose seta on inner edge near distal end; second segment armed with two strong apical spines which are densely fringed with fine spinules bilaterally, 
and two finely spinulose setae on outer edge.

L e g 1 (Fig. 8-1). Free edge of intercoxal plate forming a pair of round protuberances, each bearing five prominent spinules marginally. Coxa very wide, furnished with some arched rows of spinules on anterior and posterior surfaces; outer edge much inclining. Basis very low, about four times as wide as long, with no spiniform projection on distal edge between exopodite and endopodite; outer seta a little shorter than first exopodite segment, fringed with long hairs bilaterally;

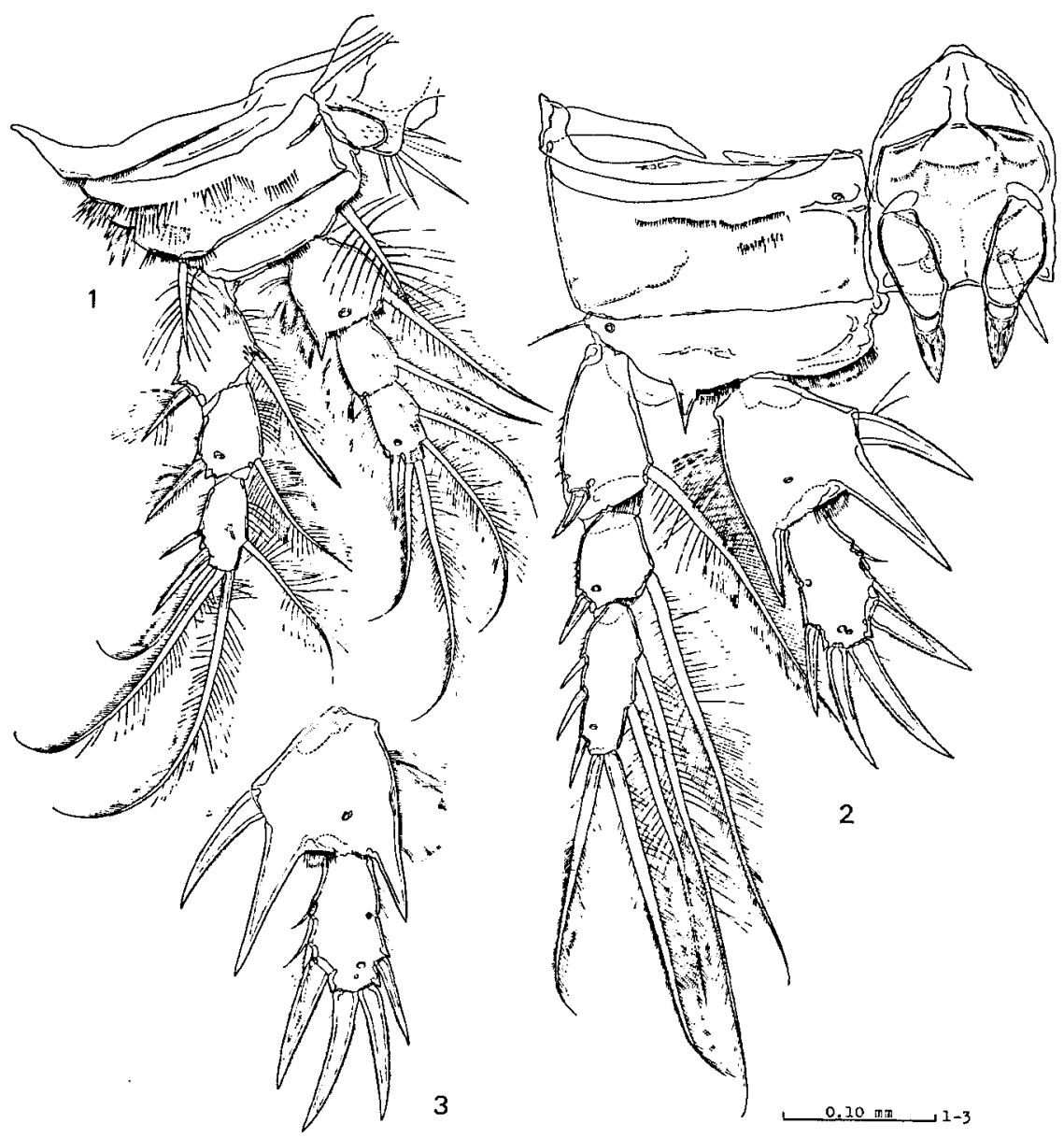

Fig. 8. Cervinia langi Montagna. Female: 1. $\operatorname{leg} 1 ; 2 . \operatorname{leg} 2 ; 3$. endopodite of left leg 2.

inner seta similar to outer seta, longer than first endopodite segment; a row of short spinules attached onto distal edge near base of inner seta and near base of endopodite. Both rami three-segmented. Exopodite: first segment about 1.5 times as long as second segment, second and third segments subequal in length; first segment armed with one outer spine, which is fringed with long spinules, and one stout inner seta, which bears hairs on its proximal half and very fine spinules along its 
distal half; second segment with a secretory pore on its anterior face near outer distal angle, armed with one spinulose outer spine and one plumose inner seta; third segment with a secretory pore on its posterior face, armed with three setae, of which the first two are short and rather spiniform, along distal half of its inner edge, two long terminal setae, and one plumose inner seta which arises from a point at two-thirds the length from the base of inner edge, the third (distalmost) outer seta and the terminal setae fringed with spinules along outer edge and with hairs along inner edge. Endopodite shorter than exopodite, three-segmented; first segment longer and wider than other segments, forming a spinous projection at outer distal angle, with a prominent secretory pore on its anterior face near the middle of distal edge, armed with one thick seta near inner distal angle; second segment with two short rows of spinules on its posterior face, armed with one thick inner seta; third segment with a secretory pore on its anterior face, three short rows of spinules on posterior face, armed with one spinulose outer spine subapically, two terminal setae, which bear spinules outwards and hairs inwards, and two inner setae; outer edge of each segment densely fringed with long hairs. L e g 2 (Fig. 8-2) markedly bigger than leg 1. Intercoxal plate armed with a pair of strong horny structures on its anterior face, and with a pair of stout spines (the right broken) on posterior face. Coxa with a long transverse row of spinules and a short row of roughly arranged spinules on its anterior face; a fine hair (? sensory hair) attached onto posterior face near outer distal angle; outer edge with no spinule. Basis forming a prominent triangular projection between exopodite and endopodite; outer seta small, hairy; inner half of free edge densely fringed with spinules; a secretory pore occurring on anterior face near outer edge. Exopodite three-segmented; first segment about twice as long as second segment, with no spinous projection on outer edge, armed with a short outer spine which arises from anterior face near outer distal angle, and one plumose inner seta; second segment armed with one short outer spine and one plumose inner seta; a secretory pore occurring on anterior face near each outer spine of first two segments; third segment about 1.5 times as long as second segment, armed with three short outer spines which are subequal in length, two thick terminal setae which bear fine spinules outwards and hairs inwards, and two long plumose inner setae. Endopodite two-segmented; first segment much wider than second segment, forming a very strong spinous projection at each of inner and outer distal angles, the outer projection reaching the middle of second segment, the inner projection longer than the outer; first segment armed with a short thick spine on its inner edge, a secretory pore on anterior surface, and densely fringed with long hairs along outer edge; second segment not forming a spinous projection at inner distal angle, with two close secretory pores on subapical anterior face, armed with one outer spine on a stepped edge on a point at three-quarters the length from the base, two strong terminal spines, three small setae along inner edge, and one strong spine on subapical inner edge; outer rim of second segment interrupted by a notch accompanied by a secretory pore almost medially (see also Fig. 8-3). L e g 3 (Fig. 9-1). Intercoxal plate wider than long, armed with a 
pair of strong horny structures on posterior face, a pair of simple spines on free edge. Coxa with two sensory hairs on anterior face, one sensory hair on posterior face near outer edge. Basis forming a spinous projection on free edge between exopodite and endopodite; stout spinules attached onto inner distal edge; outer seta

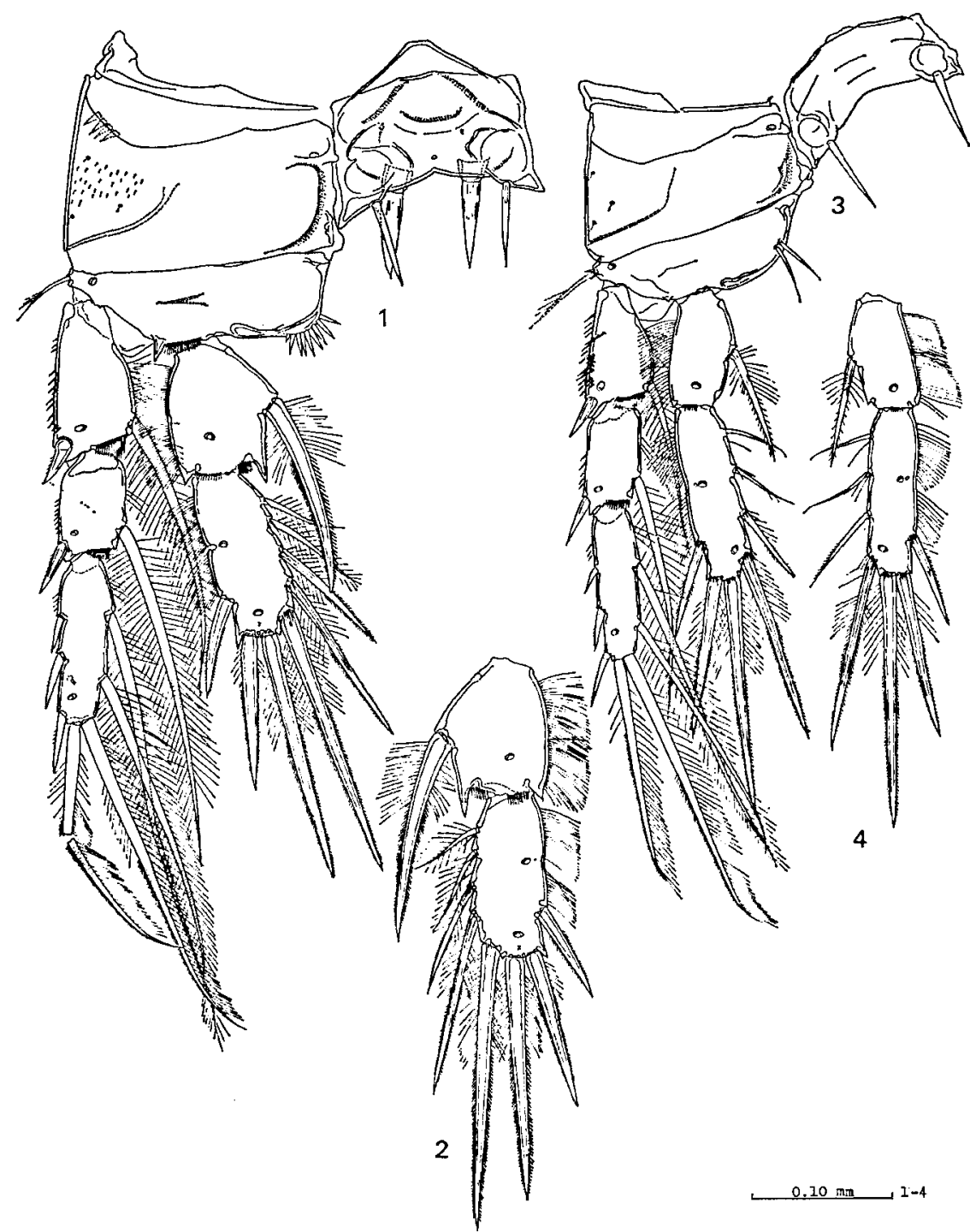

Fig. 9. Cervinia langi Montagna. Female: 1. $\operatorname{leg} 3 ; 2$. endopodite of left leg 3;

3. leg $4 ; 4$. endopodite of left leg 4 .

small, hairy; a prominent secretory pore on anterior face near outer edge. Exopodite three-segmented; setal and spinal ornamentation as in leg 2 . Endopodite two-segmented; first segment a little longer than wide, forming a small triangular projection at each of inner and outer distal angles, with a secretory pore on 
anterior face, armed with one big spine, which extends beyond the middle of second segment, on a stepped inner edge; second segment 2.2 times as long as wide, forming a short triangular projection at outer distal angle, no prominent projection at inner distal angle, armed with one outer spine arising from a stepped edge on a point at two-thirds the length from the base, two straight and long terminal spines, and five, equally spaced, inner appendices, of which the first two are setae and the other three are spines, the distalmost is the biggest; outer rim of second segment interrupted by a notch (not clear in the left leg: see Fig. 9-2) located at a proximal third the length. L e g 4 (Fig. 9-3). Intercoxal plate much wider than long, armed with a pair of simple spines on free edge. Coxa with two sensory hairs on anterior face and one sensory hair on posterior face near outer edge. Basis forming a very small triangular projection on distal edge between exopodite and endopodite; outer seta small and hairy (broken in the leg illustrated); two slender spinules near inner distal angle; a secretory pore occurring on anterior face near outer edge. Exopodite three-segmented; setal and spinal armature as in leg 3. Endopodite two-segmented; first segment twice as long as wide, not forming a prominent projection at outer or inner distal angles, armed with one spiniform inner seta medially; second segment about three times as long as wide, armed with one outer spine arising from a stepped edge on a point at four-fifths the length from the base, two long terminal spines, and four, equally spaced, inner appendices, of which the first three are short setae, and the rest is a long spine; outer rim of second segment not interrupted medially but a little concaved; outer edge of each segment fringed with long hairs. L e g 5 (Figs. 6-2, 6-3) small. Baseoendopodite with no inner expansion, armed with a hairy seta on outer distal edge. Exopodite segment longer than wide, armed with three apical and subapical setae, the middle (apical) longest.

Remarks. In the segmentation and the setal and spinal armature of thoracic legs, the present specimen accords with Cervinia langi described by Montagna (1979) based on a material collected from the Beaufort Sea, Alaska. However, it must be pointed out that minor but many differences are found. The present Pacific specimen has no prominent projection at the inner distal angle of the second endopodite segment of leg 2, but Montagna's Alaskan material has a prominent projection. The spinous projection of outer distal angle of the first endopodite segment of Alaskan material is not so prominent. Intercoxal plate of the leg 2 of Alaskan material is armed as in the present specimen, but the armature is not "dramatic" (Montagna, pers. comm.). Situation of the endopodite outer spine of $\operatorname{leg} 2, \operatorname{leg} 3$, and leg 4 seems to be slightly different: the outer spines of the present specimen locate more distally.

Incidentally, Montagna's figure (Montagna, op. cit., fig. 2) of the antenna with only one seta on its allobasis is incorrect (Montagna, pers. comm.). 


\section{Cervinia sp. aff. langi Montagna}

(Figs. 10-12)

Material. A female (?) of the fourth copepodid stage was dissected. The specimen was collected with Murano's net (Southeast off Mindanao, the Pacific Ocean; 6-II-1979).

Female (the fourth copepodid stage). Body (Figs. 10-1, 10-2) $1.1 \mathrm{~mm}$ long, colorless and semitransparent, composed of nine somites. Cephalon wider than other somites, somewhat depressed dorsoventrally, forming a wide rostrum which is not defined at base. Labrum (Fig. 10-5) wide, trapezoid, with fine spinules
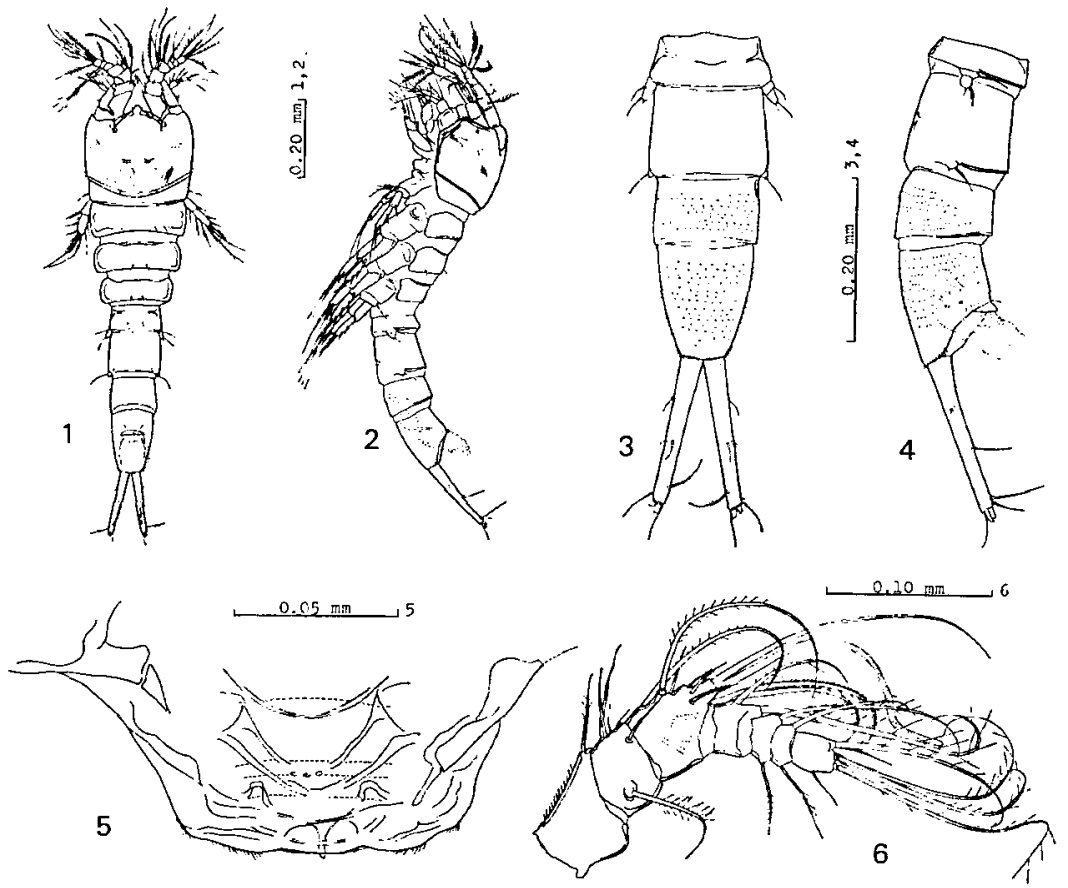

Fig. 10. Cervinia sp. aff. langi Montagna. Fourth copepodid stage: 1. habitus, dorsal; 2. habitus, lateral; 3 . leg 5 and abdomen, ventral; 4. leg 5 and abdomen, lateral; 5. labrum; 6. antennule.

along distal edge. Pleurotergite of first thoracic somite clearly demarcated from cephalic integument. Each pleurotergite of second, third, and fourth thoracic somite well differentiated. Fifth thoracic somite short. Seventh somite (with leg 6) twice as long as the preceding somite. Eighth somite shorter than seventh somite, bearing delicate spinules ventrally. Ninth somite about 1.5 times as long as eighth somite, tapering posteriorly, with delicate spinules ventrally; anal operculum semicircular. Furcal rami divergent; each ramus cylindrical, 1.4 times as long as the last somite.

A n te n n u le (Fig. 10-6) seven-segmented; first segment a little protruded posteriorly; a slender aesthetasc arising from third segment. Antenna (Fig. 
11-1). Segmentation and principal armature as in C. langi. $\mathrm{M}$ a $\mathrm{ndible}$ (Figs. 11-2, 11-3). Coxa-basis armed with three setae apically. Exopodite threesegmented; first segment thickening apically, subdivided into two parts by an obscure suture, armed inwards with one short hairy seta on the proximal part, one spinluose seta on the distal part; second segment short, armed with one spinulose inner seta; third segment small, armed apically with one spinulose seta and one

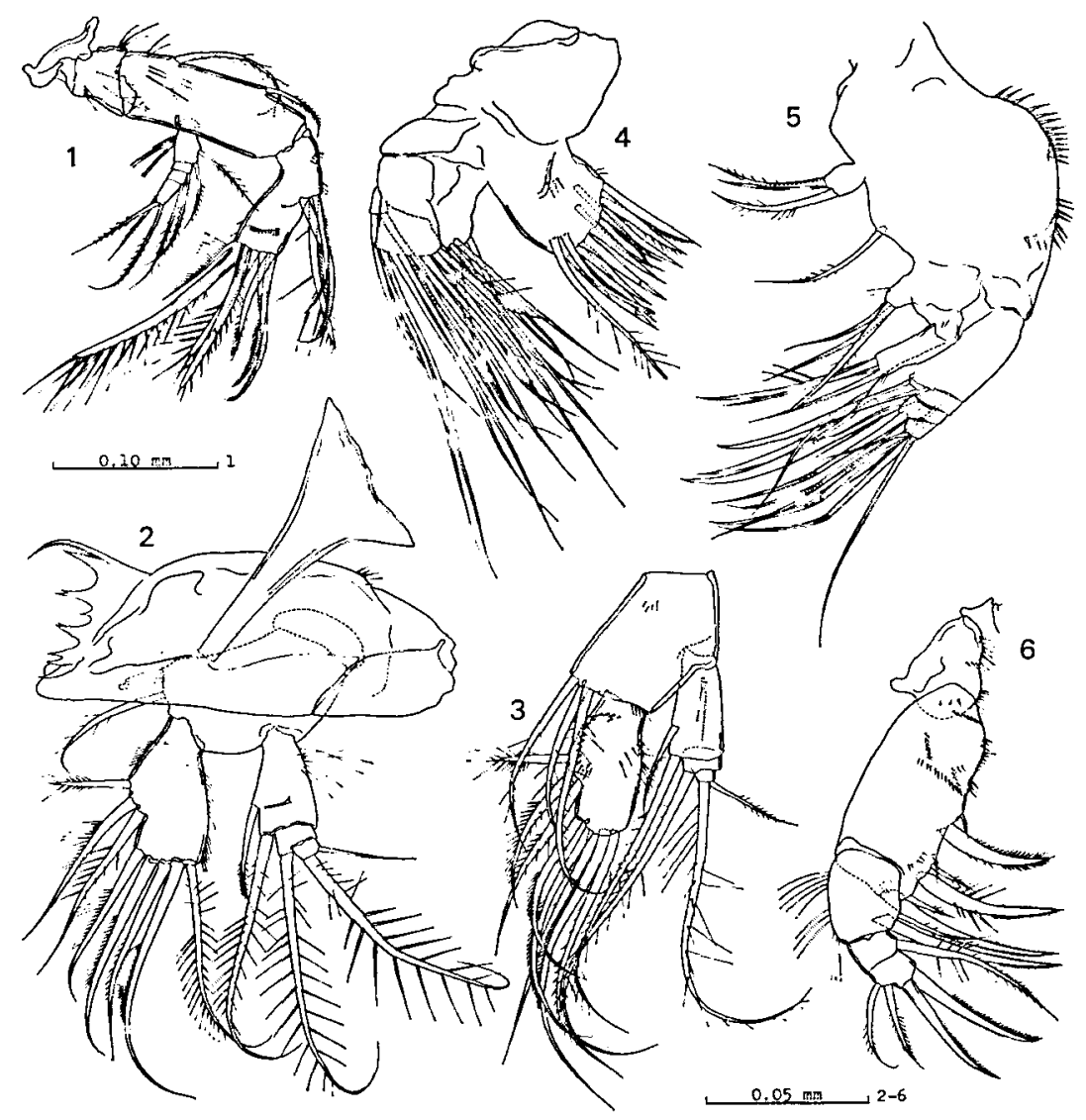

Fig. 11. Cervinia sp. aff. langi Montagna. Fourth copepodid stage: 1. antenna; 2. mandible; 3. mandible (precoxa omitted) ; 4. maxillula; 5. maxilla; 5. maxillipede.

small seta. Endopodite represented by a segment, about twice as long as wide, armed with three spinulose inner setae (not spiniform) which are close to each other, five spinulose setae on distal end. $M$ axillula (Fig. 11-4). Coxa with no epipodite seta. Other principal armature as in C. langi. Maxilla (Fig. 11-5). Outer edge of syncoxa not so protruded. Principal armature as in C. langi. Maxillipede (Fig. 11-6). Coxa with no long hairs on its outer edge. Segmentation and principal armature as in C. langi.

L e g 1 (Fig. 12-1). Free edge of intercoxal plate forming a pair of swellings 
which are fringed with long hairs. Coxa not widening particularly, furnished with hairlike spinules on outer edge and short spinules on anterior face sparsely. Basis armed with one spinulose outer spine, and one hairy inner seta. Both rami twosegmented, subequal in length. Exopodite: first segment with a few spinules on anterior face near inner distal angle, armed with one outer spine which bears spinules sparsely, and one hairy inner seta; second segment as long as first segment, armed with two outer spines, three setae apically and subapically, and two hairy inner setae. Endopodite: first segment longer than wide, forming a very small,

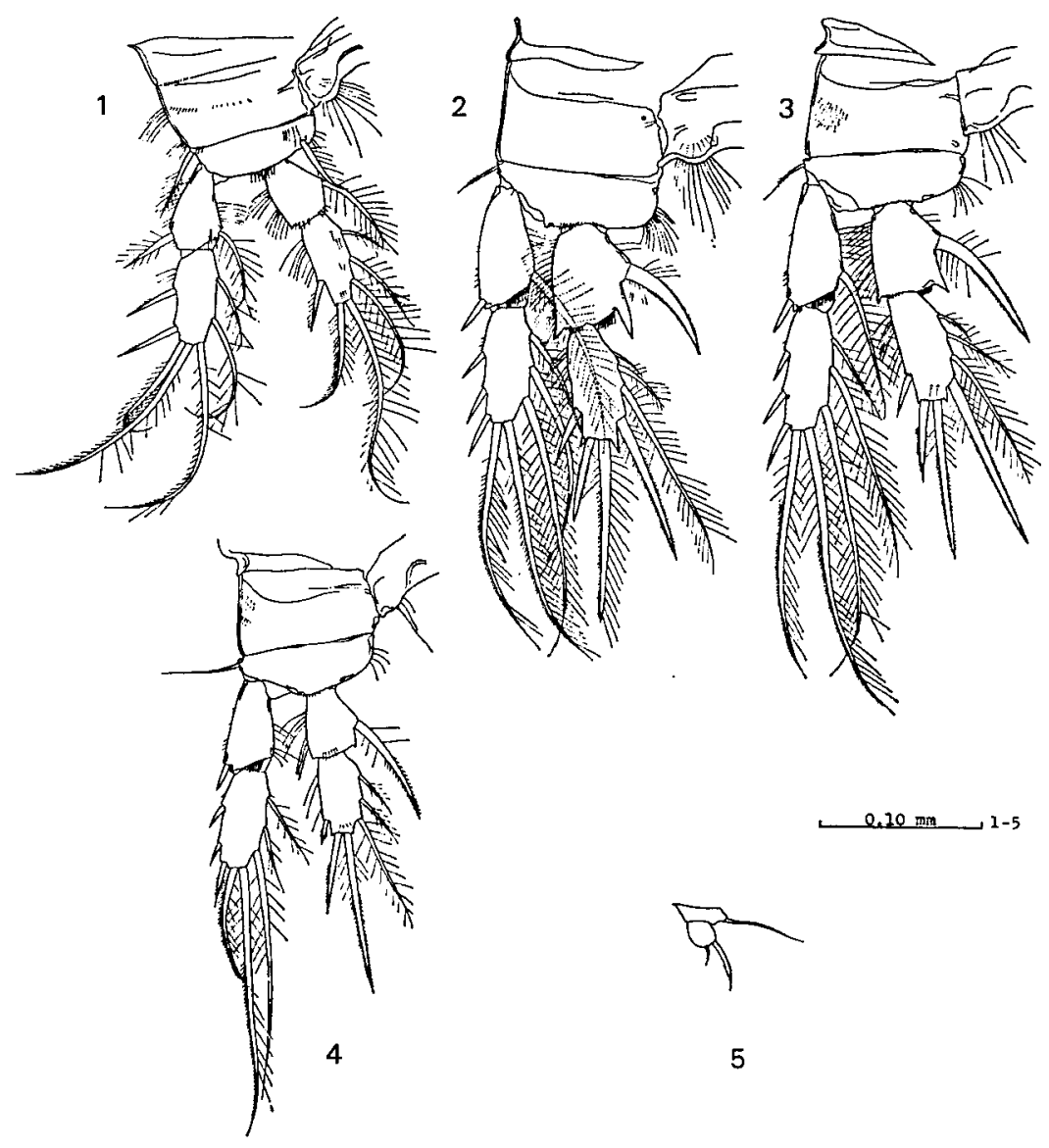

Fig. 12. Cervinia sp. aff, langi Montagna. Fourth copepodid stage: 1. leg 1; 2. $\operatorname{leg} 2 ; 3 . \operatorname{leg} 3 ; 4$. $\operatorname{leg} 4 ; 5$. leg 5 .

apically pointed projection at outer distal angle, armed with one hairy inner seta almost medially; second segment longer than wide, armed with one outer spine which arises from a point at two-thirds the length of outer edge from the base, two setae apically, which bear spinules outwards and hairs inwards, and three inner setae. L e g 2 (Fig. 12-2). Intercoxal plate with neither spinous formation nor any spine, furnished with long hairs on free edge. Coxa bare. Basis with long 
hairs on inner edge, armed with one small outer seta; spinous projection between exopodite and endopodite rudimentary. Both rami two-segmented. Exopodite: first segment armed with one short outer spine and one hairy inner seta; second segment as long as first segment, armed with three outer spines, two apical setae, and three hairy inner setae. Endopodite: first segment forming a small spinous projection at outer distal angle and a prominent spinous projection at inner distal angle, armed with one thick spiniform seta on about the middle of inner edge; second segment as long as first segment, armed with one outer spine located on a point at two-thirds the length from the base, two spiniform setae apically, of which the inner is shorter than the outer, and four inner setae, the distalmost spiniform and finely spinulose. L e g 3 (Fig. 12-3). Intercoxal plate with no spine, furnished with long hairs on free edge. Coxa with fine hairs on posterior face. Basis with hairs on inner edge, armed with one small outer seta. Segmentation and principal armature as in leg 2, though spinal projection at inner distal angle of first endopodite segment not prominent. L e g 4 (Fig. 12-4). Intercoxal plate with a few hairs on free edge. Coxa with fine spinules on posterior face near outer edge. Basis with a few hairs on inner edge, armed with one small outer seta. Both rami two-segmented. Exopodite: first segment armed with one short outer spine, no inner seta; second segment as long as first segment, armed with three outer spines, two apical setae, and three inner setae. Endopodite shorter than exopodite; first segment scarcely protruded at outer and inner distal angles, armed with one thick spiniform seta on about the middle of inner edge; second segment longer than first segment, armed with one small outer spine subapically, two apical setae which are spiniform, and three inner setae. Leg 5 (Fig. 12-5) small. Baseoendopodite without inner expansion, armed with one slender outer seta. Exopodite represented by a rounded small segment with two short setae. L eg 6 (Fig. 10-4) represented by a small protuberance with two setulae.

Remarks. The described copopedid well accords with C. langi Montagna, 1979, in many characters, especially of the antennule, antenna, maxilla, and maxillipede, though the final decision on the specific identification is postponed.

Segmentation of the endopodites of leg 2, leg 3, and leg 4 is very much important for the taxonomy within the genus (see Montagna, 1979). Although each distal segment of the two-segmented endopodites at this fourth copepodid stage has no clear sign of further segmentation, it is still uncertain whether the endopodites are two-segmented even at the fifth and sixth copepodid stages. As previously described in this paper, $C$. langi has prominent armatures on the intercoxal plate of the leg 2 and leg 3. It is entirely unknown when such armatures of the intercoxal plate differentiate through the copepodid development, because our knowledge on the copepodid development of Cerviniidae genera and species is still very poor.

Although the sex of this copepodid specimen is not clear, it is probably female. I suppose Cervinia males should be characterized by the posession of plural 
aesthetascs on the antennule and, in the species whose adults showed a sexual dimorphism in the rostrum, a big rostrum (see p. 157) even at the fourth copepodid stage. The latter character is uncertain for $C$. langi since its male has not yet been reported.

\section{Cervinia sp. aff. tenuiseta Brotzkaja}

(Figs. 13-16)

Material. A female (?) of the fourth copepodid stage was dissected. The specimen was collected with Murano's net (Southeast off Mindanao, the Pacific Ocean; 6-II-1979).

Female (the fourth copepodid stage). Body (Figs. 13-1, 13-2) composed of nine somites, about $1.5 \mathrm{~mm}$ long, colorless and transparent. Cephalon a little longer than wide, as long as succeeding four thoracic somites combined, without prominent rostrum; a small anterior area of integument surface reticulate (Fig. 13-3); posterior hyaline membrane very narrow, not covering over first thoracic somite (Fig. 13-4). Paragnaths well developed (Fig. 13-5). Pleurotergite of second somite (first thoracic somite) well developed, though shorter than that of succeeding somite. Seventh somite (with leg 6) forming a pair of small projections dorsoposteriorly (Fig. 13-6). Eighth somite (Figs. 13-6, 13-7, 13-8) with no spinule or hair. Last somite twice as long as preceding somite, furnished with a transverse row of minute spinules ventrally; anal operculum defined at base. Furcal rami divergent; each ramus cylindrical, a little longer than last two abdominal somites, furnished with a longitudinal row of very small spinules on dorsal face; a short seta arising from a point at a proximal third the length of outer face; a short seta arising from a point at two-thirds the length of dorsal face from the base; a basally geniculate hairy seta attached onto subapical dorsal face; a seta arising from subapical outer face; two setae and a setula on apical end.

Antennule (Fig. 14-1) eight-segmented; proximal four segments much thicker than others; first segment a little longer than its diameter, with spinules on anterior face, armed with a short spinulose seta anteriorly; a dorsal seta of second segment sparsely plumose; a narrow aesthetasc arising from apical end of third segment; fourth segment very short; eighth segment a little longer than preceding two segments combined; most of setae bearing short spinules sparsely. A n t e n $\mathbf{n}$ a (Fig. 14-2). Coxa short, with minute spinules. Basis thickening distally, armed with a well-developed spinulose seta on its anterior face near distal extremity; minute spinules scattered on outer face. Exopodite four-segmented; first segment as long as three apical segments combined, with long hairs on posterior face, armed with two setae, each located subapically and apically; second and third segments short, each armed with a seta; fourth segment as long as preceding two segments combined, with a few spinules subapically, armed with two long terminal setae and a subapical seta; all setae bearing short spinules sparsely. Endopodite composed of two segments, which are subequal in length. First endopodite segment armed with a seta on the middle of its anterior face. Second endopodite segment with a 


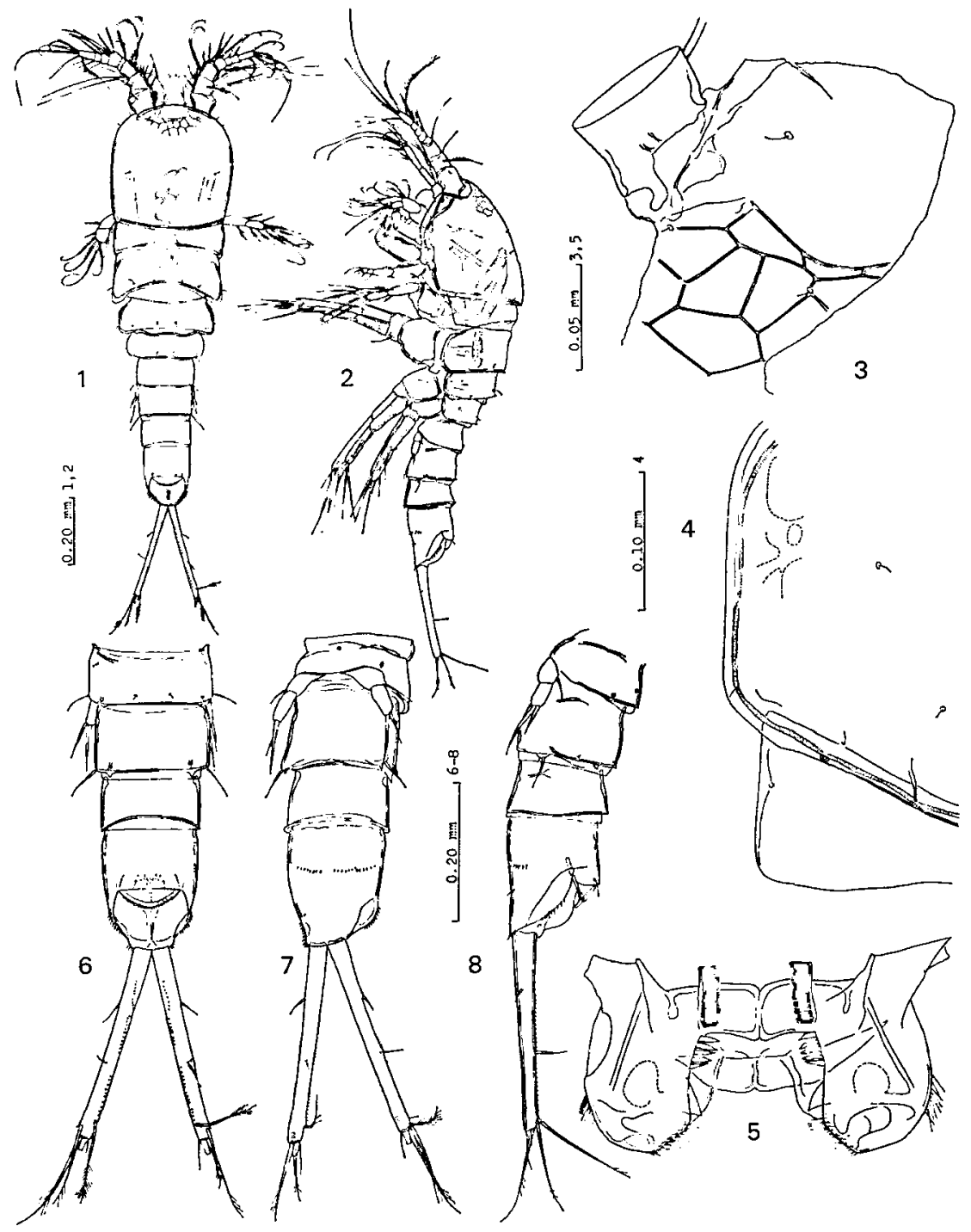

Fig. 13. Cervinia sp. aff. tenuiseta Brotzkaja. Fourth copepodid stage: 1. habitus, dorsal; 2. habitus, lateral; 3. anterior portion of cephalic integument; 4. cephalic integument and pleurotergite of first thoracic somite; 5. paragnaths; 6. leg 5 and abdomen, dorsal; 7. leg 5 and abdomen, ventral; 8. leg 5 and abdomen, lateral. 


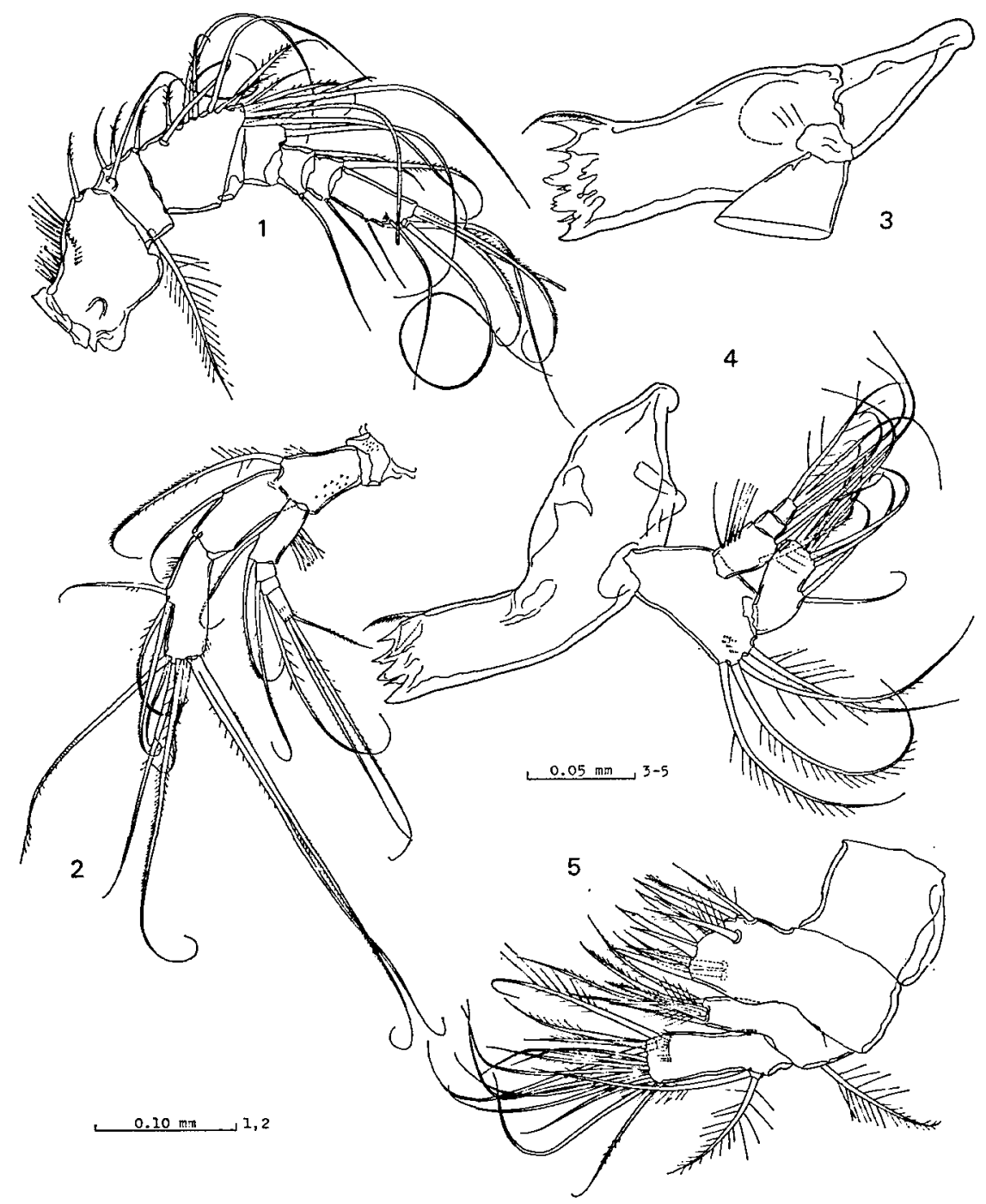

Fig. 14. Cervinia sp. aff. tenuiseta Brotzkaja. Fourth copepodid stage: 1. antennule; 2. antenna; 3. mandibular precoxa; 4. mandıble; 5 . maxillula.

longitudinal row of spinules on proximal half of anterior face, armed with three closely set setae on the middle of its anterior face; apical end armed with five setae, two of which are slender and short, and a basally bifurcate long seta; most of setae bearing minute spinules. Mandible (Figs. 14-3, 14-4). Precoxa with welldeveloped dents and a spinulose seta on cutting edge. Coxa-basis twice as long as wide, armed apically with four setae which bear spinules sparsely and are subequal in length. Exopodite three-segmented; first segment longer than apical two segments combined, with long spinules on outer edge, armed with two inner setae; second segment armed with one inner seta; third segment armed apically with 
one hairy seta and one basally bifurcate seta. Maxillu la (Fig. 14-5). Arthrite of precoxa armed with eight spines and setae along cutting edge, two parallel setae on anterior face, and two setae on posterior face near inner dorsal angle. Coxal inner process not reaching inner end of precoxal arthrite, armed with six setae in all apically. Epipodite represented by a seta with hairs bilaterally. Basal inner process with a row of spinules on subapical anterior face, armed with 14 setae in all apically or subapically. Endopodite represented by a very small segment terminating in two hairy setae. Maxilla (Fig. 15-1). Syncoxa tapering apically, with four endites which are almost equally spaced; first endite represented by a short process armed with five short setae in all; second endite represented by

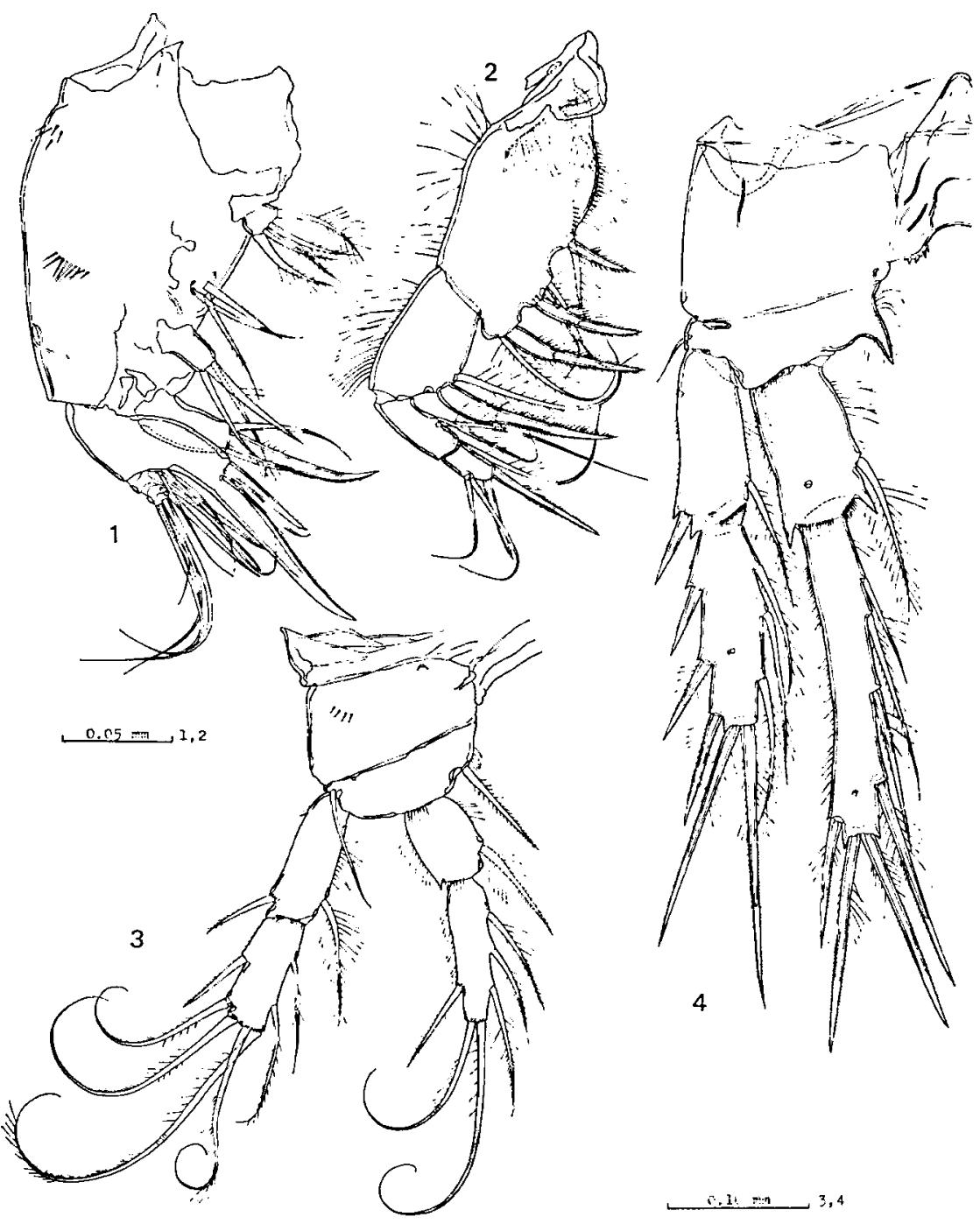

Fig. 15. Cervinia sp. aff. tenuiseta Brotzkaja. Fourth copepodid stage:

1. maxilla; 2. maxillipede; $3 . \operatorname{leg} 1 ; 4$. leg 2. 
three, closely set, short setae; third endite represented by a short cylindrical process armed apically with three setae, one of which is spiniform; fourth endite represented by a well-developed cylindrical process armed apically with a strong arched spine and two setae. Basis: inner process forming a strong claw accompanied with a spinule and two setae dorsally; three (?) slender setae arising from ventral edge close to endopodite. Endopodite two-segmented (? three-segmented), armed as shown in figure (not precisely traced). M axilli pede (Fig. 15-2). Precoxa short. Coxa about twice as long as wide, furnished with long spinules on its proximal half of posterior face, hairs along outer edge, hairs and short spinules along proximal half of inner edge; three, equally spaced, sets of appendices attached onto inner edge, the first located medially, consisting of one spiniform seta and one hairy seta, the second consisting of one spiniform seta and two hairy setae, and the third located on distal angle, consisting of one thick spiniform seta and one hairy seta; all spiniform setae spinulose. Basis about 1.5 times as long as wide, fringed with hairs along outer edge, armed with one inner seta which bears hairs sparsely, and one spiniform inner seta which much thickens at its proximal third; both setae close to each other. Endopodite consisting of two slender segments; two segments combined as long as basis; first segment twice as long as second segment, armed with two slender, closely set, setae on about the middle of inner edge and a seta on subapical inner edge; second segment armed with two, closely set, slender setae on subapical outer edge, and two spiniform setae apically.

L e g 1 (Fig. 15-3). Intercoxal plate low, unornamented. Coxa furnished with a few spinules on anterior face. Basis forming no spinous projection on its free edge, armed with a slender seta near outer basal angle, a spinulose spine on inner subapical angle. Both rami two-segmented. Exopodite: first segment 2.5 times as long as wide, fringed with hairs along inner edge, armed with one outer spine subapically and one hairy inner seta subapically; second segment a little shorter than first segment, armed with one spine on the middle of outer edge, two soft curly setae on subapical outer edge, two soft curly setae on distal end, and two short inner setae which are widely spaced. Endopodite a little shorter than exopodite; first segment 1.3 times as long as wide, forming a triangular projection at outer distal angle, armed with one thick seta on subapical inner edge; second segment slender, about 1.8 times as long as first segment, armed with one outer spine on a point at three-quarters the length from the base, two soft curly setae on distal end, three equally spaced setae along inner edge; each outer edge hairy. L e g 2 (Fig. 15-4). Intercoxal plate concaved at free edge, with a few short spinules on both sides of concaved edge. Coxa unornamented. Basis forming a strong spinous projection at inner distal angle, accompanied with long hairs; no spinous projection occurring between exopodite and endopodite; outer seta small. Both rami two-segmented; exopodite segments combined shorter than endopodite segments combined. Exopodite: first segment armed with one outer spine and one inner seta; second segment a little longer than first segment, armed with three, equally spaced, outer spines, two long terminal spines, and three, equally spaced, 
inner setae. Endopodite: first segment about twice as long as wide, forming a short spinous projection at each of outer and inner distal angles, armed with one inner seta; second segment elongate, twice as long as first segment, armed with one outer spine subapically, two terminal spines, and three setae and one pine along inner edge. L e g 3 (Fig. 16-1) smaller than leg 2. Free edge of intercoxal plate a little concaved, with a few hairs. Coxa and basis as in leg 2. Segmentation and setal and spinal armature of both rami as in leg 2. L e g 4 (Fig. 16-2) smaller than leg 3. Intercoxal plate low, scarcely concaved at free edge, with a few hairs. Coxa and basis as in leg 3; spinous projection of basis rudimentary.
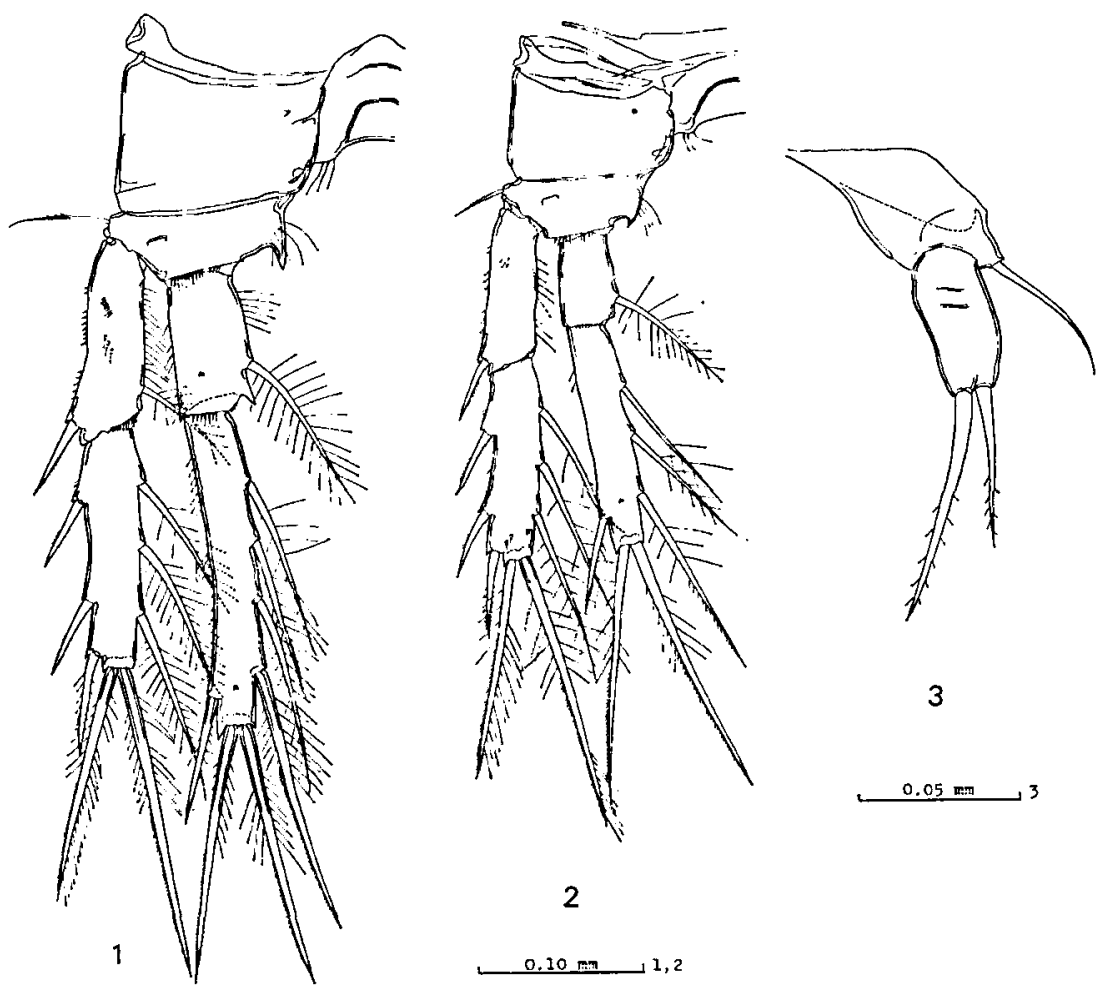

3

Fig. 16. Cervinia sp. aff. tenuiseta Brotzkaja. Fourth copepodid stage: 1. $\operatorname{leg} 3 ; 2 . \operatorname{leg} 4 ; 3 . \operatorname{leg} 5$.

Both rami two-segmented; exopodite segments combined a little longer than endopodite segments combined. Exopodite: first segment armed with one outer spine subapically, with no inner seta; second segment longer than first segment, armed with three outer spines, two long terminal spines, and three, equally spaced, inner setae. Endopodite: first segment forming no projection at either outer or inner distal angle, armed with one inner seta subapically; second segment 2.5 times as long as first segment, armed with one outer spine subapically, two long terminal 
spines, and three, equally spaced, inner setae. Leg 5 (Fig. 16-3). Baseoendopodite with no inner expansion, armed with a bare outer seta. Exopodite represented by a segment about twice as long as wide, armed with two apical setae, both bearing spinules sparsely.

Remarks. Although it is difficult to identify the present young copepodite, this specimen closely resemble Cervinia tenuiseta Brotzkaja, 1963, reported from the Japan Trench, the Pacific Ocean. C. tenuiseta was reported also by Por (1969) from the Indian Ocean near Madagascar, but this record is dubious. Brotzkaja's material clearly shows the following characteristics: 1) the leg 1 armed with curly setae on its last exopodite and endopodite segments; 2) the third endopodite segment of leg 1 armed with two inner setae; 3) the endopodite segments of leg 2 slender and much longer than its exopodite segments; 4) the first two endopodite segments of leg 2 armed with usual slender inner setae; 5) the outer spine of each endopodite of leg $2, \operatorname{leg} 3$, and leg 4 (especially the former two) locating near apical end. In contrast to these, Por's material shows different characteristics: 1) the leg 1 armed with no curly setae; 2) the third endopodite segment of leg 1 armed with only one inner seta; 3) the endopodite segments of leg 2 not slender, as long as exopodite segments; 4) the first two endopodite segments of leg 2 armed with very thick inner setae; 5) the outer spine of each endopodite of leg 2, leg 3 , and leg 4 not very close to the apical end. The present copepodite, on the other hand, accords with Brotzkaja's material in all of these characteristics. The endopodite of leg 1 of the present copepodite does not fully differentiate. However, its second segment (the second and third segments in the adult) has three inner setae, which correspond with the single inner seta of the second segment and the two inner setae of the third segment of the adult.

The present specimen has very large cells within the fore body (see Fig. 13-1). It is unlikely that these cells are eggs, because the specimen is too young. The cells may be gregarines. Although the sex of this specimen is uncertain, I suppose it is female (see p. 157 and p. 171).

\section{Eucanuella longirostrata n. sp.}

(Figs. 17-20)

Material. An adult male dissected was designated as the holotype. Type-locality: Southeast off Mindanao, the Pacific Ocean. The specimen was collected with Murano's net (6-II-1979).

Male (holotype). Body (Figs. 17-1, 17-2) about $1.7 \mathrm{~mm}$ long, colorless; integuments fairly sclerotized. Rostrum (Fig. 17-3) very big, not defined at base, bending ventrally, with a sensory hair on each lateral edge. Cephalic integument with reticulate texture (Figs. 17-3, 17-4) and numerous minute pores, fringed with short hairs along posterior edge; a pair of prominent pores occurring near presumed base of rostrum. Pleurotergite of first thoracic somite (Figs. 17-4, 17-5) short, 


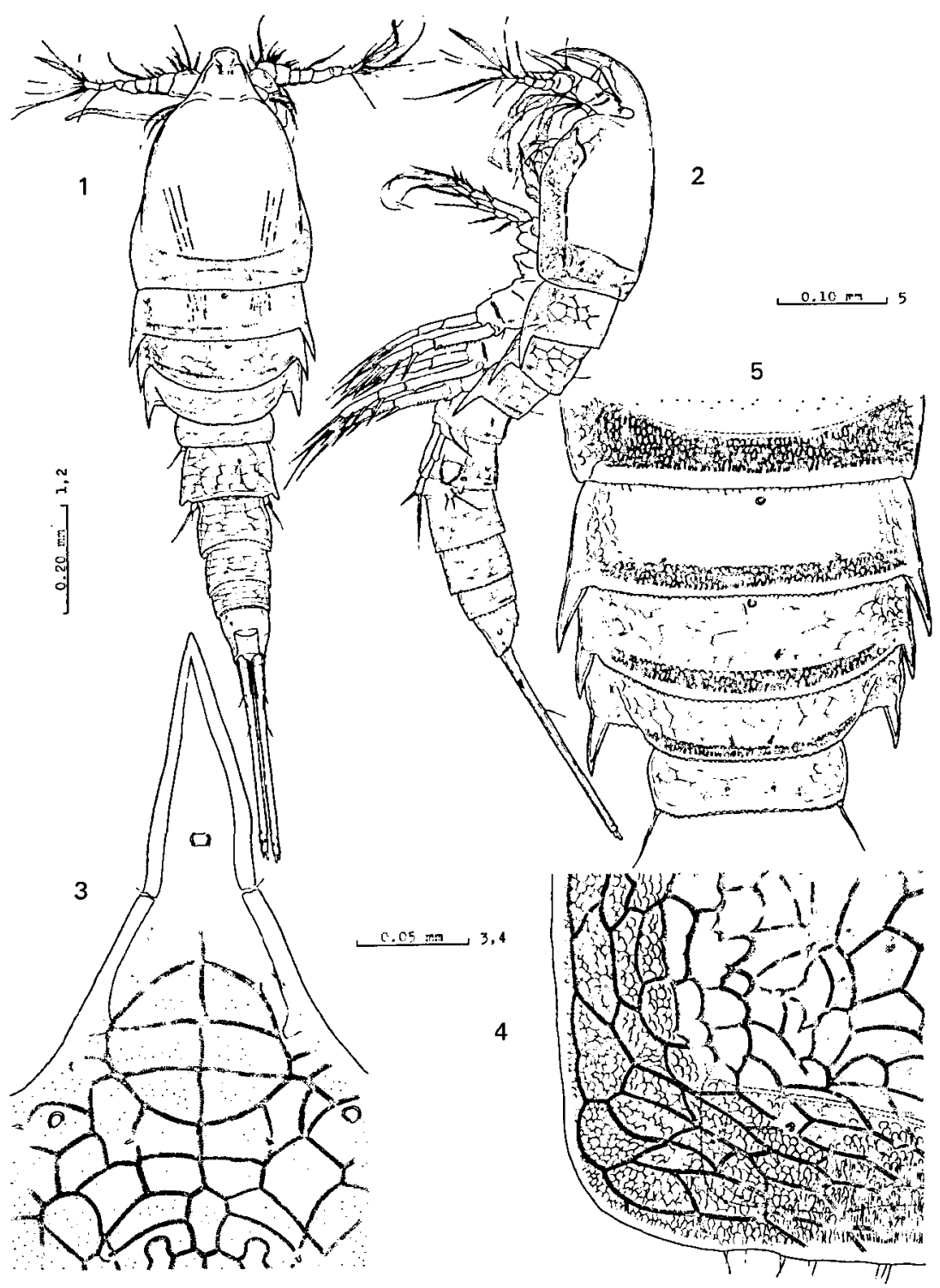

Fig. 17. Eucanuella longirostrata n. sp. Male (holotype): 1. habitus, dorsal; 2. habitus, lateral; 3. rostrum and anterior cephalic integument; 4. cephalic integument and pleurotergite of first thoracic somite; 5 . dorsal view of thorax.

inserted under posterior hyaline membrane of cephalic integument. Each pleurotergite of second, third, and fourth thoracic somites (Fig. 17-5) more or less reticulate, forming a prominent spiniform projection at each posterior lateral angle; posterior edge finely serrated. Fifth thoracic somite with no prominent lateral projection; dorsal half of posterior edge serrated. Abdomen (Figs. 18-1, 18-2, 18-3) gradually tapering posteriorly, reticulated on each surface. First abdominal somite (with leg 6) 

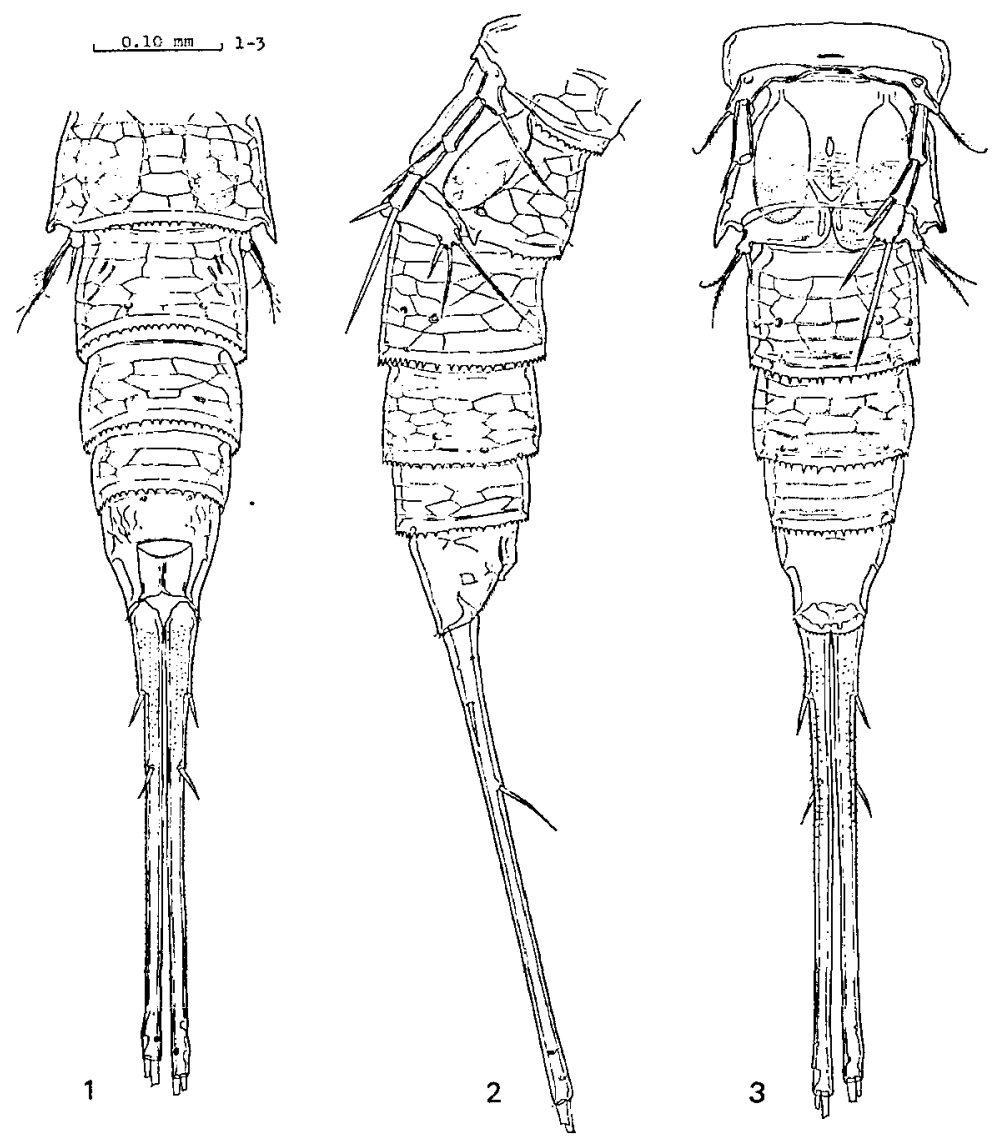

Fig. 18. Eucanuella longirostrata n. sp. Male (holotype): 1. hind body, dorsal; 2. leg 5 and abdomen, lateral; $3 . \operatorname{leg} 5$ and abdomen, ventral.

forming a spiniform projection at each lateral posterior edge; a pair of welldeveloped spermatophores present. Anal somite almost pyliform; anal operculum defined at base, semicircular. Furcal rami separated from each other, parallel; right ramus a little longer than the counterpart, about $0.4 \mathrm{~mm}$ long, cylindrical, with minute scattering spinules, armed with a short outer seta on a point at a proximal sixth the length, a short dorsal seta on a point at a proximal third the length; terminal and subterminal setae broken.

Antennule (Fig. 19-1) haplocer, composed of eight segments; second, third, and fourth segments armed with thick aesthetascs; seventh segment subdivided into two parts by a suture, armed apically with a multi-geniculate seta together with a short aesthetasc; apical segment slim, terminating in an aesthetasc together with slender bare setae; most setae of first six segments bearing very short spinules. Antenna (Fig. 19-2). Coxa (broken) with five spinules posteriorly. Basis about twice as long as thick, with spinules anteriorly and posteriorly. Exopodite four-segmented; first segment longer than three apical segments combined, 


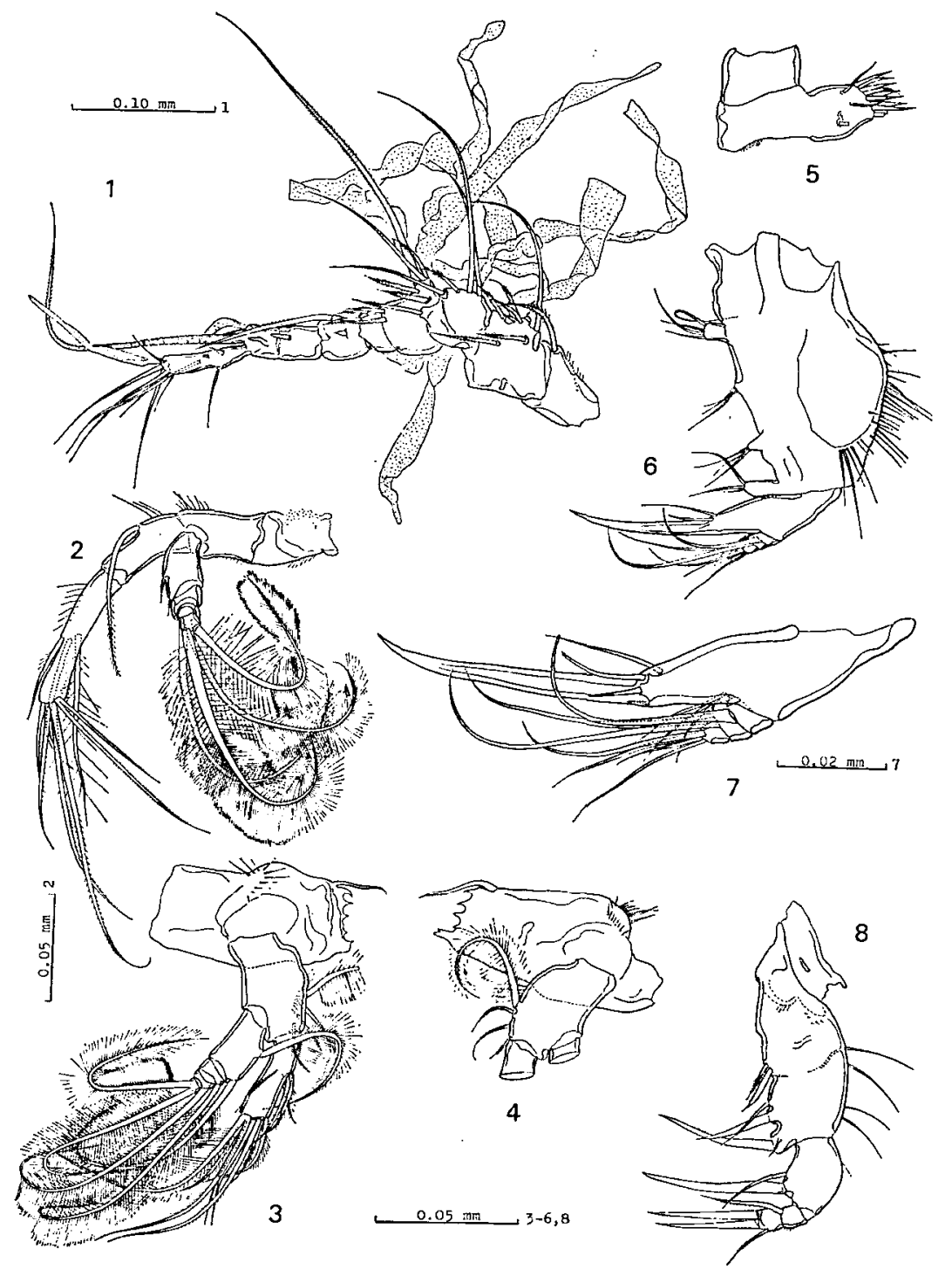

Fig. 19. Eucanuella longirostrata n. sp. Male (holotype): 1. antennule; 2. antenna; 3. mandible; 4. precoxa and coxa-basis of mandible; 5 . maxillula (broken); 6. maxilla; 7. maxilla (syncoxa omitted); 8. maxillipede.

armed with two small setae anteriorly; each of second and third segments armed with one long plumose seta; fourth segment armed with two long plumose setae apically. First endopodite segment demarcated from basis by a suture, as long as basis, armed with one spinulose seta on about the middle of anterior face. Second endopodite segment twice as long as first endopodite segment, with a row of spinules on its proximal half of anterior face, armed with three setae medially, one of which bears long hairs sparsely; five spinulose setae, one of which is proximally bifurcate, attached onto its distal end. M a n dible (Fig. 19-3). Precoxa with 
a semicircular row of spinules dorsally; armature of cutting edge not so developed (orientation of the precoxa of Fig. 19-3 is not good; see Fig. 19-4). Coxa-basis scarcely widening apically, armed with one plumose well-developed seta and three small setae on inner edge near distal angle. Exopodite four-segmented; first segment cylindrical, about twice as long as apical three segments combined, armed with two inner setae, one located medially, the other located subapically; each of second and third segments armed with one inner seta; fourth segment armed with two apical setae; all setae well-developed and plumose. Endopodite consisting of a subcylindrical segment, as long as four exopodite segments combined, with a longitudinal row of short spinules along outer margin, armed with three short setae on about the middle of inner edge; seven hairy setae attached onto distal end, one of which is proximally bifurcate. Maxillula (Fig. 19-5). Both maxillulae were damaged during dissection, and their structures could not be examined. Maxilla (Figs. 19-6, 19-7). Syncoxa about twice as long as wide, with long spinules on and near round outer edge, furnished with four endites, which are almost equally spaced; first endite represented by a short cylindrical process armed apically with four slender bare setae; second and third endites each represented by a rudimentary projection with three fine setulae; fourth endite represented by a cylindrical process (the counterpart of the unillustrated maxilla bearing a few spinules near its apex) armed apically with three slender setae. Inner process of basis forming a strong claw which is accompanied proximally with two slender setae dorsally, one fine setula ventrally, and one slender small.spine anteriorly; three juxtaposed fine setae arising from distal edge near inner base of endopodite. Endopodite consisting of three short segments; first segment armed with one stout seta on anterior distal edge; second segment armed with two stout setae, one located on inner distal edge, the other on anterior distal edge; third segment armed with three slender setae and one stout seta. Maxil1i pede (Fig. 19-8). Precoxa with a few spinules on anterior distal edge. Coxa with several long hairs on round outer margin and a few short spinules on posterior face near its outer proximal angle, armed with six inner appendices; first two appendices close to each other, located almost medially, each represented by a small seta with very short spinules; third appendix widely separated from the former, represented by a slender seta; fourth appendix close to third appendix, represented by a spine arising from a short projection; fifth appendix represented by a spine arising from a prominent projection posteriorly bearing a setula which represents the sixth appendix. Basis 1.5 times as long as wide, armed with one slender seta and one strong spine on inner subapical angle. Endopodite consisting of two small segments which are subequal in length; first segment with short spinules on outer edge, armed with one finely spinulose seta on inner distal edge; second segment armed with two spines terminally and one slender seta on outer subapical edge.

L e g 1 (Fig. 20-1). Intercoxal plate wide, with long hairs on each rounded lateral edge. Coxa with a big pore encircled with a chitinous rim on anterior face near inner edge, a transverse row of prominent fine spinules on anterior face along 
proximal edge, many hairlike spinules along outer edge. Basis with a big pore on anterior face near outer edge, a few very long spinules on anterior face near base of endopodite, armed with one spinulose outer spine, one short spine on inner distal angle. Both rami three-segmented. Exopodite: first segment a little shorter than

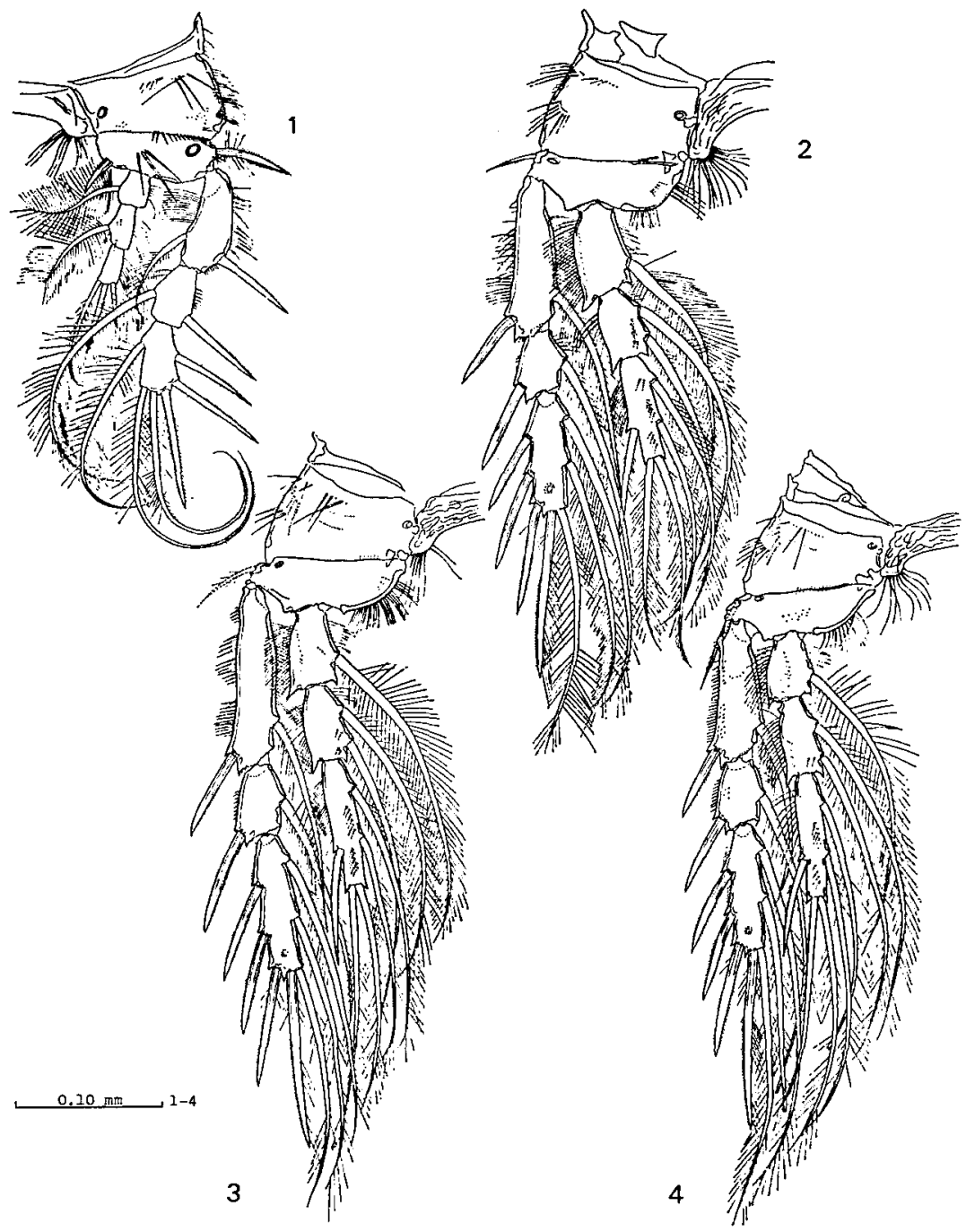

Fig. 20. Eucamuella longirostrata n. sp. Male (holotype): $1 . \operatorname{leg} 1 ; 2 . \operatorname{leg} 2 ; 3 . \operatorname{leg} 3$; 4. leg 4 .

apical two segments combined, with spinules on outer edge and hairs densely on inner edge, armed with one outer spine, which is very finely serrated dorsally, and one plumose inner seta; second segment with short spinules outwards, a few hairs inwards, armed with one outer spine and one plumose inner seta; third segment as long as second segment, armed with two outer spines, one spine and two setae, 
which bear hairs densely and spinules, on distal end, and one plumose inner seta on a point at a proximal third the length. Endopodite smaller than exopodite, three segments combined shorter than proximal two exopodite segments combined; first and second segments each armed with one plumose inner seta; third segment armed with one small spine near outer distal angle, two short setae on distal edge. L e g 2 (Fig. 20-2). Intercoxal plate wide, wrinkly, with long hairs on each lateral protrusion of free edge. Coxa with a big pore encircled with a chitinous rim on anterior face near inner edge, furnished with transverse and arched rows of spinules near outer edge; distal extremity a little inclining. Basis forming a pointed projection between exopodite and endopodite, with a prominent pore on anterior face near outer proximal angle, some hairlike spinules along inner edge and posterior face near inner edge, armed with one small outer seta. Both rami threesegmented. Exopodite longer than endopodite; first segment elongate, about as long as apical two segments combined, pointed at outer distal angle, with many fine spinules on outer edge and hairs densely on inner edge, armed with one outer spine and one inner seta; second segment short, pointed at outer distal angle, armed with one outer spine and one inner seta which is located medially; third segment twice as long as second segment, armed with three outer spines, one outer terminal spine and one inner terminal seta, and three inner setae; all outer spines finely serrate, all setae plumose. Endopodite: first segment pointed at outer distal angle and inner distal angle, armed with one inner seta; second segment shorter than first segment, pointed at outer distal angle and inner distal angle, with a few spinules on posterior face, armed with two inner setae; third segment 1.5 times as long as second segment, a little pointed at outer and inner distal angles, with longitudinal rows of spinules posteriorly, armed with one outer spine which arises from a clearly stepped edge located on a point at two-thirds the length from the base, two terminal setae, and two inner setae, of which the distal one is located at almost the same level as the outer spine; all setae plumose; outer edge of each segment fringed with long hairs. Leg 3 (Fig. 20-3). Segmentation and principal armature as in leg 2, but exopodite and endopodite segments longer than the counterparts of leg 2. Le g 4 (Fig. 20-4). Segmentation and principal armature as in leg 2, but protopodite smaller than the counterpart of leg 2. First two exopodite segments furnished with spinules scattered on each anterior face. Endopodite: first segment shorter than second segment; second segment forming a small, apically pointed, projection on proximal outer edge. L e g 5 (Fig. 18-3). Both baseoendopodites confluent with each other; each with a big pore on anterior face near proximal outer angle, not forming inner expansion, armed with a short hairy outer seta. Both exopodites were so damaged that complete armature could not be seen. Exopodite consisting of four subcylindrical segments; first segment armed with one short outer spine distally; second segment armed with one short inner spine distally, with no outer seta (or any scar of a lost seta on the outer edge); third segment probably armed with four setae (Two setae exist, and other two are represented by scars.). L e g 6 (Fig. 18-3) represented by a broad plate forming a short 
outer distal process armed with one short spine and two slender setae.

Remarks. The present new species resembles Eucanuella reticulata Soyer, 1970, reported from the Mediterranean Sea off France, in having peculiar reticulate texture on the surface of body integuments. However, the new species is easily discernible from the latter in the setal armature of a leg: the middle exopodite segment of leg 5 has no outer seta in the new species, though the counterpart has one outer seta in $E$. reticulata. In the setal armature of the leg 4 , the new species accords with not only $E$. reticulata but also $E$. langi Por, 1964, reported from the bathyal bottom of the Mediterranean Sea off Israel. The new species, however, is discernible from $E$. langi in the shape of the rostrum, the armature of the maxilla, the proportion and setal arrangements of the furcal rami, and the great difference in the body size. Although the shape of the rostrum of $E$. reticulata is unknown, Coull (1973) provides a figure of a fairly elongate rostrum of a male from the deep sea off North Carolina, which was breafly reported under the name Eucanuella aff. reticulata.

Although the present new species seems to be unique within the family in the possession of a pointed projection on the middle endopodite segment of leg 4 (This assertained on the unillustrated left leg too.), the leg 4 of any other congeneric species has not been illustrated in the papers so far published (see Scott, 1901; Sars, 1903; Por, 1964; Soyer, 1970; Coull, 1973).

The specific name of the new species denotes its very much elongated rostrum.

\section{Cerviniopsis muranoi n. sp.}

(Figs. 21-26)

Material. An adult female dissected and an adult male dissected were designated as the holotype and the allotype, respectively. Type-locality: Southeast off Mindanao, the Pacific Ocean. The specimens were collected with Murano's net (6-II-1979).

Female (holotype). Body (Figs. 21-1, 21-2) about $2 \mathrm{~mm}$ long, colorless and semitransparent, furnished with numerous short hairs or spinules especially on dorsal surfaces; in both dorsal and lateral views, the biggest being cephalon, gradually tapering toward posterior thoracic somites. Cephalon about as long as succeeding four thoracic somites combined, forming a big triangular rostrum, which is not defined at base, with a pair of fine sensory hairs subapically (Fig. 21-3); each lateral portion of integument beside rostrum much extending toward anterior and fringed with many spinules; posterior hyaline membrane markedly extending toward posterior at each lateral (ventral) portion and covering over first thoracic somite, but dorsal portion of this hyaline membrane scarcely developing and not covering first thoracic somite (see Fig. 21-4). First thoracic somite short, covered with tergite which is fringed with spinules along posterior edge (Fig. 21-4; broken during dissection). Each pleurotergite of second, third, and fourth thoracic somites well developed, forming a pointed extension at each posterolateral angle, serrated along 


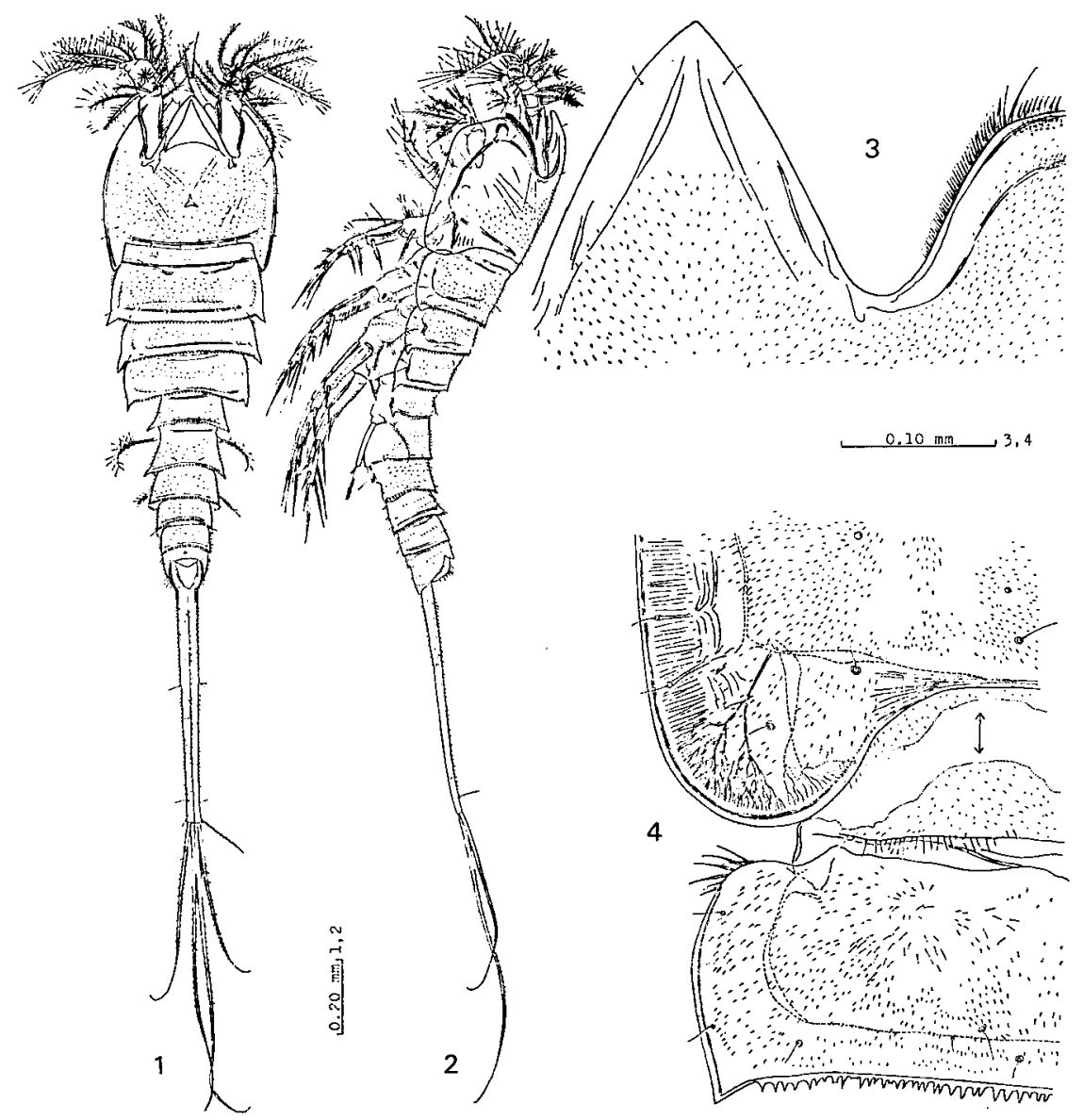

Fig. 21. Cerviniopsis muranoi n. sp. Female (holotype): 1. habitus, dorsal; 2. habitus, lateral; 3. rostrum; 4. cephalic integument and pleurotergites of first two thoracic somites (broken).

posterior edge. Pleurotergite of fifth thoracic somite not clearly defined laterally (see Fig. 22-2), serrated along posterior edge. Genital double-somite clearly subdivided dorsally, much swelling out ventrally, ornamented with a pair of leg 6 , each of which consists of a cylindrical segment terminating in two setae; dorsoposterior edge of anterior subdivision and circumambient hyaline membrane of posterior subdivision serrated; anterior subdivision forming a pointed projection at each lateral extremity of posterior dorsal edge. Antepenultimate and penultimate somite serrated along each circumambient hyaline membrane. Anal somite longer than penultimate somite, tapering posteriorly, with a prominent secretory pore dorsally; anal operculum semicircular, fringed with spinules. Furcal rami (Figs. $22-1,22-2,22-3,22-4$ ) confluent, much elongate, occupying about $30 \%$ of body length, furnished with numerous spinules dorsally and laterally; principal terminal setae well developed, hairy; a setula arising from a point at two-fifths the length 


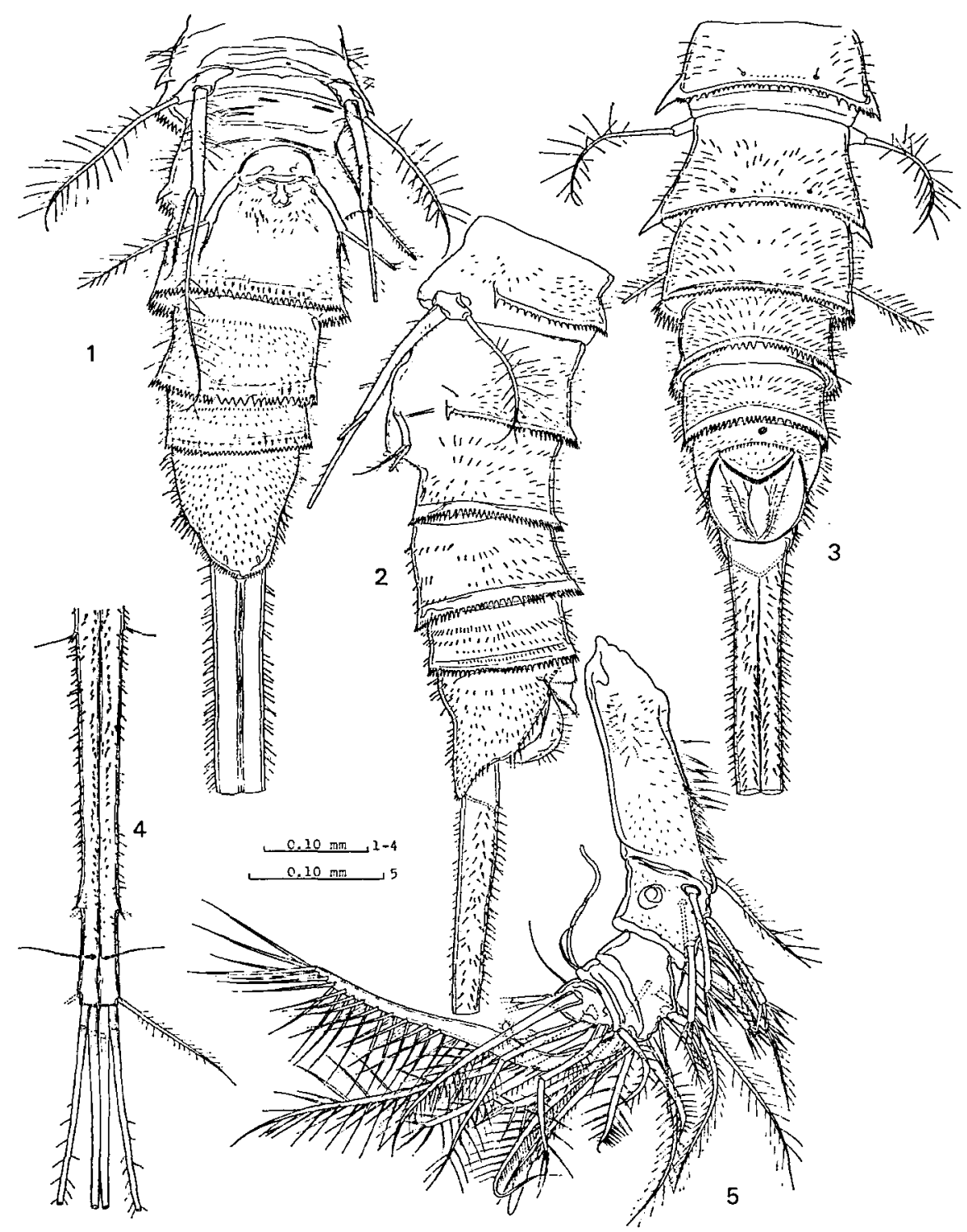

Fig. 22. Cerviniopsis muranoi n. sp. Female (holotpye): 1. leg 5 and abdomen, ventral; 2. leg 5 and abdomen, lateral; 3 . leg 5 and abdomen, dorsal; 4. furcal rami; 5. antennule.

of outer face from the base; a basally geniculate setula arising from dorsal face near posterior end; a setula (broken) arising from a point at four-fifths the length of outer face from the base; a hairy seta attached onto subapical outer face.

Antennule (Fig. 22-5) five-segmented; first segment longer than other segments combined, with many prominent spinules anteriorly, fine spinules scattered dorsally and ventrally, armed with a spinulose seta on anterodistal face; second segment as thick as first segment, with fine spinules scattered dorsally, armed 
with rod-shaped setae which are markedly spinulose; third segment tapering proximally, armed with spinulose and hairy setae and a thick aesthetasc; fourth segment very short, armed with a slender aesthetasc posteriorly, and a very big sinuate spine, which arises from anterior edge and is furnished with many long spinules, together with several spinulose setae; fifth segment small, terminating in two, closely set, slender aesthetascs. Antenna (Fig. 23-1). Coxa short, with fine spinules on its posterior face. Allobasis three times as long as thick, with a concavity near the middle of anterior face, armed anteriorly with two long spinulose setae, one

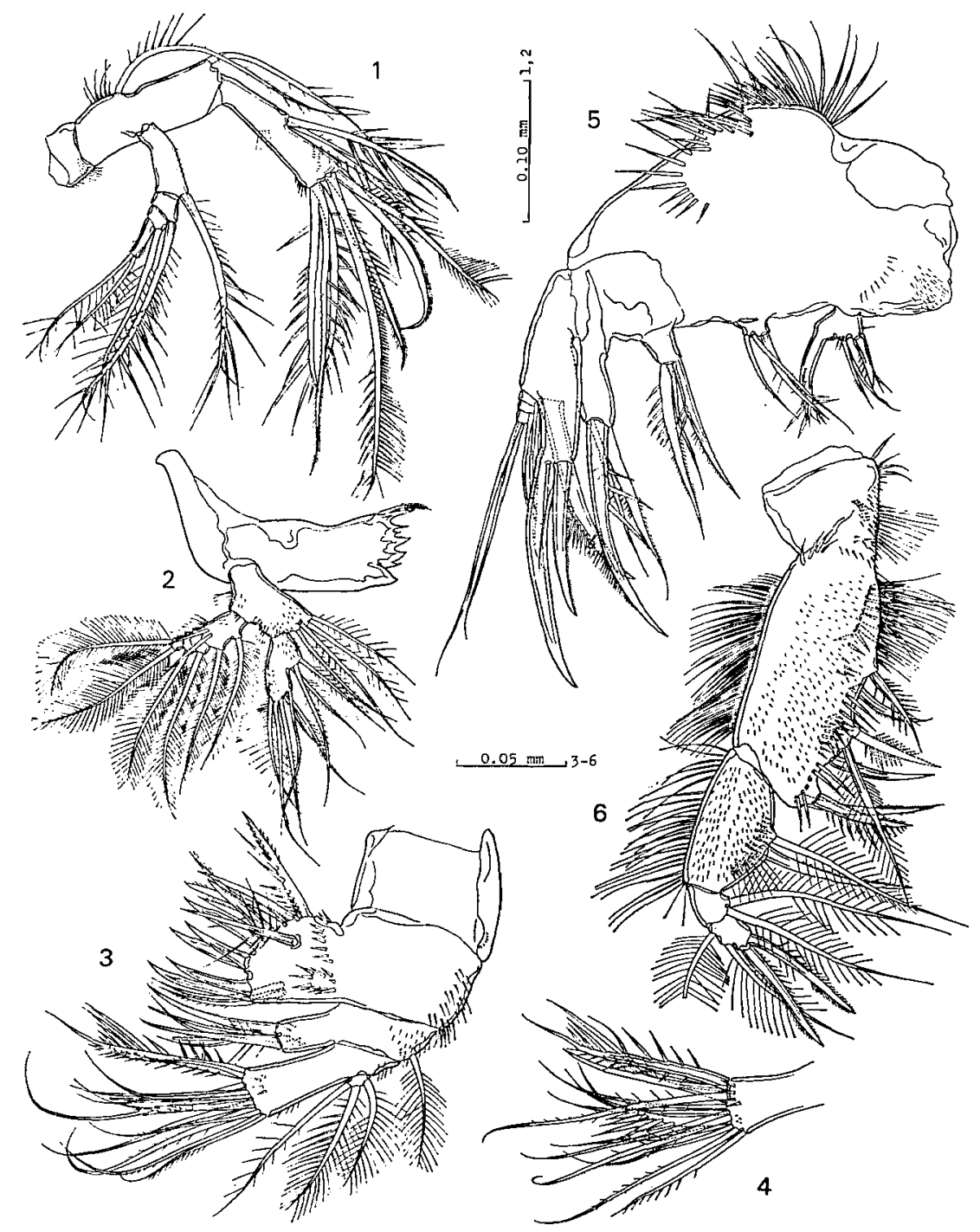

Fig. 23. Cerviniopsis muranoi n. sp. Female (holotype): 1. antenna; 2. mandible; 3. maxillula; 4. inner process of basis of left maxillula; 5 . maxilla; 6 . maxillipede. 
proximal to the concavity, the other located subapically; spinules occurring on anterior face near proximal end. Exopodite four-segmented; first segment as long as other segments combined, thickening towards apical, with very short spinules anteriorly, armed with one spinulose stout seta apically; second and third segments short, each armed with one spinulose seta anteriorly, fourth segment slender, terminating in two spinulose setae. Endopodite as long as allobasis, armed with three closely set setae which arise from a stepped edge at about the middle of anterior face, two of which are furnished with spatulate spinules; apical end armed with six spinulose setae in all, one of which is basally bifurcate. Mandible (Fig. 23-2). Precoxa well sclerotized. Coxa-basis with many fine spinules, armed with four spinulose setae in all, which are subequal in length and locate apically or subapically. Exopodite four-segmented; first segment as long as other segments combined, with two prominent spinules subapically together with minute spinules, armed with two inner setae; second and third segments each armed with one inner seta; fourth segment small, terminating in two setae; all setae subequal in length, plumose. Endopodite consisting of one segment as long as exopodite segments combined, with minute spinules, armed with three setae on a stepped rim at the middle of inner edge, and six setae apically and subapically; all setae plumose or spinulose. Maxillula (Fig. 23-3). Arthrite of precoxa with many spinules on posterior face, armed with two parallel setae, both bearing spinules sparsely, on anterior face near ventral edge, 10 spines and one seta along cutting edge, and one sharp spine, which is fringed with long spinules, on posterior face. Inner process of basis not reaching inner edge of precoxal arthrite, with minute spinules on its anterior face, apically armed with two sharp spines and four slender setae. Epipodite represented by a plumose seta. Inner process of basis much extending beyond apical end of inner process of basis, apically armed with 14 (the right maxillula lacking a seta; see Fig. 23-4) setae in all, of which at least three are furnished with prominent spinules. Endopodite represented by a rudimentary segment armed with one somewhat spinulose and two plumose setae. Each outer edge of precoxa, coxa, and basis spinulose. Maxilla (Fig. 23-5). Syncoxa about twice as long as its greatest width, with many long spinules along outer edge and on anterior face, furnished with four endites which are almost equally spaced; first endite short and wide, ventrally forming a thick spiniform process with spinules, armed with a short spinulose spine at dorsal inner angle, and two, closely set, slender setae on inner edge; second endite very short, armed with one spine and two slender setae; third endite cylindrical, armed apically with two spinulose spines and one slender seta; fourth endite represented by a well-developed cylindrical process, armed apically with one strong claw, which is fringed with a few prominent spinules dorsally and many short spinules ventrally, one spinulose thick seta, and one slender seta. Basis with thick inner process forming apically a strong claw, which is accompanied with one spine and a slender seta on its anteroproximal face; one strong claw arising from posterior face near base of endopodite; a slender seta attached onto distal edge close to endopodite. Endopodite consisting of three short segments; each of 
first two segments armed with one slender inner seta; third segment terminating in two slender setae. Maxillipede (Fig. 23-6). Precoxa demarcated from coxa by a constriction, about as long as wide, with many short spinules anteriorly and posteriorly, and fringed with long hairs along inner edge. Basis about twice as long as its greatest width, armed with seven appendices in all along inner edge; first and second appendices closely set, represented by a short spinulose seta and a spinulose spine, respectively; third, fourth, and fifth appendices closely set, represented by a spinulose short seta, a well-developed plumose seta, and a spine, respectively; sixth and seventh appendices closely set, represented by a spinulose spine and a spinulose seta; prominent spinules on anterior face along subproximal inner edge; long hairs along outer edge and proximal half of inner edge; many short hairs scattering on posterior face. Basis about twice as long as its greatest width, a little swelling out inwards, armed with a well-developed plumose seta and a finely spinulose spine, which are close to each other, on about the middle of inner edge; long hairs attached onto outer edge; many short hairs scattering on posterior face; spinules roughly arranged vertically on anterior face near inner edge. Endo podite inclining toward inner, represented by two short segments which are subequal in length; first segment with two long, closely set, plumose setae on inner edge; second segment armed apically with two spinulose spines which are subequal in length, two slender plumose setae on outer edge.

L e g 1 (Fig. 24-1). Free edge of intercoxal plate forming a pair of low swelling fringed with long spinules. Coxa furnished with many long spinules on and near outer edge, several rows of short spinules on anterior face and posterior face near distal extremity. Basis forming no prominent spinous projection on free edge between exopodite and endopodite, with two transverse rows of long spinules on inner half of anterior face, armed with one outer seta which bears hairs sparsely, and one spinulose inner spine which is strong and reaches the middle of second endopodite segment. Both rami three-segmented, subequal in length. Exopodite: first segment a little longer than other two segments combined, gradually widening toward apical; second and third segments subequal in length, as long as wide; each of first and second segments armed with one, finely spinulose, outer spine and one plumose inner seta; third segment armed with three outer spines, of which the distal two are short, and two apical setae which are thick, spinulose outwards and hairy inwards; slender spinules attached onto outer edge of each segment; hairs attached onto inner edge of each segment. Endopodite: first two segments subequal in length, each armed with one plumose inner seta almost medially, an oblique row of long spinules on anterior surface, a few spinules near each inner seta, and many hairs along outer edge; third segment a little shorter than preceding segment, armed with one outer spine subapically, two thick terminal setae which are spinulose outwards and hairy inwards, and one plumose inner seta almost medially, and with slender spinules along outer edge, short spinules on anterior and posterior faces. Leg 2 (Fig. 24-2). Intercoxal plate furnished with numerous spinules and hairs on and near free edge. Goxa with many slender spinules. Basis 

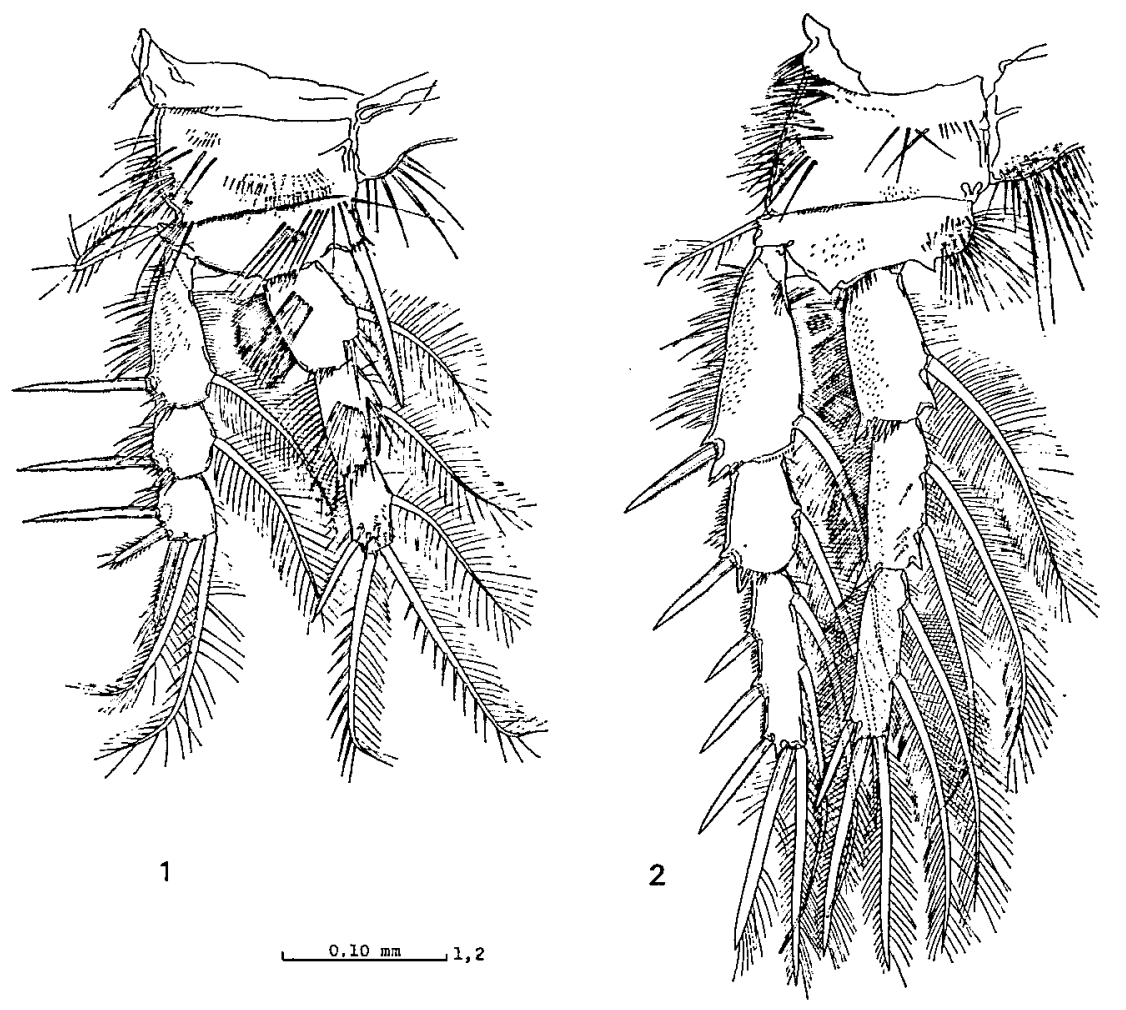

Fig. 24. Cerviniopsis muranoi n. sp. Female (holotype): 1. leg 1; 2. leg 2.

forming two small spinous projections, one placed between exopodite and endopodite, the other placed near inner distal angle; outer seta bearing hairs sparsely; many slender spinules and long hairs on and near inner distal angle. Both rami three-segmented, subequal in length. Exopodite: first segment gradually widening toward apical, twice as long as second segment; each of first and second segments armed with one outer spine and one plumose inner seta; third segment 1.5 times as long as second segment, armed with three, equally spaced, outer spines, two long terminal spines, and two plumose inner setae, one located subproximally, the other located medially; each segment fringed with spinules on outer edge and fine hairs on inner edge; many short hairs attached onto both anterior and posterior faces of first segment. Endopodite segments subequal in length; first two segments forming a spinous projection at each of outer and inner distal angles; first segment armed with one inner seta on a point at two-thirds the length from the base; second segment armed with two, widely spaced, inner setae; third segment armed with one outer spine on a clearly stepped subapical edge, two long terminal spines, and two widely spaced inner setae; all inner setae well-developed and plumose; outer edge of each segment densely fringed with long hairs; short hairs scattering on each anterior face of first two segments. L e g 3 (Fig. 25-1). Intercoxal plate, coxa, and 
basis as in leg 2. Both rami three-segmented. Exopodite armed as in leg 2. Endopodite: general shape of first two segments as in leg 2; first segment armed with one plumose inner seta which is thick and stout; second segment armed as in leg 2; third segment armed with one outer spine subapically, two long terminal
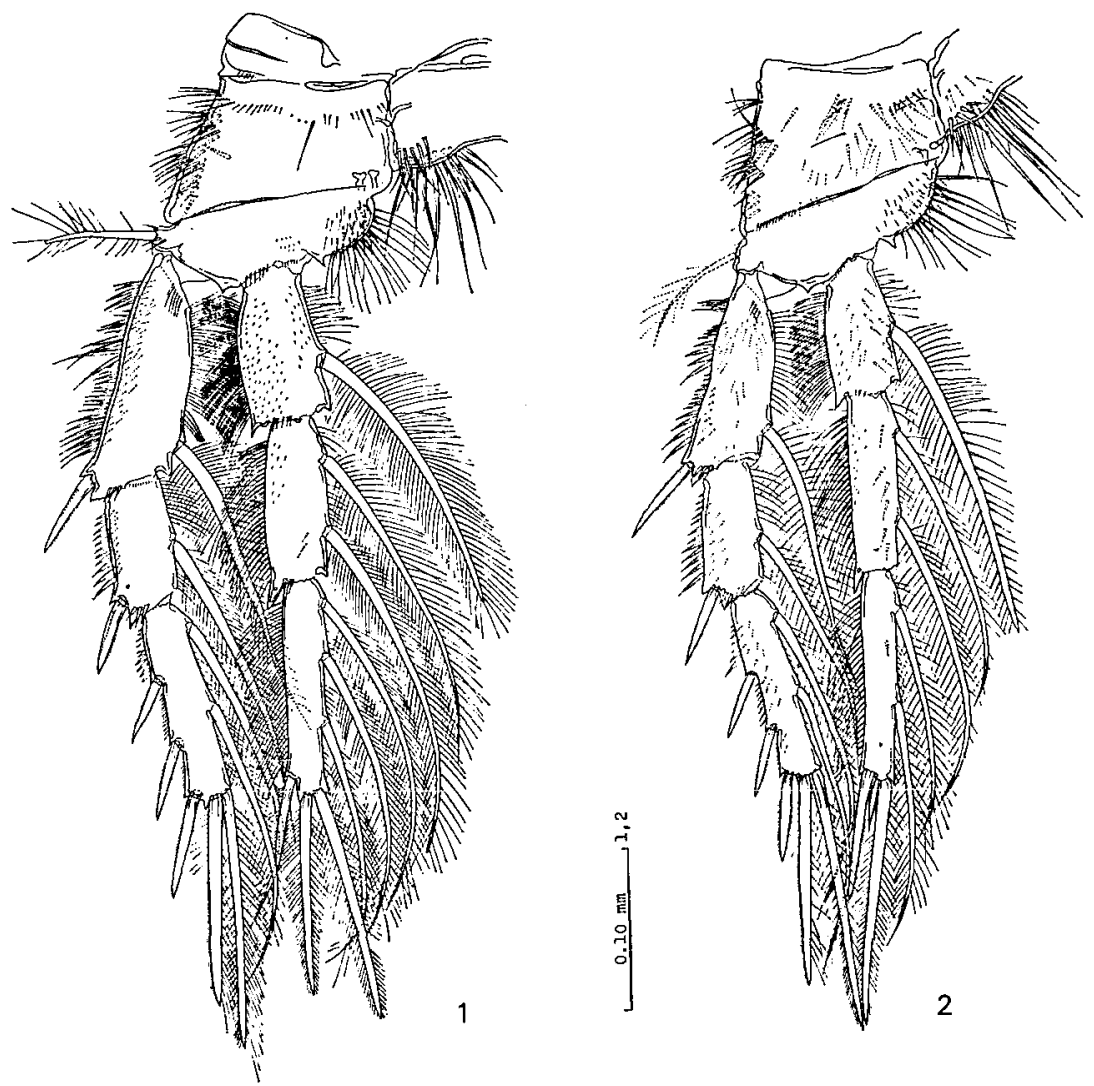

Fig. 25. Cerviniopsis muranoi n. sp. Female (holotype): 1. leg 3; 2. leg 4.

spines, and three plumose inner setae which are equally spaced. L e g 4 (Fig. 25-2). Intercoxal plate, coxa, and basis almost as in leg 3. Many spinules scattered on posterior face of coxa. Both rami three-segmented. Principal armature of exopodite and first two endopodite segments as in leg 2. Third endopodite segment armed with one outer spine subapically, two terminal spines, of which the outer is dwarf, and two, widely spaced, inner setae. L e g 5 (Fig. 22-1). Baseoendopodite small, with no inner expansion, armed with a long, somewhat hairy, outer seta. Exopodite represented by a subcylindrical segment which reaches the middle of genital double-somite, armed with one outer seta subapically and one long terminal seta which reaches the penultimate abdominal somite and is sparsely with hairs bilaterally. 
Male (allotype). Body (Figs. 26-1, 26-2) about $1.8 \mathrm{~mm}$ long, somewhat slimmer than the body of female. Two spermatophores occurring within hind body (Figs. 26-3, 26-4). Antennule (Fig. 26-5). Segmentation as in female.

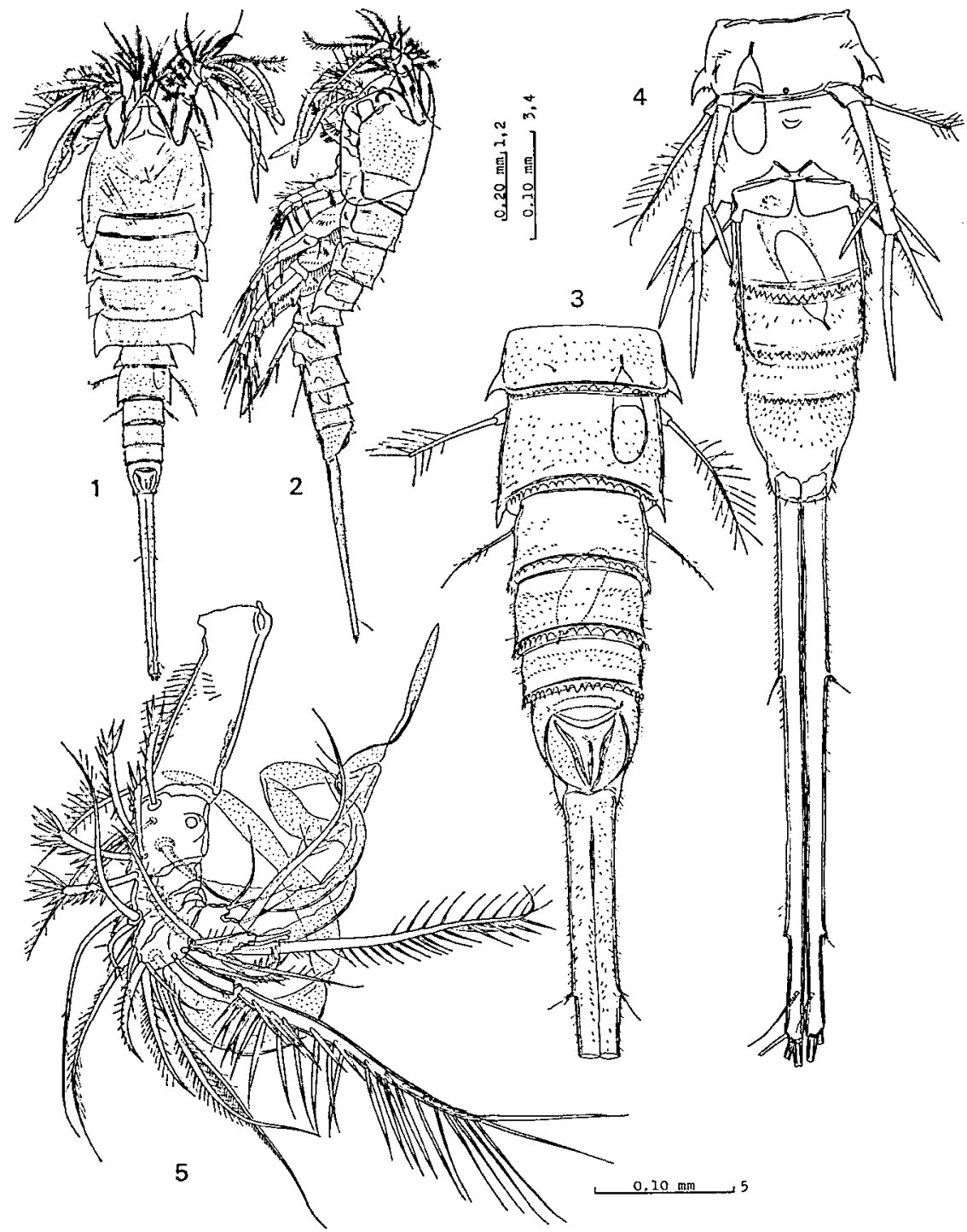

Fig. 26. Cerviniopsis muranoi n. sp. Male (allotype): 1. habitus, dorsal; 2. habitus, lateral; 3. leg 5 and abdomen, dorsal; 4. leg 5 and abdomen, ventral; 5. antennule.

First segment elongate as in female. A very thick aesthetasc arising from second, third, and fourth segments. Antenna, mandible, maxillula, maxilla, and $\mathrm{maxillipede}$ as in female. 
Leg 1,1 eg 2, $\operatorname{leg} 3$, leg 4 as in female. Leg 5 (Fig. 26-4). Baseocndopodite as in female. Exopodite represented by a long cylindrical segment, armed with one spine on a point at three-quarters the length of inner edge, two spines terminally and one spine on outer edge subapically. L eg 6 (Fig. 26-4) represented by a broad rectangular plate forming a short process at outer distal angle, terminating in two slender setae.

Remarks. The present new species resembles Cerviniopsis stylicauda Lang, 1936, which was reported from Spitzbergen, in having very much elongated furcal rami. Although Lang's description of $C$. stylicauda was very brief, the new species is discernible from $C$. stylicauda by a characteristic of the antennule. The antennule of the male of C. stylicauda illustrated by Lang (1936) shows that its first segment is scarcely longer than thick, whilst the first antennular segment of the present new species is very long, about three times as long as thick. This characteristic can be easily ascertained even in undissected specimens.

The specific name is in honor of Dr. M. Murano, Tokyo University of Fishcries, who gave me valuable samples collected with his net.

\section{Cerviniopsis minutiseta $\mathrm{n}$. sp.}

(Figs. 27-30)

Material. An adult malc dissected was designated as the holotype. Type-locality: Southeast off Mindanao, the Pacific Ocean. The specimen was collected with Murano's net (6-II-1979).

Male (holotype). Body (Figs. 27-1, 27-2) about $1.4 \mathrm{~mm}$ long, colorless and semitransparent, slim. Cephalon as long as second, third, and fourth thoracic somites combined; cephalic integument forming a triangular rostrum (Fig. 28-1), which is not defined basally and extends almost horizontally, furnished with many spinules attached onto frontal edges; posterior hyaline membrane extending over first thoracic somite and reaching second thoracic somite; labrum (Fig. 28-2) with short spinules along bilobate distal edge; paragnaths (Fig. 28-3) with soft hairs on inner edge of each lobe, some closely set spinules on anterior face near base of each lobe. Pleurotergite of first thoracic somite well defined under cephalic integument (see Fig. 28-1). Each pleurotergite of second (Fig. 28-4), third, and fourth thoracic somites furnished with a few spinules on each anterior lateral edge, fringed with a smooth hyaline membrane. Posterior hyaline membrane of each somite of hind body finely serrated (Figs. 27-3, 27-4, 27-5). Numerous very fine spinules scattered on hind body. Anal somite almost pyriform; anal operculum defined at base, semicircular. Furcal rami confluent with each other proximally, parallel; each ramus a little shorter than last five somites combined, armed with a setula on about the middle of outer edge, a setula on subapical outer edge, a basally geniculate fine seta on subapical dorsal face, and two principal terminal setae (broken). 


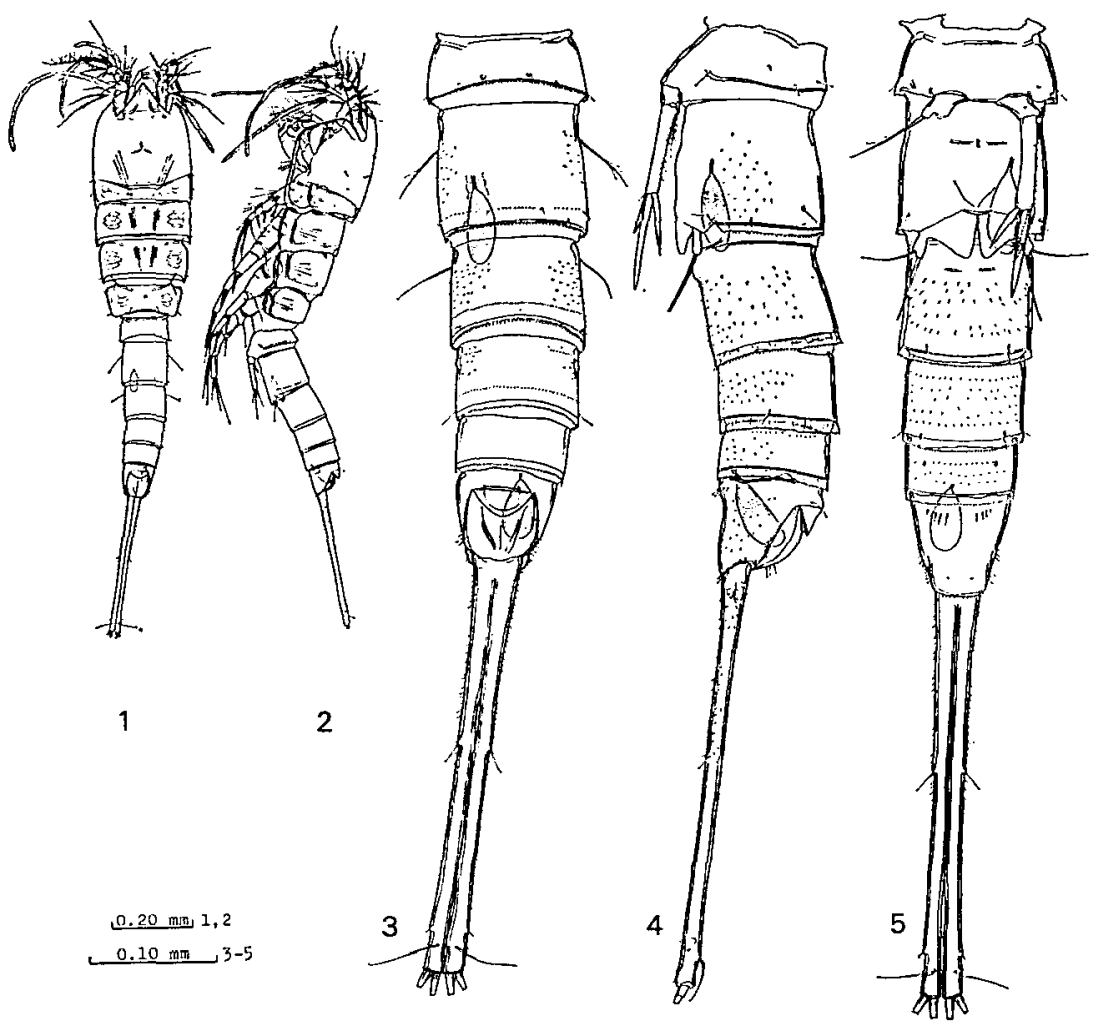

Fig. 27. Cerviniopsis minutiseta n. sp. Male (holotype): 1. habitus, dorsal;

2. habitus, lateral; 3 . hind body, dorsal; 4 . leg 5 and abdomen, lateral;

5. leg 5 and abdomen, ventral.

Antennule (Fig. 28-5) seven-segmented; first segment longest, twice as long as thick, with spinules anteriorly and posteriorly, armed with one seta on anterior distal edge; second segment armed with two long aesthetascs together with many setae; third segment armed with an aesthetasc; fifth and sixth segments very short; seventh segment posteriorly bipartite, armed with an aesthetasc together with plumose and spinulose setae. An t e n n a (Fig. 28-6). Precoxa very short. Coxa about as long as thick, with hairlike spinules on anterior face near distal end, a transverse row of fine spinules on inner face, a few fine spinules on posterior face. Allobasis about three times as long as coxa, with a longitudinal row of short spinules on proximal half of outer face, armed with one long seta on a point at a proximal third the length of anterior face, and one seta on subapical anterior face. Exopodite four-segmented, well-developed; four segments combined longer than coxa and allobasis combined; first segment as long as apical three segments combined, widening toward apical, with fine spinules on posterior face, armed with two setae, one located on a stepped edge at about the middle of anterior edge, the other located on apical anterior edge; second segment short, armed with one seta, which bears hairs proximally and short spinules distally, on anterior distal edge; third 


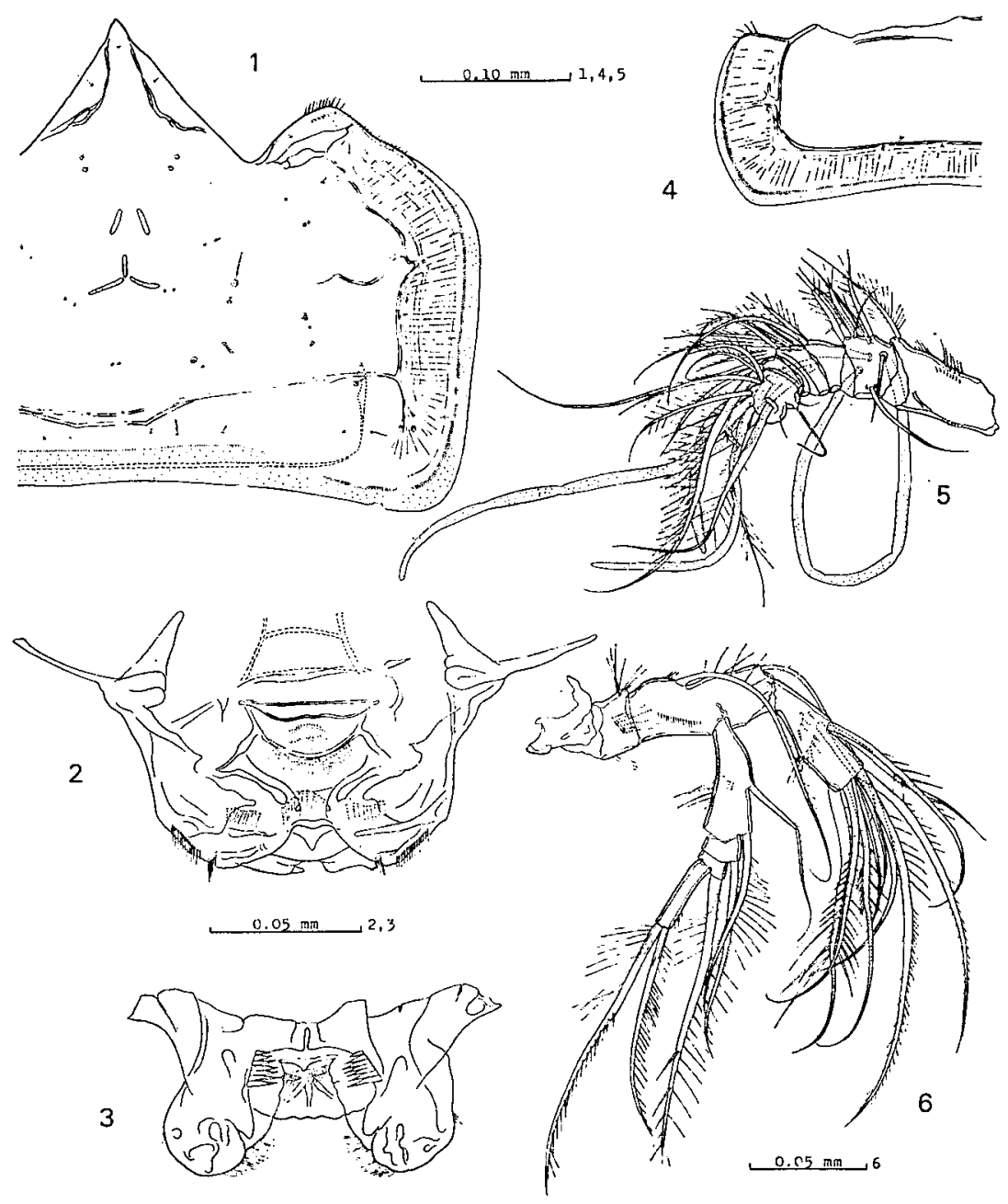

Fig. 28. Cerviniopsis minutiseta n. sp. Male (holotype): 1. rostrum, cephalic intcgument, and pleurotergite of first thoracic somite; 2. labrum; 3. paragnaths; 4. pleurotergite of second thoracic somite; 5 . antennule; 6 . antenna.

segment short, armed with one thick seta, which bears long fine spinules, on anterior distal edge; fourth segment slender, about twice as long as preceding two segments combined, terminating in two spinulose setae. Endopodite segment shorter than allobasis, as long as first exopodite segment, with two transverse rows of prominent spinules on inner face, armed with three closely set setae on a stepped edge at the middle of anterior face, seven more or less spinulose sctae on distal end. M a ndible (Fig. 29-1). Precoxa well sclerotized. Coxa-basis widening apically, as long as its greatest width, with fine spinules marginally and anteriorly, armed with four spinulose setae on inner distal angle. Exopodite consisting of four segments, apical three very short; first segment with fine long spinules on outer edge and anterior face, armed with two spaced setae which bear short spinules sparsely; 
second and third segments each armed with one inner seta; fourth segment small, terminating in two plumose setae. Endopodite consisting of one segment armed with three closely set setae on inner edge almost medially, seven setae on distal end. Maxillula (Fig. 29-2). Arthrite of precoxa with fine spinules on posterior face, armed with two parallel setae anteriorly, ten spines and setae on inner edge, and one finely spinulose seta on dorsal edge. Epipodite represented by a plumose seta. Inner process of coxa with a few spinules subapically, armed with six setae apically. Inner process of basis with a row of fine spinules posteriorly, armed with 13 (?) slender setae apically. Endopodite represented by a rudimentary short segment armed with three setae, one of which is plumose. M axilla (Figs. 293, 29-4). Syncoxa swelling outwards, with short spinules on and near outer edge,

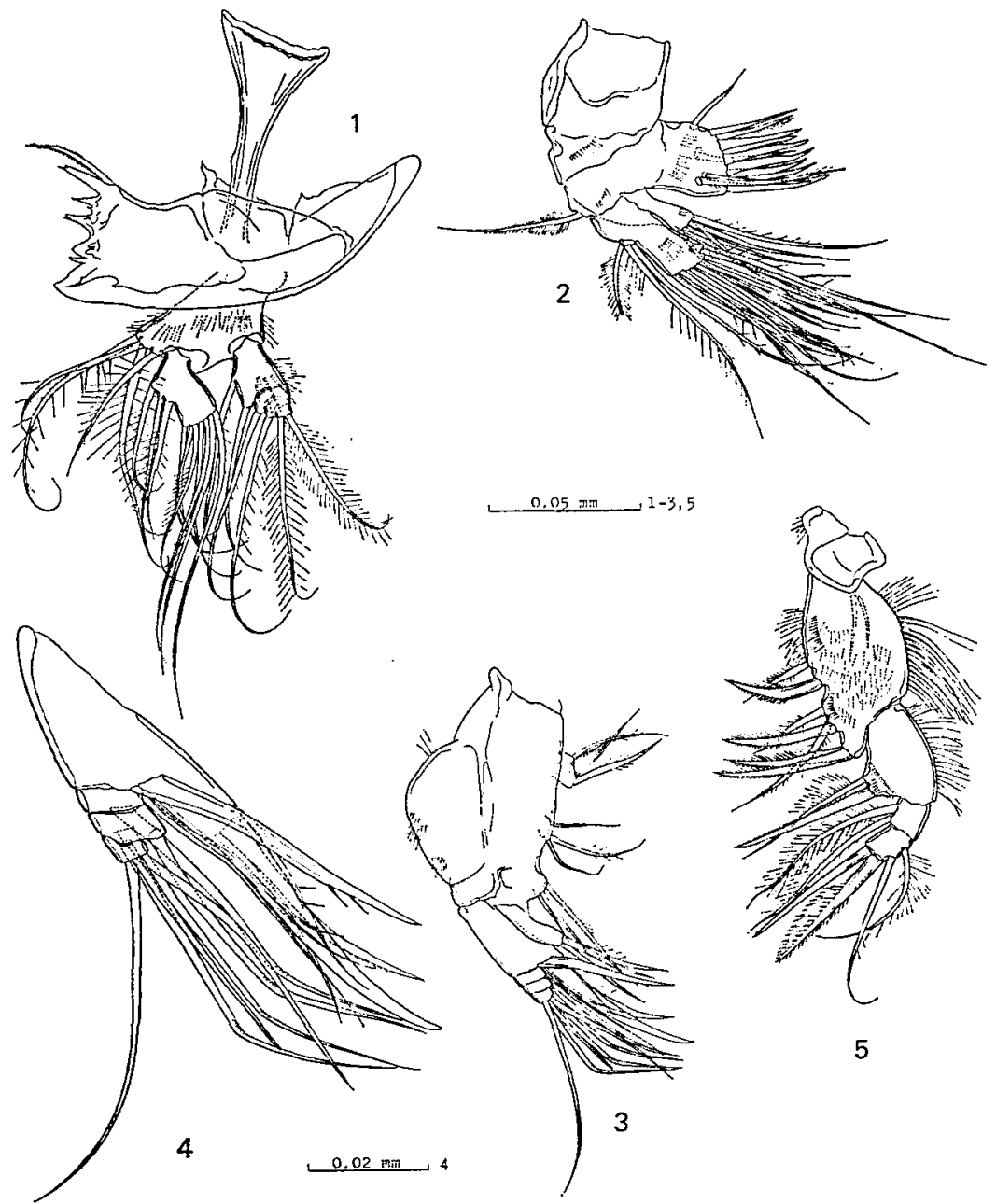

Fig. 29. Cerviniopsis minutiseta n. sp. Male (holotype): 1. mandible; 2. maxillula; 3. maxilla; 4. maxilla (syncoxa omitted); 5 . maxillipede. 
furnished with four widely spaced endites; first endite thick, armed with four slender setae and one thick hairy seta; second endite small, armed with three slender setae; third endite represented by a small protuberance with three setae; fourth endite represented by a cylindrical process armed apically with three setae, two of which are stout. Inner process of basis armed with a spine on its posterior face near dorsal base, forming apically a strong claw which is accompanied with one spine and one slender seta on its anterior base, one slender seta at its dorsal base; three very fine juxtaposed setae arising from dorsal edge close to inner base of endopodite. Endopodite consisting of three short segments; first segment armed with one geniculate spiniform seta anteriorly; second segment armed with two geniculate spiniform setae, one located anteriorly, the other placed on inner distal edge; third segment small, armed with one geniculate spiniform seta anteriorly and three simple setae apically. Maxillipede (Fig. 29-5). Precoxa with spinules on inner edge. Coxa somewhat swelling outwards, about twice as long as wide, fringed with long hairs on outer edge, with many scattered spinules together with a few cirri on posterior face, two rows of spinules on anterior face along inner edge, armed with seven inner appendices; first appendix represented by a short spinulose seta located almost medially; second appendix represented by a spinulose arched spine; third, fourth, and fifth appendices close to each other, each of the former two represented by a spinulose seta and the rest represented by a spinulose spine; sixth and seventh appendices close to each other, each represented by a spinulose spine. Basis with hairs on outer edge, short spinules on anterior and posterior faces near inner edge, armed with one plumose seta and one spinulose spine on a protruded inner edge. First endopodite segment as long as wide, armed with two plumose inner setae. Second endopodite segment as long as first endopodite segment, armed with two straight terminal spines, of which the outer is markedly spinulose, and two hairy setac on outer edge.

L e g 1 (Fig. 30-1) smaller than succeeding legs. Intercoxal plate low, furnished with hairs on free edge near each lateral end. Coxa wider than long, with rows of short spinules anteriorly and posteriorly, fringed with hairlike spinules along outer edge. Basis with two arched rows of long spinules on anterior face, hairs on inner edge, armed with one outer spine which is as long as first exopodite segment and with hairlike spinules apically, and one inner spine with spinules densely. Both rami three-segmented, subequal in length. Exopodite: first segment little longer than other segments, with fine spinules along outer edge anteriorly and posteriorly, hairs on inner edge, armed with one outer spine and one hairy inner seta; second segment as long as wide, with long spinules on anterior face near outer distal angle, armed with one arched outer spine and one hairy inner seta; third segment a little longer than wide, armed with three outer spines, the middle shortened, and two apical setae which bear hairlike spinules sparsely; outer edge of each segment fringed with fine spinules. Endopodite: first segment shorter than wide, with one plumose inner seta almost medially; second segment narrower than first segment, with a row of long spinules on anterior face, armed with one plumose 

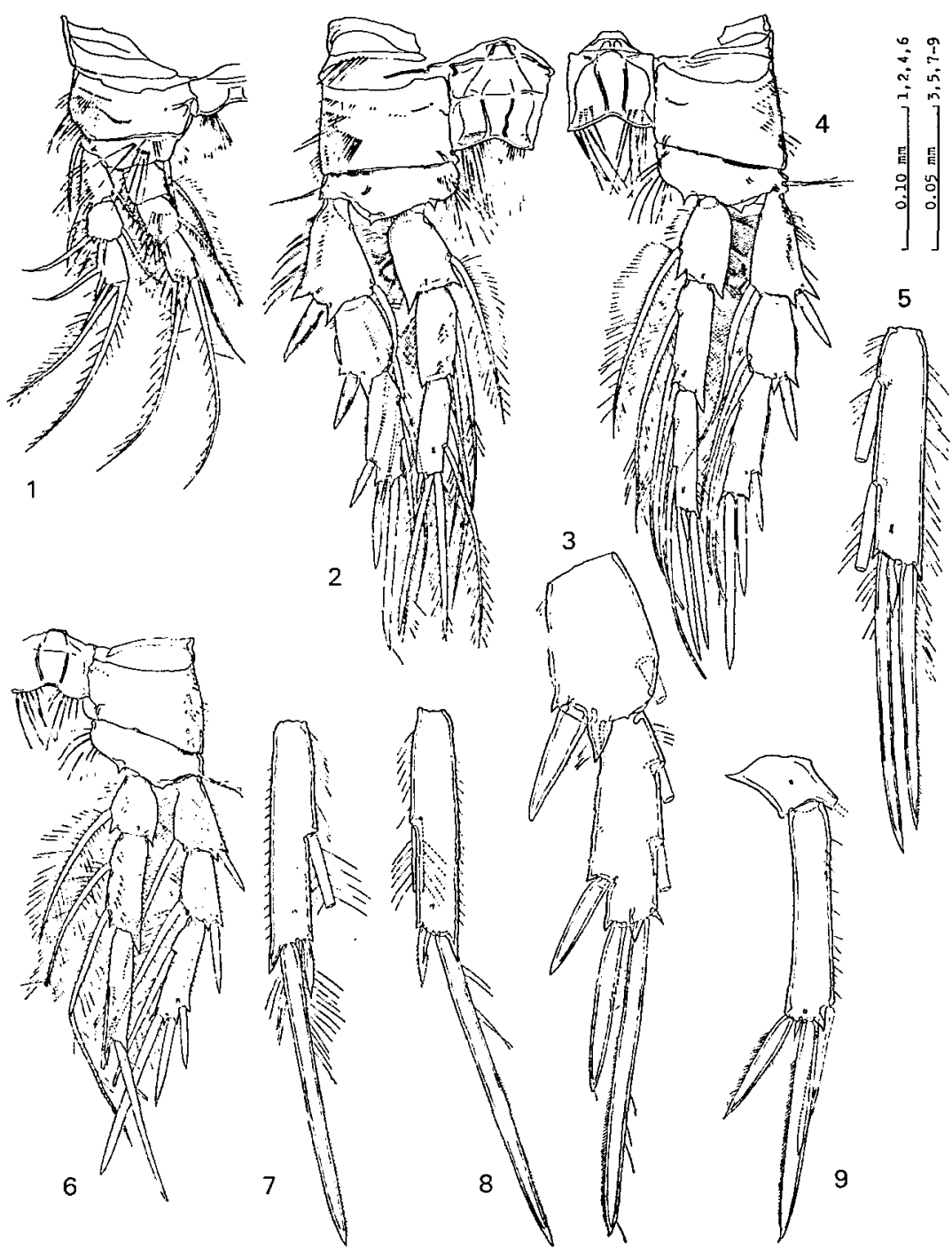

5

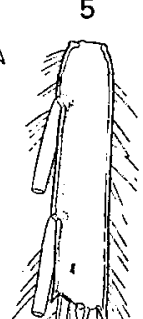

Fig. 30. Cerviniopsis minutiseta n. sp. Male (holotype): 1. leg 1; 2. leg 2; 3. apical two exopodite segments of leg 2 (inner setae omitted); 4. leg 3; 5. apical endopodite segment of leg 3 (inner setae omitted); 6 . leg $4 ; 7$. apical endopodite segment of right leg $4 ; 8$. apical endopodite segment of left leg $4 ; 9$. leg 5.

inner seta subapically; third segment with one spine on subapical outer edge, two terminal setae which bear hairlike spinules sparsely, and one seta on about the middle of inner edge; all segments fringed with fine spinules on each outer edge. L e g 2 (Fig. 30-2). Intercoxal plate as long as wide, with long hairs on free edge, short spinules on posterior face along free edge. Coxa as long as wide, with spinular rows anteriorly and posteriorly. Basis not protruded outwards, forming two small spinous projections, one placed between rami, the other placed near inner base of 
endopodite, with numerous hairs around inner edge, armed with a small outer seta. Both rami subequal in length, three-segmented. Exopodite: first segment widening apically, with long spinules on outer edge, short spinules on posterior face along outer margin, hairs densely on inner edge, armed with one thick serrate outer spine which is placed between two spinous projections, and one plumose inner seta; second segment delicately serrated outwards, armed with one thick outer spine which is placed between spinous projections, and one inner seta; third segment serrated outwards, armed with two outer spines located subapically, one long outer terminal spine and one dwarfed inner terminal seta (see Fig. 30-3), and two inner setae. Endopodite: first segment forming a spinous projection on both distal angles, armed with one plumose inner seta on a point at two-thirds the length from the base; second segment armed with two inner setae which are widely spaced; third segment armed with one short outer spine located near distal end, two hairy terminal spines which are subequal in length, and two inner setae which are widely spaced; all segments densely fringed with hairs along each outer edge. L e g 3 (Fig. 30-4). General shape and principal armature of intercoxal plate, coxa, basis, and exopodite as in leg 2 . Endopodite slimmer than the counterpart of leg 2; armature of first two segments as in leg 2; third segment armed apically with one small seta (see Fig. 30-5) which is placed between two long spines (each representing the outer spine and the inner terminal spine), and armed with two widely spaced inner setae. Leg 4 (Fig. 30-6). Intercoxal plate without spinules posteriorly. Exopodite: first two segments armed with one outer spine and one inner seta; outer edge of second and third segments not serrate but spinulose; third segment armed with two outer spines, one outer terminal spine and one dwarfed inner terminal seta, and one inner seta located on a point at a proximal third the length. Endopodite: first segment short, armed with one plumose inner seta; second segment about 1.5 times as long as first segment, with short spinules on outer edge and posterior face, armed with two widely spaced inner setae; third segment with short spinules on outer edge, armed apically with one long spine (the outer spine), one fine setula, and one dwarfed seta (see Figs. 30-7, 30-8); one seta arising from about the middle of inner edge. L e g 5 (Fig. 30-9). Baseoendopodite small, armed with a seta (broken) on a short outer process. Exopodite consisting of a subcylindrical segment which is about 6 times as long as its median width, with short spinules on outer edge, armed with one apical setula placed between two serrate spines, one spine on subapical outer edge. L e g 6 (Fig. 27-5) represented by a broad plate forming a short cylindrical outer process, which bears two slender setae.

Remarks. Within the genus, the present new species is unique in having dwarfed spines or setae on the apical segments of leg 2, leg 3, and leg 4: The specific name alludes to this characteristic. On the other hand, there is no doubt that the number of outer spines of the apical exopodite segment of leg 2, leg 3, and leg 4 is of a special taxonomic value for this genus. The new species has two outer spines on the apical exopodite segment of these legs. In this respect, the new species accords 
with Cerviniopsis obtusirostris Brotzkaja, 1963 (redescribed by Por, 1969), and C. langi Soyer, 1970, and differs from other congeneric species (C. clavicornis Sars, 1903, C. longicaudata Sars, 1903, C. intermedia Lang, 1936, C. stylicaudata Lang, 1936, C. inermis Smirnov, 1946, C. acutirostris Brotzkaja, 1963, C. curviseta Brotzkaja, 1963, C. smirnovi Por, 1969, C. muranoi mihi, and probably C. gorvnovi Smirnov, 1946).

\section{Cerviniopsis sp. aff. curviseta Brotzkaja}

(Figs. 31-33)

Material. A female (?) of the fourth copepodid stage was dissected. The specimen was collected with Murano's net (Southeast off Mindanao, the Pacific Ocean; 6-II-1979).

Female (the fourth copepodid stage). Body (Figs. 31-1, 31-2) about $1.3 \mathrm{~mm}$ long, colorless, almost transparent, furnished with short hairs scattered on surfaces. Cephalon fairly thick in lateral view (see Fig. 31-2), as long as succeeding three somites combined, forming a triangular rostrum, which is not defined basally (Fig. $32-1$ ) ; integument fringed with numerous hairlike spinules frontally and ventrally, furnished with no hyaline membrane posteriorly. Labrum (Fig. 31-4) trapezoid in outline, furnished with stout marginal spinules. Paragnaths (Fig. 31-5) with soft hairs on inner edge of each lobule. Pleurotergite of first thoracic somlte (Fig. 31-3) not covered with cephalic integument. Each pleurotergite of second, third, and fourth thoracic somites fringed with hairlike spinules laterally. Posterior hyaline membrane of hind body somites not so developed (see Figs. 31-6, 31-7, 31-8). Anal somite furnished with a transverse row of prominent spinules ventrally; anal operculum defined at base, semicircular, fringed with fine spinules. Furcal rami confluent with each other proximally, parallel; each ramus as long as last two abdominal somites combined, furnished with a fine setula on a point at a proximal third the length of outer edge, one small outer seta on a point at three-quarters the length from the base; principal terminal setae broken; a scar of a seta occurring on inner dorsal face near the posterior lateral seta.

Antennule (Fig. 32-1) five-segmented; first segment subcylindrical, as long as other segments combined, with scattered short spinules, armed with a short seta anteriorly; second segment armed with spinulose rod-shaped setae dorsally and anteriorly; third segment protruded anteriorly, and with a slender aesthetasc together with spinulose setae; fourth and fifth segments small, armed with spinulose setae. Antenna (Fig. 32-2). Coxa with fine spinules anteriorly and posteriorly. Allobasis twice as long as thick, with spinules on proximal anterior face, armed anteriorly with two setae, one placed on a point at a proximal third the length, the other located subapically. Exopodite four-segmented; four segments combined as long as allobasis; first segment as long as apical three segments combined, with spinules on posterior edge, armed with one small seta on the middle of anterior edge, one thick spinulose seta on anterior distal edge; second and third segments short, armed with a thick spinulose seta on each anterior distal edge; fourth 


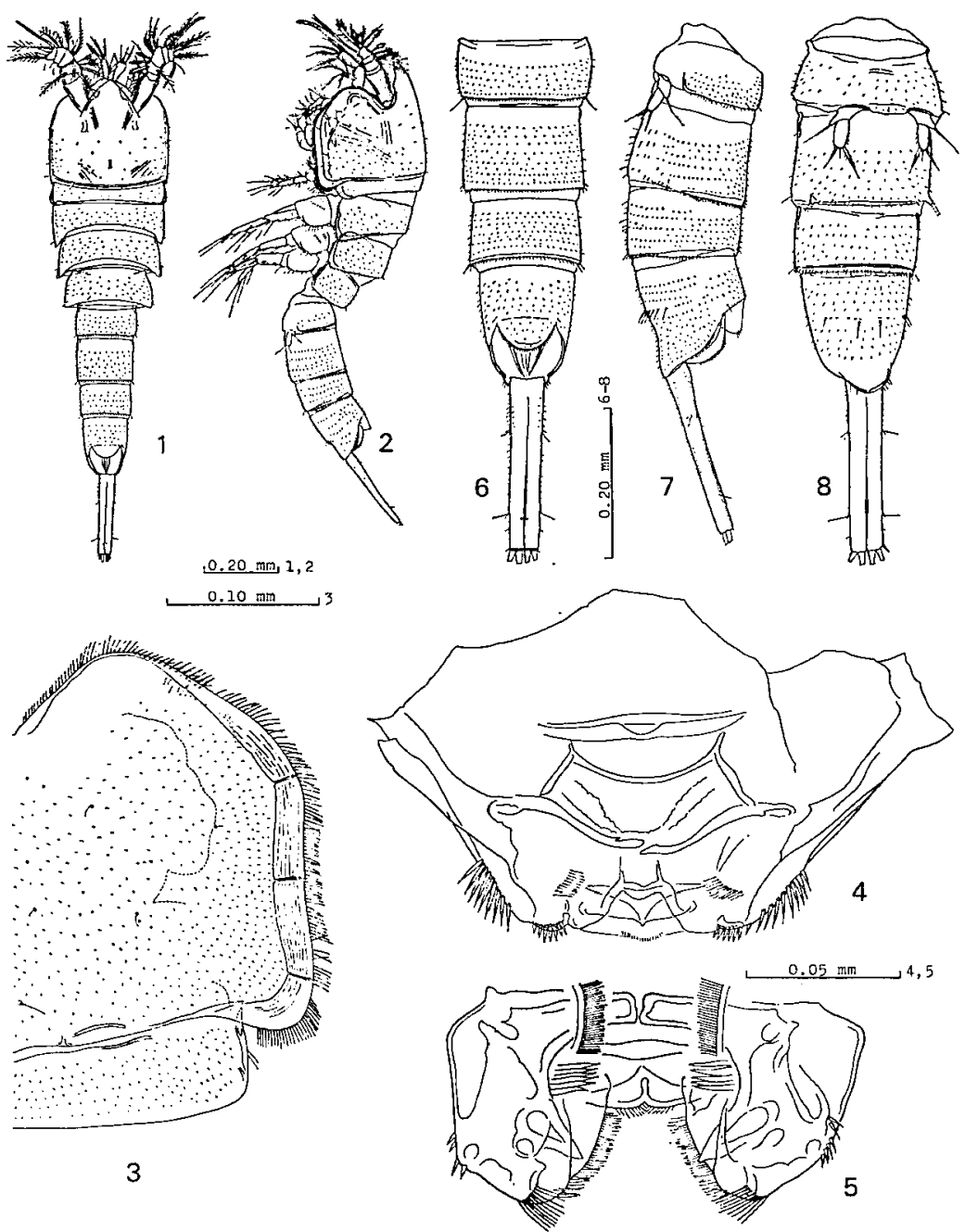

Fig. 31. Cerviniopsis sp. aff. curviseta Brotzkaja. Fourth copepodid stage: 1. habitus, dorsal; 2. habitus, lateral; 3. cephalic integument and pleurotergite of first thoracic somite; 4. labrum; 5 . paragnaths; 6 . hind body, dorsal; 7. leg 5 and abdomen, lateral; 8. leg 5 and abdomen, ventral.

segment slim, terminating in two setae which bear hairlike spinules bilaterally. Endopodite segment as long as allobasis, with an almost transverse row of long spinules medially, armed with three spinulose setae on a stepped edge at the middle of anterior face, four spinulose stout setae and one basally bifurcate seta on distal edge. Mandible (Fig. 32-3). Precoxa well sclerotized, armed with welldeveloped spines and a spinulose stout seta on cutting edge. Coxa-basis widening distally, with many prominent spinules on anterior face, armed with four setae on inner apical angle, two of which are thickened at each proximal half and markedly spinulose. Exopodite three-segmented; first segment subdivided by a suture, armed with two inner setae on proximal part and one inner seta on distal part; second 


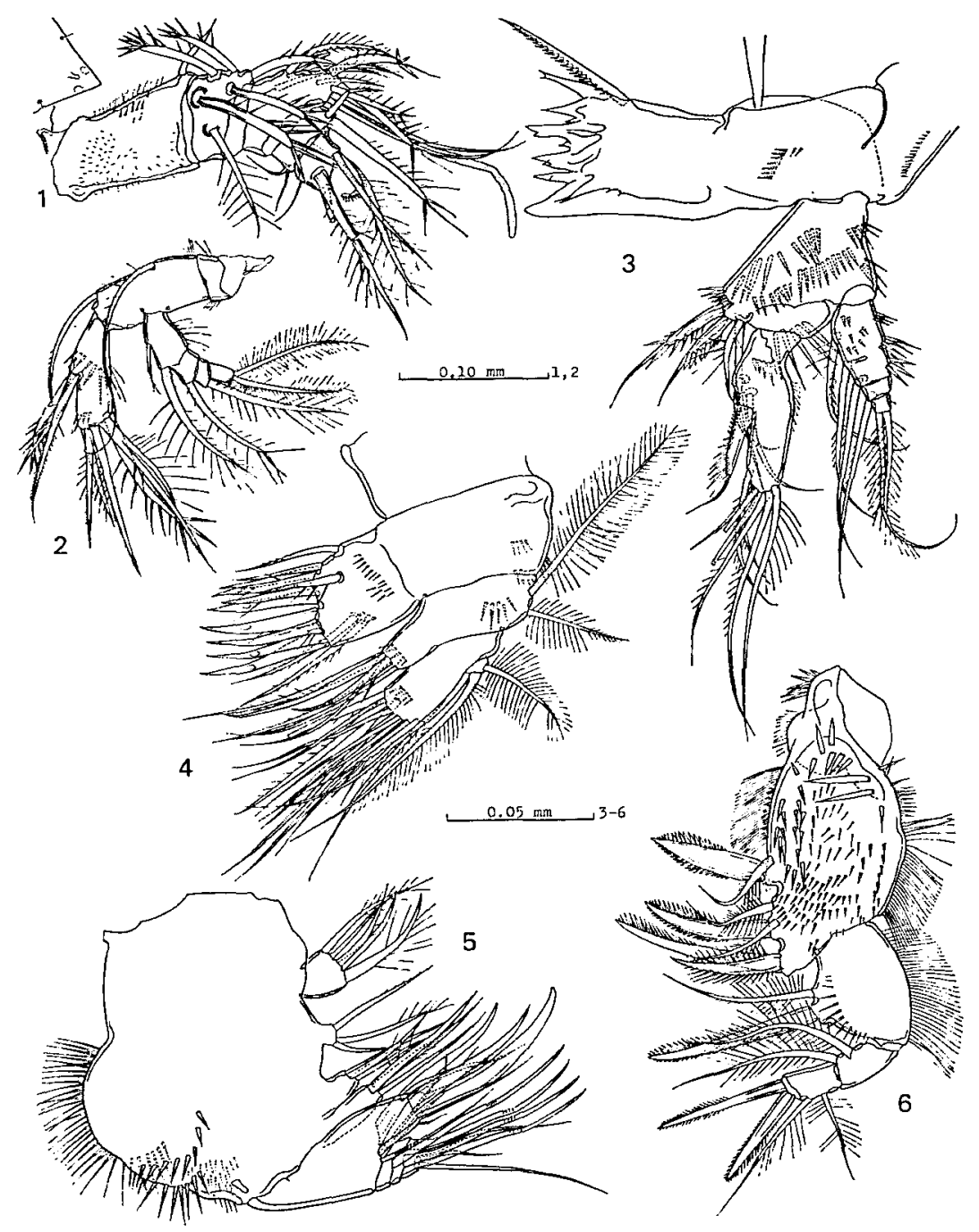

Fig. 32. Cerviniopsis sp. aff. curviseta Brotzkaja. Fourth copepodid stage: 1. rostrum and antennule; 2. antenna; 3. mandible; 4. maxillula; 5. maxilla; 6. maxillipede.

segment short, armed with one inner seta; third segment small, terminating in two hairy setae. Endopodite consisting of a segment which is longer than three exopodite segments combined and somewhat sinuate, with a transverse row of spinules on anterior face near its base, armed with one unilaterally spinulose spine, which is accompanied with two setae near its base, on a clearly stepped edge at about the middle of outer margin, eight hairy setae around its apex. Maxill u l a (Fig. 32-4). Precoxa with spinules on anterior face near outer distal angle; arthrite with vertically arranged spinules on posterior face, armed anteriorly with two parallel setae which bear hairs sparsely, eight spines and one short seta on inner 
edge, one seta on dorsal edge, and one seta, which bears a few spinules, on posterior face near inner dorsal angle. Epipodite represented by two plumose setae. Coxa with an arched row of spinules on anterior face; inner process with spinules on anterior face near apex, armed apically with six setae. Inner process of basis thicker than coxal inner process, with spinules on anterior face near apex, armed apically with 10 setae. Exopodite represented by a small segment with three plumose setae. Maxilla (Fig. 32-5). Syncoxa swelling outwards, furnished with numerous spinules on and near outer edge, with four endites; first endite well developed, armed apically with two slender setae and three spiniform setae, most of which bear hairlike spinules; second endite small, with three setae; third endite short, cylindrical, with three setae; fourth endite close to third endite, cylindrical, armed with two spiniform setae and one slender seta. Inner process of basis forming a strong arched claw which is accompanied with one seta on dorsal base, one setula near ventral base, one spine and one slender seta on anterior base, one spine arising from posterior face; three slender setae attached onto inner distal edge close to base of endopodite. Endopodite consisting of three short segments; first segment armed with one medially geniculate elongate spine on anterior distal edge; second segment with two medially geniculate elongate spines, one located on anterior distal edge, the other placed on inner (dorsal) distal edge; third segment small, with one geniculate elongate spine and three slender setae apically. Maxillipede (Fig. 32-6). Precoxa indistinctly demarcated from coxa, with spinules and hairs on inner edge. Coxa about 1.5 times as long as wide, rounded at outer margin, with numerous scattered spinules posteriorly, fringed densely with hairs on inner and outer edges, armed with seven inner appendices; first appendix represented by a spinulose short seta located almost medially; second appendix close to the first, represented by a very thick spinulose spine; third appendix separated from the second by a notch, represented by a spinulose short seta; fourth appendix represented by a spinulose seta arising from posterior face near third appendix; fifth appendix represented by a spinulose thick spine; sixth and seventh appendices close to each other, separated from fifth appendix by a notch, each represented by a spinulose spine. Basis about half as long as coxa, protruding inwards, with long hairs on outer edge, an arched row of spinules along inner edge, armed with one hairy seta and one spinulose long spine on protruded inner edge. Endopodite consisting of two segments which are subequal in length; first segment armed with two hairy inner setae; second segment armed with two spinulose spines apically, two hairy setae on outer edge.

L e g l (Fig. 33-1). Intercoxal plate bilaterally protruded on free edge, fringed with hairlike spinules. Coxa shorter than wide, with transverse rows of prominent spinules on anterior face. Basis with two rows of long spinules on anterior face above endopodite, armed with a spinulose outer spine and a spinulose spine at inner distal angle. Both rami two-segmented. Exopodite: first segment with prominent spinules on anterior face and outer edge, hairs on inner edge, armed with one outer spine which bears short spinules, and one hairy short inner seta; second 
segment as long as first segment, armed with one spine on about the middle of outer edge, two short spines on subapical outer edge, two hairy setae apically, two short inner setae. Endopodite: first segment as long as wide, with long spinules on anterior face and inner distal angle, armed with one hairy inner seta; second segment 1.8 times as long as first segment, armed with one spinulose short spine on subapical stepped outer edge, two stout setae apically, and two hairy inner setae; each outer edge with fine spinules. L e g 2 (Fig. 33-2) bigger than leg 1. Intercoxal plate as long as wide, scarcely concaved, with many minute spinules scattered on anterior face, a row of spinules on anterior face along free edge, on which long hairs are placed; a few prominent spinules on posterior face along free edge. Coxa furnished with rows of spinules anteriorly and posteriorly. Basis forming a small spinous projection between exopodite and endopodite and at inner distal angle,

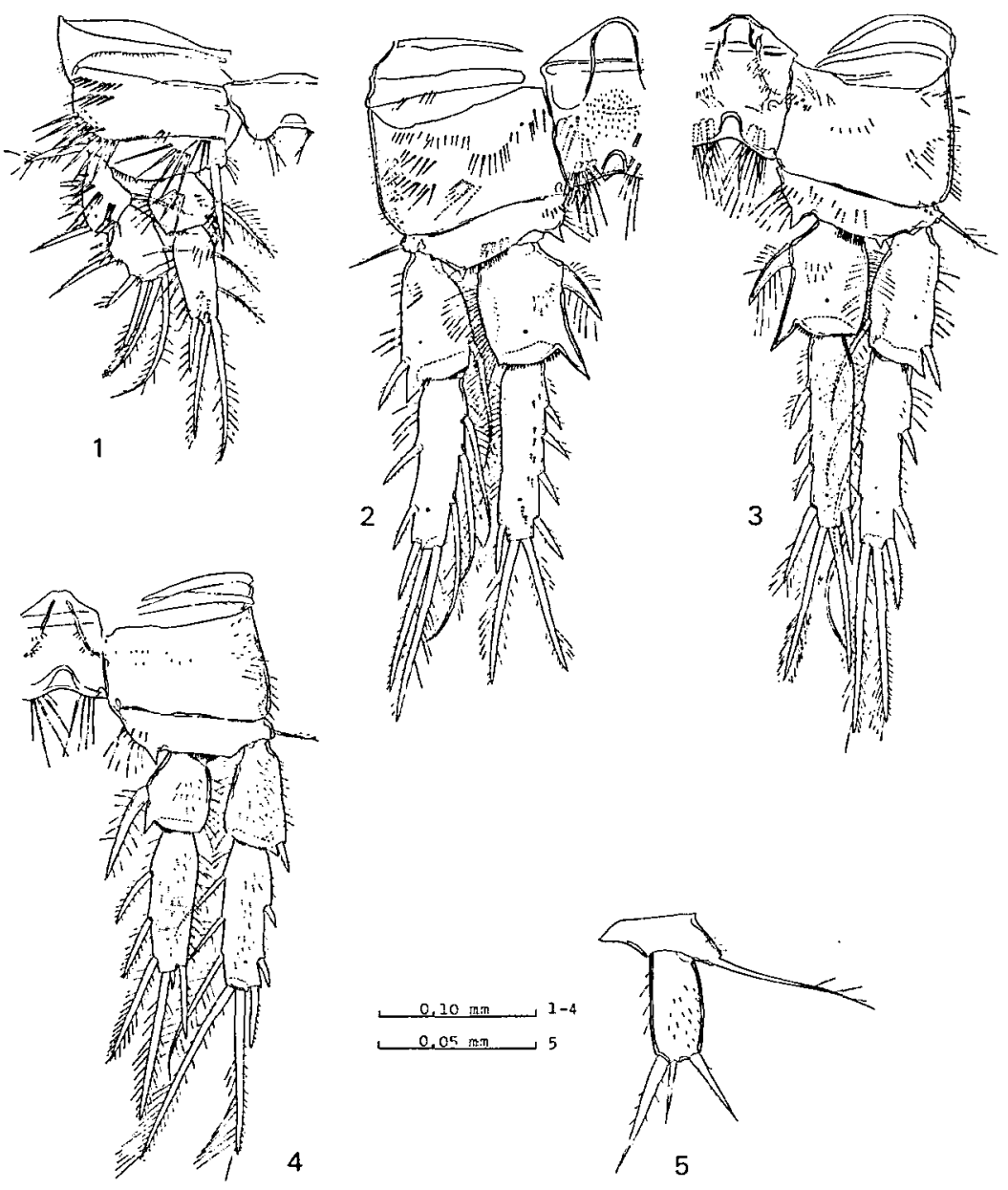

Fig. 33. Cerviniopsis sp. aff. curviseta Brotzkaja. Fourth copepodid stage:

1. $\operatorname{leg} 1 ; 2 . \operatorname{leg} 2 ; 3$. $\operatorname{leg} 3 ; 4$. leg $4 ; 5$. leg 5. 
furnished with hairs on inner edge; outer seta small. Both rami two-segmented, subequal in length. Exopodite: first segment about twice as long as wide, forming a spinous projection at outer distal angle, fringed with hairs on inner edge, armed with one outer spine and one hairy inner seta; second segment 1.4 times as long as first segment, armed with three short outer spines, two long spines apically, and three inner setae which are almost equally spaced and hairy. Endopodite: first segment thick, forming a strong spinous projection at inner angle, fringed with hairs on outer edge, minute spinules on distal edge, armed with one thick spiniform seta on a point at a proximal third the length of inner edge; second segment 1.5 times as long as first segment, fringed with hairs on outer edge, armed with one short outer spine on a subapical stepped edge, two spines apically, four very short setae on inner edge. L e g 3 (Fig. 33-3). Segmentation and principal armature as in leg 2. L e g 4 (Fig. 33-4) smaller than leg 2 and leg 3. Spinous projection of basis between two rami very small. Both rami two-segmented. Exopodite: first segment forming a rudimentary projection at outer distal angle, armed with one short outer spine, without inner seta; second segment 1.3 times as long as first segment, armed with three outer spines, two spiniform setae apically, three slender inner setae. Endopodite: first segment forming a small spinous projection at inner distal angle, armed with one thick spiniform seta on the middle of inner edge; second segment 1.6 times as long as first segment, armed with a spine on subapical outer edge, two apical spines, the outer rudimentary, and three short inner setae. Leg 5 (Fig. 33-5). Baseoendopodite not forming inner expansion, armed with one outer seta which bears a few hairs subapically. Exopodite consisting of a segment which is twice as long as wide, with hairlike spinules on inner edge and anterior (ventral) face, armed with two short apical setae, the outer very small, and one short seta on subapical outer edge. L e g 6 (Fig. 31-8) represented by a small projection terminating in a seta (broken).

Remarks. The present single specimen of the fourth copepodid stage resembles Cerviniopsis curviseta Brotzkaja, 1963, and C. acutirostris Brotzkaja, 1963, in the posession of shortened inner setae on the endopodites of $\operatorname{leg} 2, \operatorname{leg} 3$, and leg 4 . The present specimen has three inner setae on the second exopodite segment of leg 4 . There is no doubt that the proximalmost seta represents the single inner seta of the middle segment of the three-segmented leg; therefore, the presumed adult of this copepodid has (at least) two inner setae on its third exopodite segment of leg 4 . In this respect, the present specimen differs from $C$. acutirostris because $C$. acutirostris has only one seta on the third exopodite segment of leg 4 . The present specimen, moreover, closely resembles $C$. curviseta in the general shape and armature of the maxillipede with very thick spines on its coxa (see Brotzkaja, 1963, Fig. 7).

Although the sex of this copepodid is not clear, its thickset appearance of the cephalon (see Fig. 31-2) suggests it is female. 


\section{Pseudotachidius bipartitus Montagna pacificus n. subsp.}

(Figs. 34-39)

Material. An adult female dissected was designated as the holotype, and a dissected female of the fifth copepodid stage was designated as a paratype. Type-locality: Southeast off Mindanao, the Pacific Ocean. The specimens were collected with Murano's net (6-II-1979).

Female (holotype). Body (Figs. 34-1, 34-2) including rostrum about $1.8 \mathrm{~mm}$

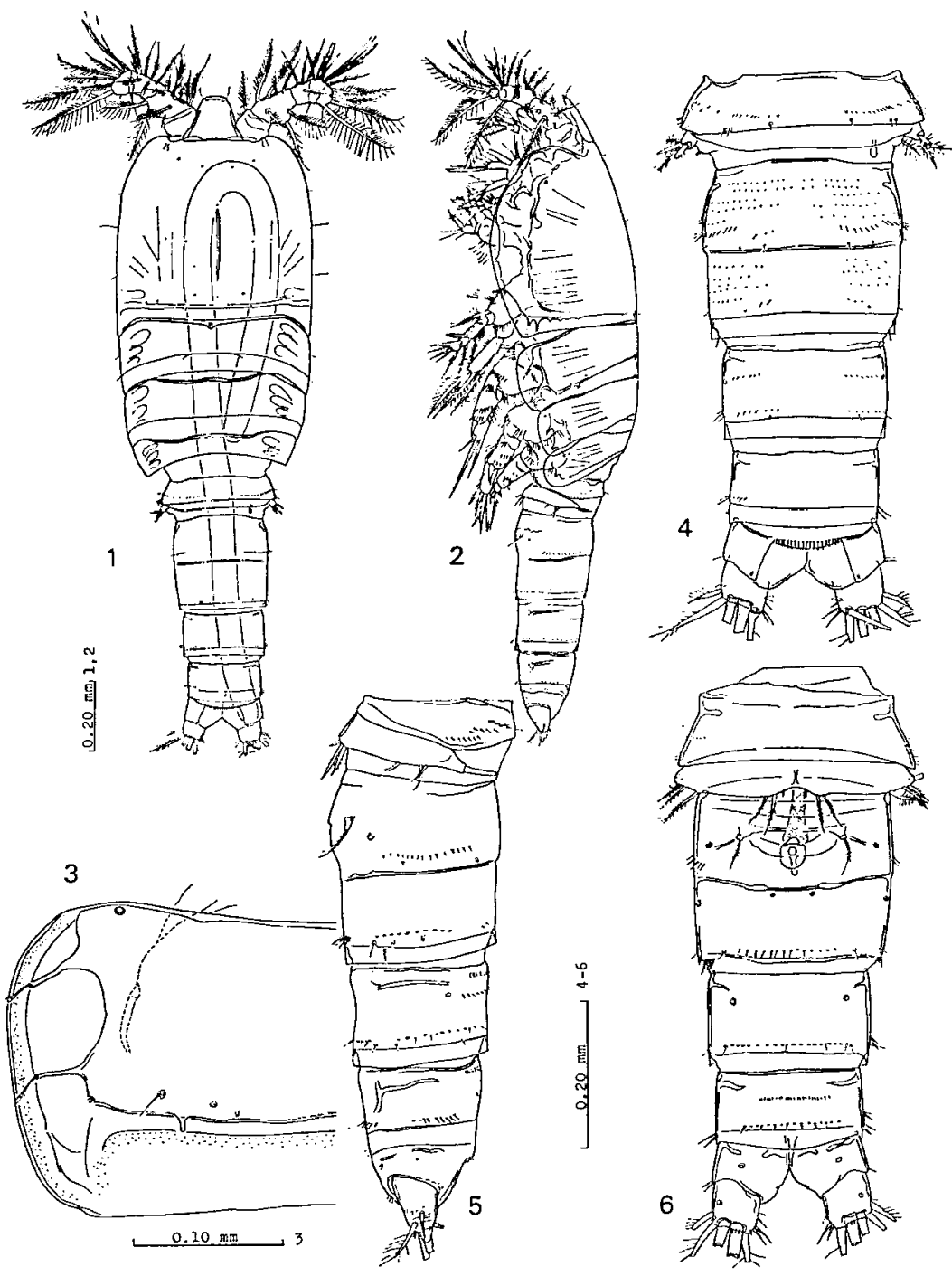

Fig. 34. Pseudotachidius bipartitus Montagna pacificus n. subsp. Female (holotype): 1. habitus, dorsal; 2. habitus, lateral; 3. pleurotergite of first free thoracic somite; 4 . leg 5 and abdomen, dorsal; 5. leg 5 and abdomen, lateral; 6. $\operatorname{leg} 5$ and abdomen, ventral. 
long, somewhat depressed dorsoventrally, colorless, glossy. Rostrum (Fig. 35-1) clearly defined at base, furnished with a sensory hair at both sides of flat frontal edge; three pores occurring on dorsal face. Cephalothorax $0.55 \mathrm{~mm}$ wide, rostrum excluded, as long as wide, a little longer than succeeding three thoracic somites combined; prominent pores occurring especially on dorsal face. Each pleurotergite of first three thoracic somites forming a well-developed hyaline membrane (see Fig. 34-3). Hind body (fourth thoracic somite and abdomen) much slimmer than fore body. Fourth thoracic somite (Figs. 34-3, 34-5) short, furnished with fine spinules roughly arranged transversely; hairs occurring on dorsal face along posterior edge. Genital double-somite (Figs. 34-4, 34-5, 34-6) as long as wide, subdivided by a circumambient narrow suture; structure of genital area rather simple (Fig. 34-6); a small protuberance, which terminates in a setula, located at both lateral extremities of genital area; fine spinules occurring along posterior end of each lateral face of anterior and posterior subdivisions; a transverse row of spinules on ventral face of posterior subdivision; very short hairs (? spinules) scattered dorsally. Antepenultimate and penultimate somites furnished with spinules arranged into transverse rows ventrally and laterally. Anal somite bipartite posteriorly, not forming a prominent anal operculum, furnished with spinules on flat edge above anus. Furcal ramus short, somewhat depressed dorsoventrally, armed with a basally geniculate short seta on dorsal face near posterior inner edge, a short seta on outer face near posterior end; principal terminal setae (broken) accompanied with two short spinulose setae each located outwards and inwards.

Antennule (Fig. 35-1) five-segmented, stumpy, armed with spinulose setae; first segment much shorter than rostrum, furnished with spinules on its anterior face; second segment as long as apical three segments combined; fourth segment short, protruding anterodistally, terminating in an aesthetasc. A n t e $\mathbf{n} \mathbf{n}$ a (Fig. 35-2). Coxa short, with spinules on posterior face. Allobasis about 2.5 times as long as its proximal diameter, armed with one spinulose thick seta on a point at three-quarters the length of anterior face from the base; a few spinules on outer face near proximal end. Exopodite three-segmented; first segment as long as apical two segments combined, armed with two setae anteriorly; second segment short, armed with one seta anterodistally; third segment armed with one seta on subproximal anterior face, two setae apically, and with prominent spinules around its apex; all setae thick and spinulose. Endopodite segment as long as three exopodite segments combined, slimmer than allobasis, somewhat thickening medially, armed with two finely spinulose setae and one spinulose spine on about the middle of anterior face, and one spinulose short seta on posterior face; apical end with one bifurcate seta and five spinulose setae, three of which are rather spiniform; a group of closely set long spinules attached onto subproximal anterior face. M a ndible (Fig. 35-3). Precoxa well sclerotized, with a row of long spinules near base of coxa-basis; pars incisiva and lacinia (? mobilis) tridentate; many spinules occurring along cutting edge; a short spinulose seta attached onto dorsal inner angle. Coxa-basis furnished with a row of spinules near base of endopodite, armed 


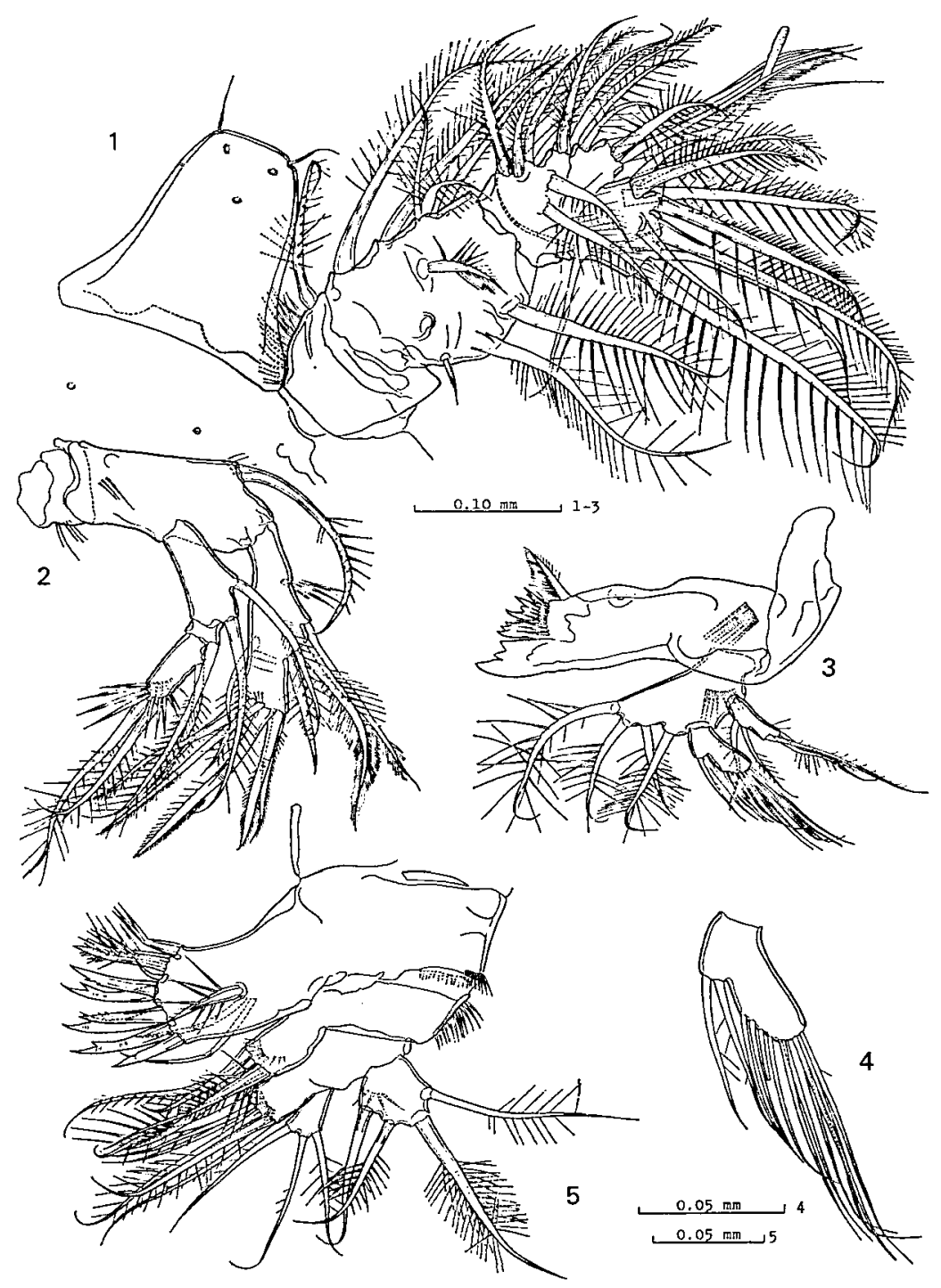

Fig. 35. Pseudotachidius bipartitus Montagna pacificus n. subsp. Female (holotype): 1. rostrum and antennule; 2 . antenna; 3 . mandible; 4. mandibular endopodite; 5. maxillula.

apically with four thick setae which are fringed with long spinules. Exopodite and endopodite represented by a small segment. Exopodite armed with three inner setae and two terminal setae; all setae slender and bearing spinules sparsely. Endopodite segment (Fig. 35-4) wider than exopodite segment, armed with two closely set setae on a stepped inner edge, four setae along subapical inner edge, and six apical setae; all setae slender and almost bare. M axillula (Fig. 35-5). Precoxa furnished with a transverse row of spinules around outer edge near distal extremity; arthrite armed with two, medially geniculate, parallel setae on its anterior face, six spines, one setula, and three spinulose spiniform setae along cutting 
edge. Coxa furnished with spinules along its outer edge; inner process thick, furnished with an arched row of spinules on subapical anterior face, armed with five more or less spinulose setae apically. Basis forming a thick inner process with a row of spinules on its subapical anterior face, armed with six spinulose or hairy setae apically. Exopodite represented by a segment as long as wide, armed with four setae in all; all setae bearing hairs or fine spinules; a few spinules attached onto anterior face. Endopodite represented by a slender segment with three spinulose setae apically or subapically. M axill a (Fig. 36-1). Syncoxa with many long spinules around subapical outer edge, furnished with three endites which are equally

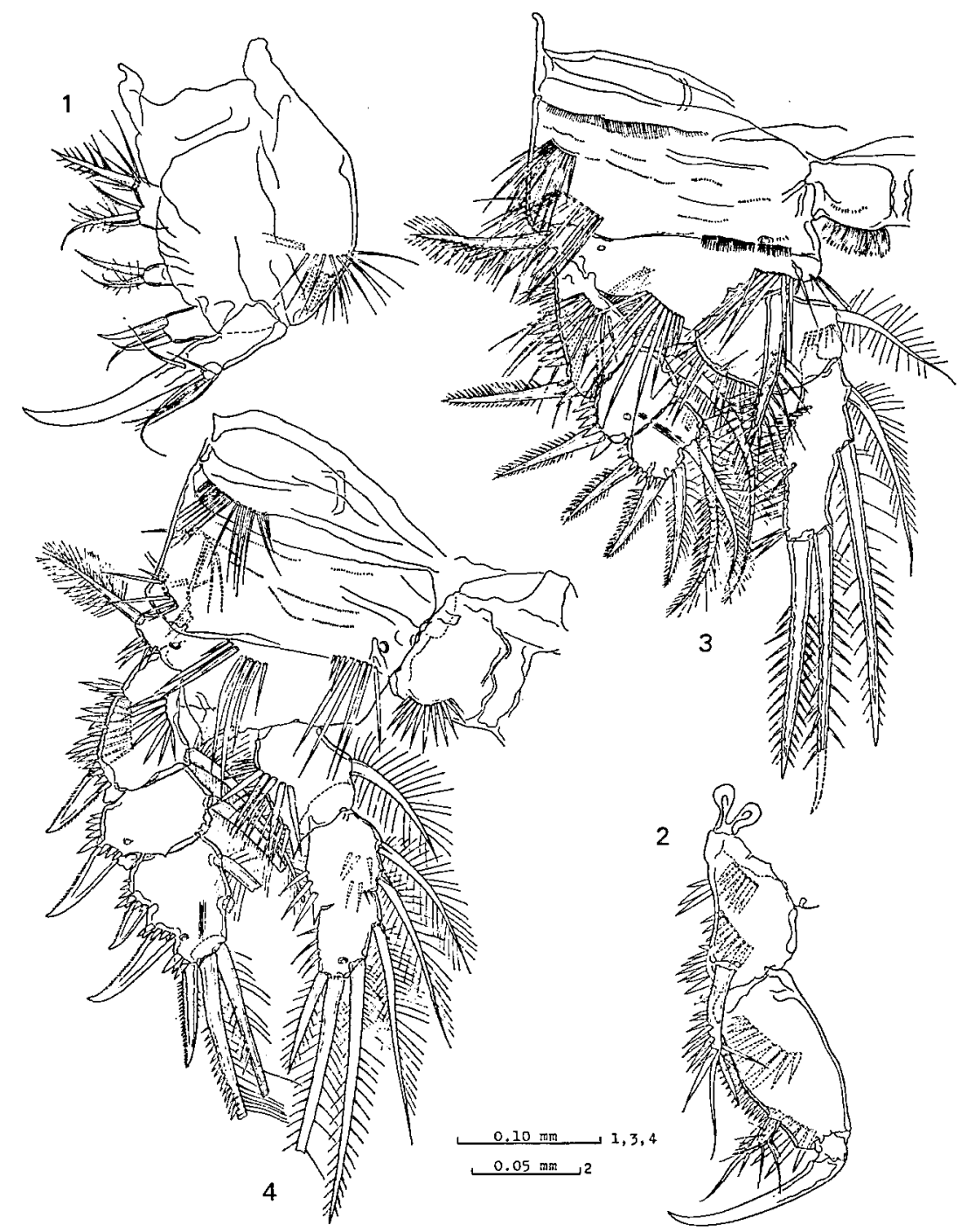

Fig. 36. Pseudotachidius bipartitus Montagna pacificus n. subsp. Female (holotype): 1. maxilla; 2. maxillipede; 3 . leg 1; 4. leg 2. 
spaced; first endite bilobular, dorsal lobule armed with one spinulose apical spine accompanied with long spinules around its base, ventral lobule armed with three spinulose small setae; second endite small, armed with one spinulose spine and two small setae apically; third endite thicker than second endite, armed with one bare spine and two short setae apically. Basis forming a strong claw accompanied with two setulae, one occurring anteriorly, the other close to endopodite. Endopodite consisting of two very small segments, each armed with two fine setae. M axi 11 i pede (Fig. 36-2) smaller than maxilla. Basis armed subapically with one stout seta which bears prominent spinules on its proximal half and is markedly slenderized through its apical half; inner edge spinulose; two oblique rows of closely set spinules attached onto posterior face. First endopodite segment a little longer than basis, tapering apically, armed with one short spinulose seta on inner edge subapically, fringed with spinules along inner edge; two oblique rows of closely set spinules on posterior face. Second endopodite segment represented by an arched claw.

L e g 1 (Fig. 36-3). Intercoxal plate wide, furnished with numerous fine hairs along its free edge. Coxa much wider than long, with two rows of very long spinules on anterior face near outer edge, some transverse rows of minute spinules on anterior face; a prominent pore occurring on anterior face near inner distal angle; at least two rows of long spinules occurring on posterior face near outer edge. Basis low, triangular, with a pore on anterior face above exopodite; outer spine close to coxa, thick, as long as first exopodite segment, with numerous spinules especially ventrally; inner spine thick, longer than first endopodite segment, furnished with spinules; a row of long spinules occurring along edge between both rami; a transverse row of long spinules attached onto anterior face near base of inner spine. Exopodite three-segmented; first segment about as long as apical two segments combined, widening toward apical, furnished with spatulate spinules along outer edge, a longitudinal row of long spinules on both anterior and posterior faces, hairs along inner edge, and armed with one outer spine which is as Iong as this segment and bilaterally spinulose; second segment wider than long, with a pore on anterior face near outer distal angle, spatulate spinules along outer edge, and armed with one outer spine like the outer spine of preceding segment, one thick inner seta which is plumose. Third exopodite segment shaping into a peculiar outline: inner half of segment much shortened, so that outer half relatively protruding apically; a muscle band attached onto inner base of the protruded outer part, and extending into second segment; three spinulose spines attached onto its outer half, two on outer edge, the rest on apical edge; two thick setae arising from apical edge of inner half, the outer plumose, the inner spinulose outwards and hairy inwards. Endopodite two-segmented; first segment thick, much wider than second segment, with a pore near the center of anterior face, long spinules along outer edge, an oblique row of spinules on posterior face near inner distal angle, armed with one inner seta which is thick and hairy; second segment about 1.5 times as long as first segment, about three times as long as its greatest width, with a pore on anterior face 
near the middle of outer edge, spinules along outer edge, armed with two apical spines which are markedly spinulose and longer than this segment, one hairy thick seta on a subproximal inner edge, and one big spinulose spine on a stepped edge at about the middle of inner margin. Leg 2 (Fig. 36-4). Intercoxal plate a little wider than long, furnished with a pair of arched rows of spinules on anterior face near free edge. Coxa wide, with rows of long spinules on both anterior and posterior faces near outer edge, a transverse row of very long spinules on anterior face along an inner portion of distal extremity, a prominent pore on anterior face near inner distal angle, several transverse rows of minute spinules scattered on anterior face. Basis forming an apically pointed projection between exopodite and endopodite, with a prominent pore on anterior face near base of exopodite, an arched row of long spinules on anterior face near the middle of proximal extremity, armed with one outer seta which is thick and bears numerous fine hairs. Exopodite consisting of three stumpy segments; first segment widening toward apical, with a serrate hyaline membrane on anterodistal end, a longitudinal row of spatulate spinules, which extends outwards, on anterior face near inner margin, a longitudinal row of fine spinules on posterior face, armed with one serrate thick outer spine and one thick plumose inner seta; second segment shorter than first segment, with a pore on anterior face near outer distal angle, a serrate membrane along inner distal end, armed with one outer spine and one inner seta as in preceding segment; third segment as long as first segment, tapering apically, with a pore on anterior face near outer distal angle, armed with three thick outer spines, of which the first (dorsal) two each arises from a clearly stepped edge, two apical spiniform setae which are spinulose outwards and hairy inwards, and two thick plumose inner setae (broken). Endopodite two-segmented; first segment forming a pointed protuberance at outer distal angle, furnished with an oblique row of prominent spinules on anterior face near outer margin, many spinules along outer edge, armed with one thick short inner seta which is sparsely plumose. Second endopodite segment composed of two fused segments, which are delimited from each other by a medially interrupted suture; proximal part forming a pointed process at outer distal angle, with a few spinules along outer edge, two transverse rows of a few spinules on posterior face, armed with two inner setae which are sparsely plumose; distal part tapering apically, with slender spinules along outer edge, a pore on anterior face near apical end, one spinulose spine on outer subapical edge, one long spinulose spine on apical end, one sparsely plumose inner seta and one spinulose long inner spine which is located subapically. Le g 3 (Fig. 37-1). Intercoxal plate with no spinule. Coxa and basis almost as in leg 2. Both exopodites were damaged (see description of the paratype and Fig. 39-1). Endopodite three-segmented; first two segments forming a pointed protuberance at each outer distal angle, each armed with one thick, sparsely plumose, inner seta; third segment almost oval in outline, with a pore on anterior face near apical end, two transverse rows of a few spinules on posterior face, armed with one short outer spine subapically, two terminal spines, the outer 


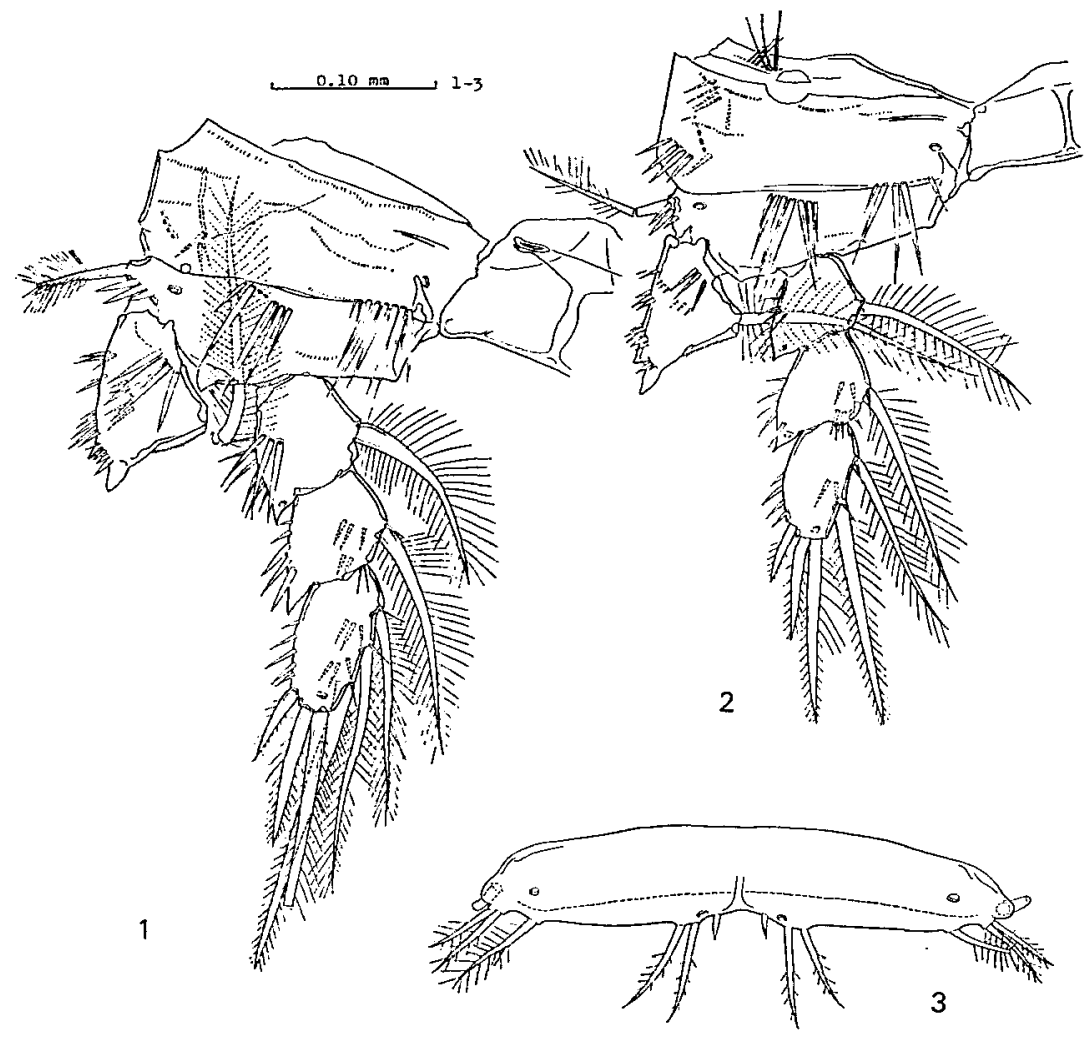

Fig. 37. Pseudotachidius bipartitus Montagna pacificus n. subsp. Female (holotype): 1. leg 3 (exopodite broken); 2. leg 4 (exopodite broken); 3. leg 5.

is short, and three, equally spaced, inner appendices, each of the first two represented by a sparsely plumose seta, and the rest represented by a long spinulose spine. L e g 4 (Fig. 37-2) smaller than leg 3. Intercoxal plate low, with no spinule. Coxa and basis almost as in leg 2. Projection of basis between exopodite and endopodite not prominent. Both exopodites were damaged (see description of the paratype and Fig. 39-2). Endopodite three-segmented; third segment armed with two inner appendices, the first represented by a sparsely plumose seta, the second represented by a long spinulose spine; otherwise armed as in leg 3 . Leg 5 (Fig. 37-3). Both legs confluent, forming a short and very wide common plate, delimited from each other by a vertical chitinous suture. Armature of each leg represented by three short setae on free edge near inner limit, one separate and two closely set short setae on free edge near outer limit, and one seta (broken) arising from outer extremity.

Fifth copepodid female (paratype). Body (Figs. 38-1, 38-2) about $1.3 \mathrm{~mm}$ long. Abdomen (Fig. 38-3) consisting of four somites; genital double somite not yet formed; first abdominal somite furnished with rudimentary leg 6 represented by a wide common plate with three minute setulae near each outer extremity; second and 


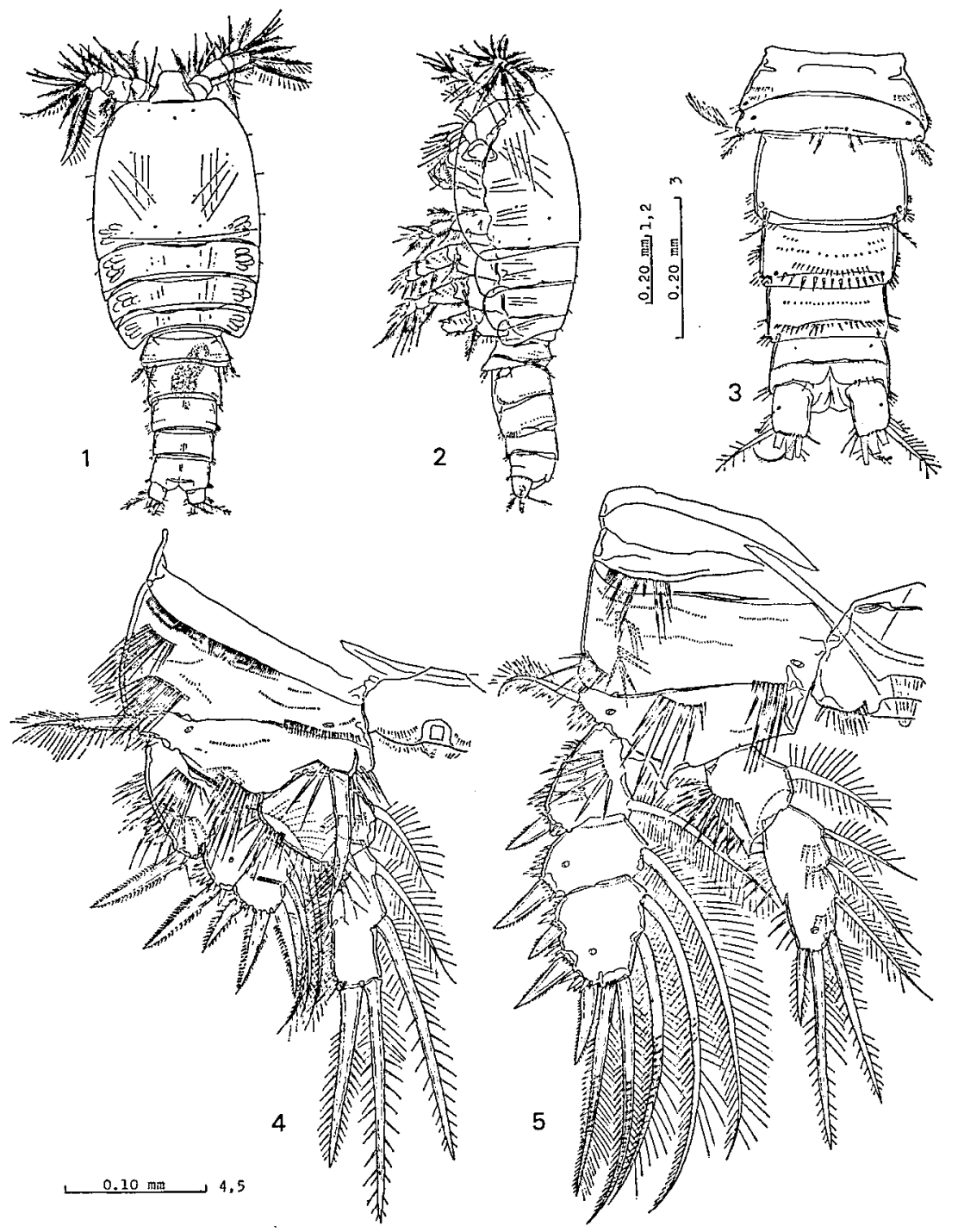

Fig. 38. Pseudotachidius bipartitus Montagna pacificus n. subsp. Fiftho cpepodid female: 1 . habitus, dorsal; 2. habitus, lateral; $3 . \operatorname{leg} 5$ and abdomen, ventral; 4. leg $1 ; 5$. leg 2.

third abdominal somites with numerous spinules ventrally; last somite bears ventrally a transverse furrow which represents the limit between penultimate and anal somites of the adult. Preoral and oral appendages principally as in adult.

L e g 1 (Fig. 38-4) armed as in adult. Second endopodite segment with no pore on its anterior face. Le g 2 (Fig. 38-5) armed as in adult. Endopodite twosegmented, and its second segment composed of two fused segments as in adult. L e g 3 (Fig. 39-1). Exopodite three-segmented; each of first two segments armed with one outer spine and one thick inner seta; third segment armed with three 


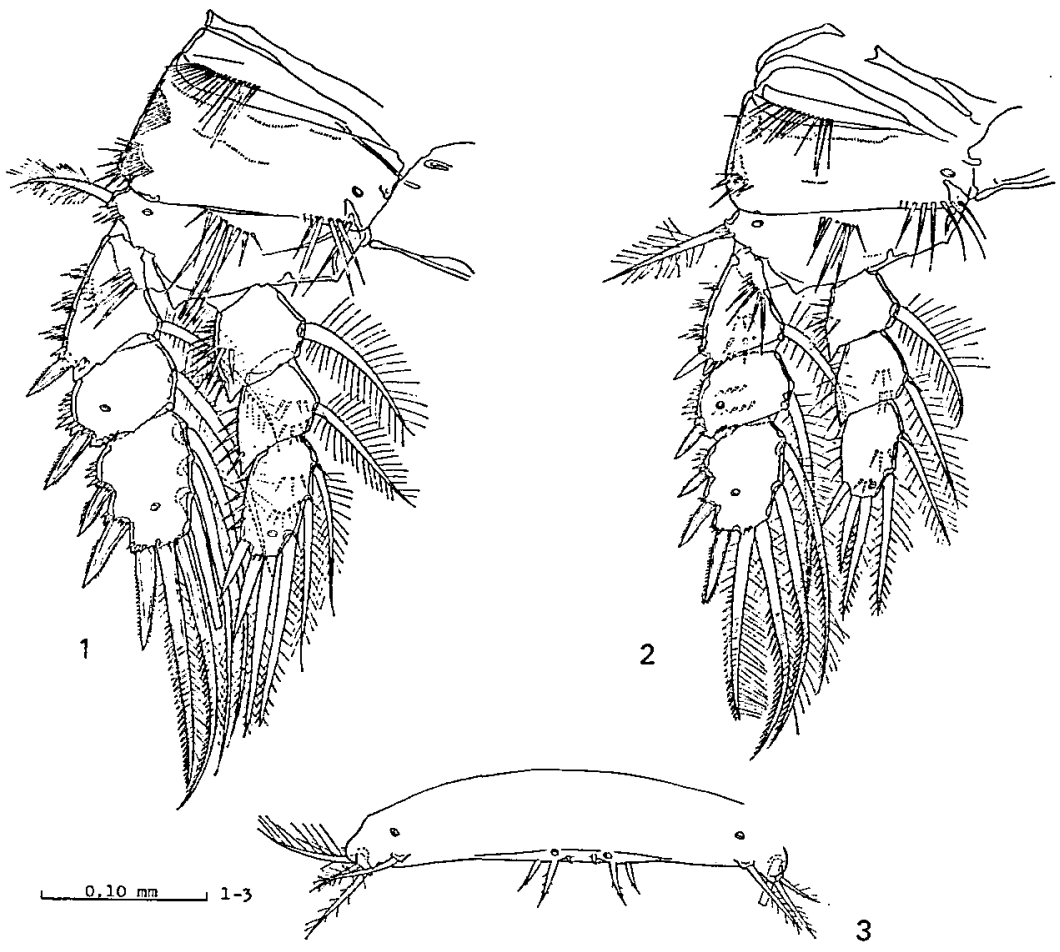

Fig. 39. Pseudolachidius bipartitus Montagna pacificus n. subsp. Fifth copepodid fermale: $1 . \operatorname{leg} 3 ; 2 . \operatorname{leg} 4 ; 3$. leg 5.

outer spines, one long spine and one stout seta on distal end, and three inner setae. L e g 4 (Fig. 39-2). Exopodite three-segmented; first two segments armed as in leg 3; third segment armed with two inner setae, otherwise as in leg 3 . L e g 5 (Fig. 39-3) with no chitinous suture medially. Outer seta hairy.

Remarks. The present material accords almost completely with Pseudotachidius bipartitus bipartitus Montagna, 1980, reported from the bathyal bottom in the Beaufort Sea, but clearly differs from the latter in the segmentation of the endopodite of leg 1. The endopodite of leg 1 of the present material consists of two segments, but the nominated subspecies described by Montagna has a three-segmented endopodite on its leg 1, and this characteristic has been reaffirmed by Dr. P. Montagna (pers. comm.). The second endopodite segment of the present material is no doubt a derivative of the apical two segments in $P$. bipartitus bipartitus, which would be formed by incomplete segmentation through the fourth copepodid molt. $I$ regard the present material as a Pacific form of $P$. bipartitus, and treat it as a separate subspecies.

The holotype female was infested with a nematode as shown in the figure (Fig. 34-1). The scientific name of the nematode is still unknown, though it is under examination. 


\section{Pseudotachidius horikoshii n. sp.}

(Figs. 40-43)

Material. An adult female dissected was designated as the holotype. Type-locality: Southeast off Mindanao, the Pacific Ocean. The specimen was collected with Murano's net (6-II-1979).

Female (holotype). Body (Figs. 40-1, 40-2) including rostrum about $1.5 \mathrm{~mm}$ long, scarcely depressed dorsoventrally, gradually tapering toward posterior through thorax and abdomen, colorless, glossy. Rostrum (Fig. 41-3) clearly defined at

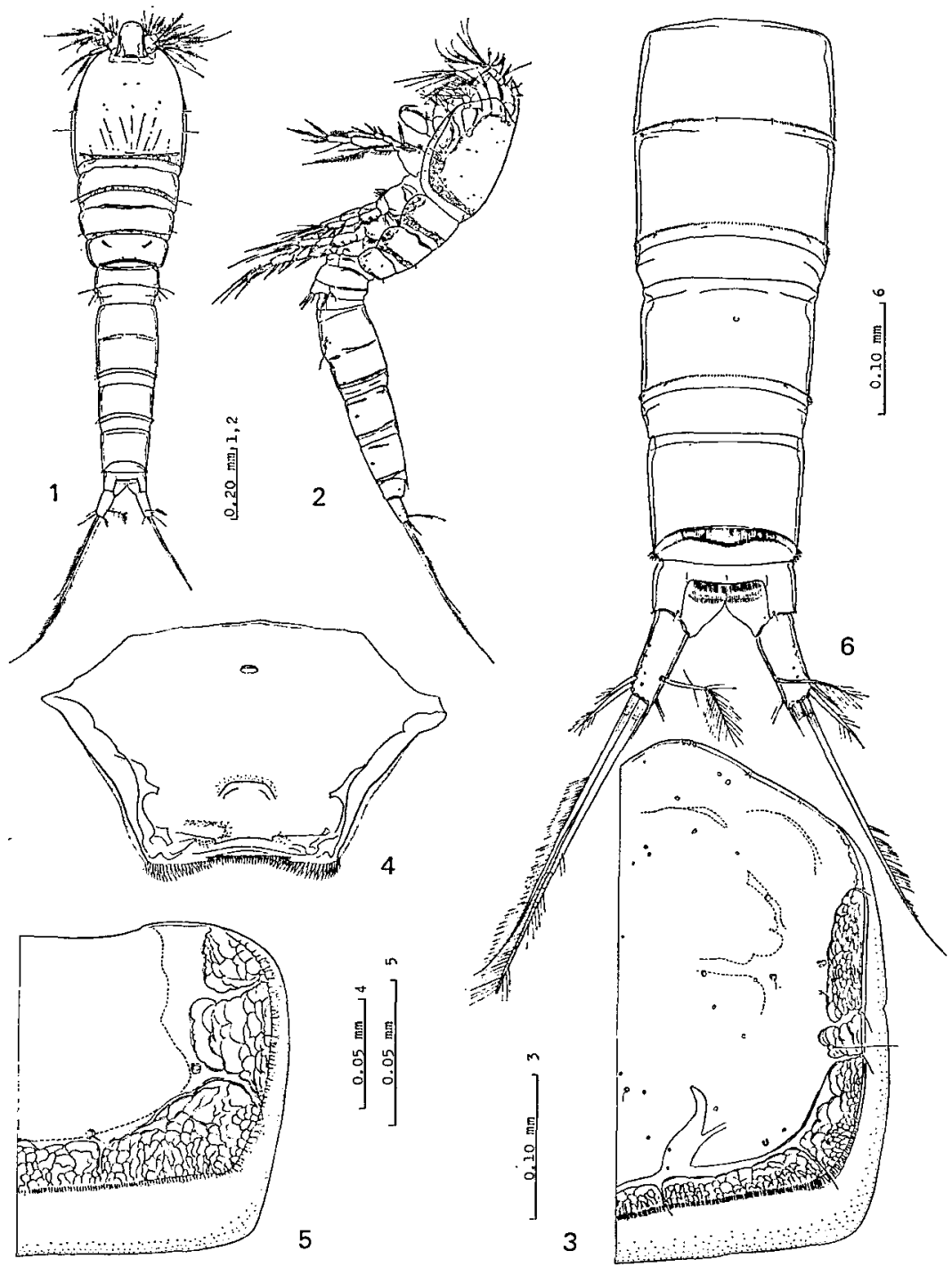

Fig. 40. Pseudotachidius horikoshii n. sp. Female (holotype): 1. habitus, dorsal; 2. habitus, lateral; 3. cephalothoracic integument; 4. labrum; 5. pleurotergite of first free thoracic somite; 6. abdomen, dorsal. 
base, elongate bell-shaped in outline, about 1.3 times as long as its basal width, furnished with two pairs of prominent sensory hairs. Cephalothorax, rostrum excluded, a little longer than three succeeding thoracic somites combined, about 0.3 $\mathrm{mm}$ wide; integument a little expanding frontally, fringed with mesh-like structures and a well-developed hyaline membrane which is notched at almost the middle of each ventral margin (Fig. 40-3); many pores and several hairs scattering on surface; labrum (Fig. 40-4) with an almost flat apical (ventral) edge fringed with numerous short spinules, fringed laterally with a narrow hyaline membrane. Pleurotergite of first three thoracic somites (Fig. 40-5) fringed with mesh-like structures and a hyaline membrane. Genital double-somite (Figs. 40-6, 41-1, 41-2) subdivided dorsally and laterally by a transverse suture accompanied with minute spinules and a few hairs; genital area with a pair of rudimentary leg 6, each of which is represented by a small protrusion terminating in a small hairy seta; an almost circumambient row of minute spinules along base of posterior hyaline frill. Antepenultimate somite with a circumambient row of spinules as in the preceding somite. Penultimate somite furnished with a transverse row of spinules on ventral face near posterior end, an arched row of spinules at each lateral face near posterior end, and a row of densely set spinules (? texture of hyaline membrane) dorsally. Anal somite short, clearly bipartite, furnished with fine hairs along anal operculum and around anus. Furcal ramus longer than anal somite, about twice as long as its basal diameter, subcylindrical, armed with two principal terminal setae accompanied inwards with a setula, two short setae on subapical outer face, and one hairy seta on dorsal face near apical end.

Antennule (Fig. 41-3) five-segmented, armed with spinulose and hairy setae; first four segments subequal in thickness, and thicker than fifth segment; first segment short, with three groups of spinules on its anterior face, armed with a seta at distal anterior face; second segment longest, about 1.5 times as long as thick, with setae dorsally and anteriorly; third and fourth segments short, subequal in length; an aesthetasc arising from fourth segment; fifth segment as long as preceding two segments combined, furnished with a very small aesthetasc subapically. Antenna (Fig. 41-4). Coxa very short, with a few spinules posteriorly. Allobasis about 3.5 times as long as its basal diameter, with an oblique row of several spinules on subproximal anterior face, armed with a stout seta which bears long and short spinules and arises from a point at about two-thirds the length of anterior face from the base. Exopodite arising from a point at a distal third of allobasis, three-segmented; first two segments combined as long as the rest; first segment thickening apically, armed with two setae; second segment short, armed with one seta; third segment with spinules around apex, armed with one seta medially and two setae apically; all setae furnished with short spinules. Endopodite represented by a segment as long: as three exopodite segments combined, with a transverse row of prominent spinules on anterior face at about a proximal third the length, armed with one long and three short spinulose setae around a stepped edge of anterior face, and five more or less spinulose setae and one basally bifurcate long seta 


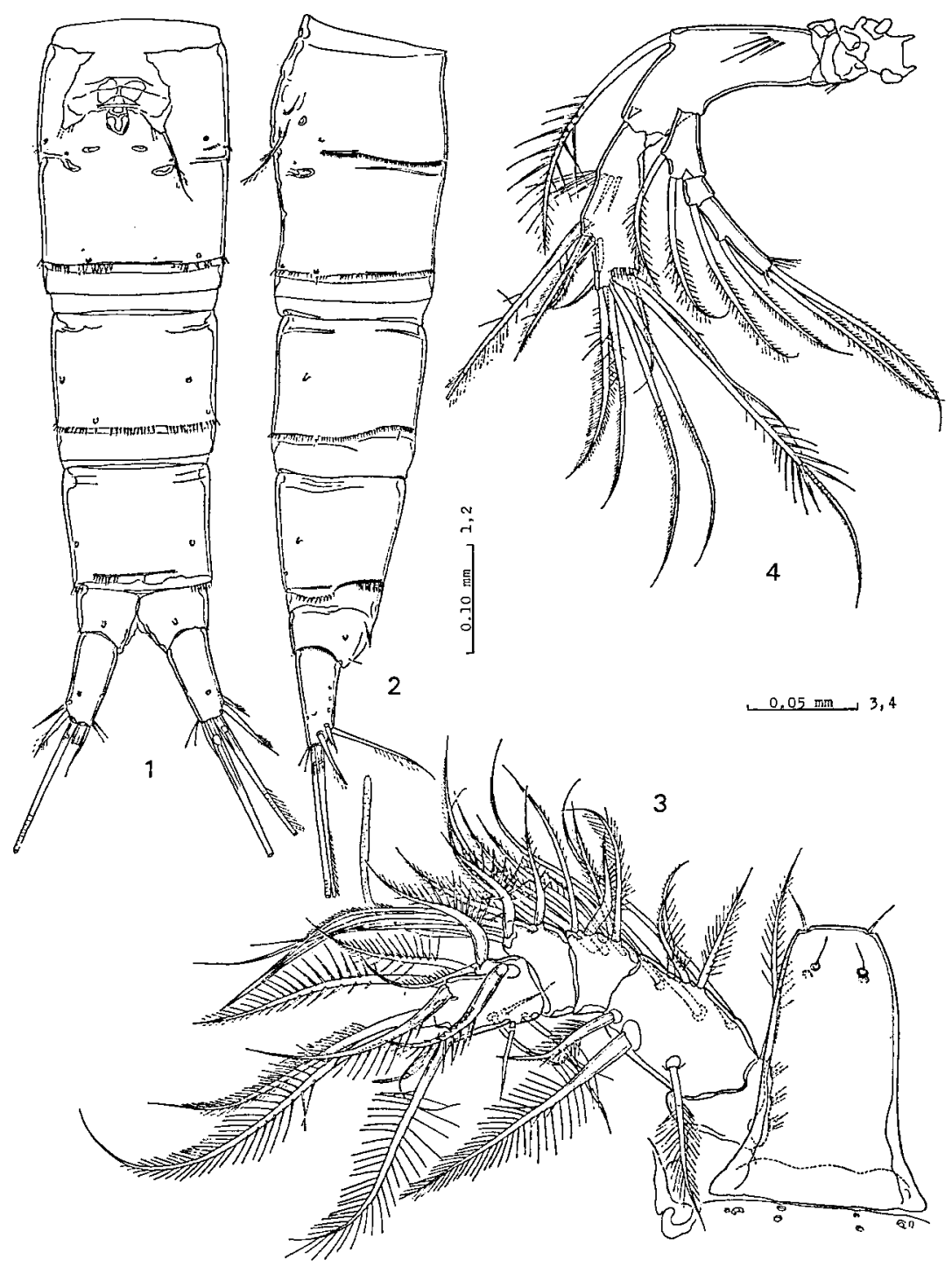

Fig. 41. Pseudotachidius horikoshii n. sp. Female (holotype): 1. abdomen, ventral; 2. abdomen, lateral; 3. rostrum and antennule; 4. antenna.

apically. Mandible (Fig. 42-1). Precoxa well sclerotized, with a group of spinules proximally; pars incisiva and lacinia mobilis tridentate. Coxa-basis much widening apically, with a transverse row of spinules on about central surface, minute spinules along base of endopodite, armed with four sparsely spinulose setae apically. Exopodite represented by a subcylindrical segment, armed with three equally spaced setae along inner edge, one long seta on subapical stepped inner edge, and one terminal seta; all setae furnished with very short spinules. Endopodite represented by a segment a little bigger than exopodite segment, aamed with three closely set setae on a stepped inner edge, two juxtaposed and four (?) juxtaposed setae 


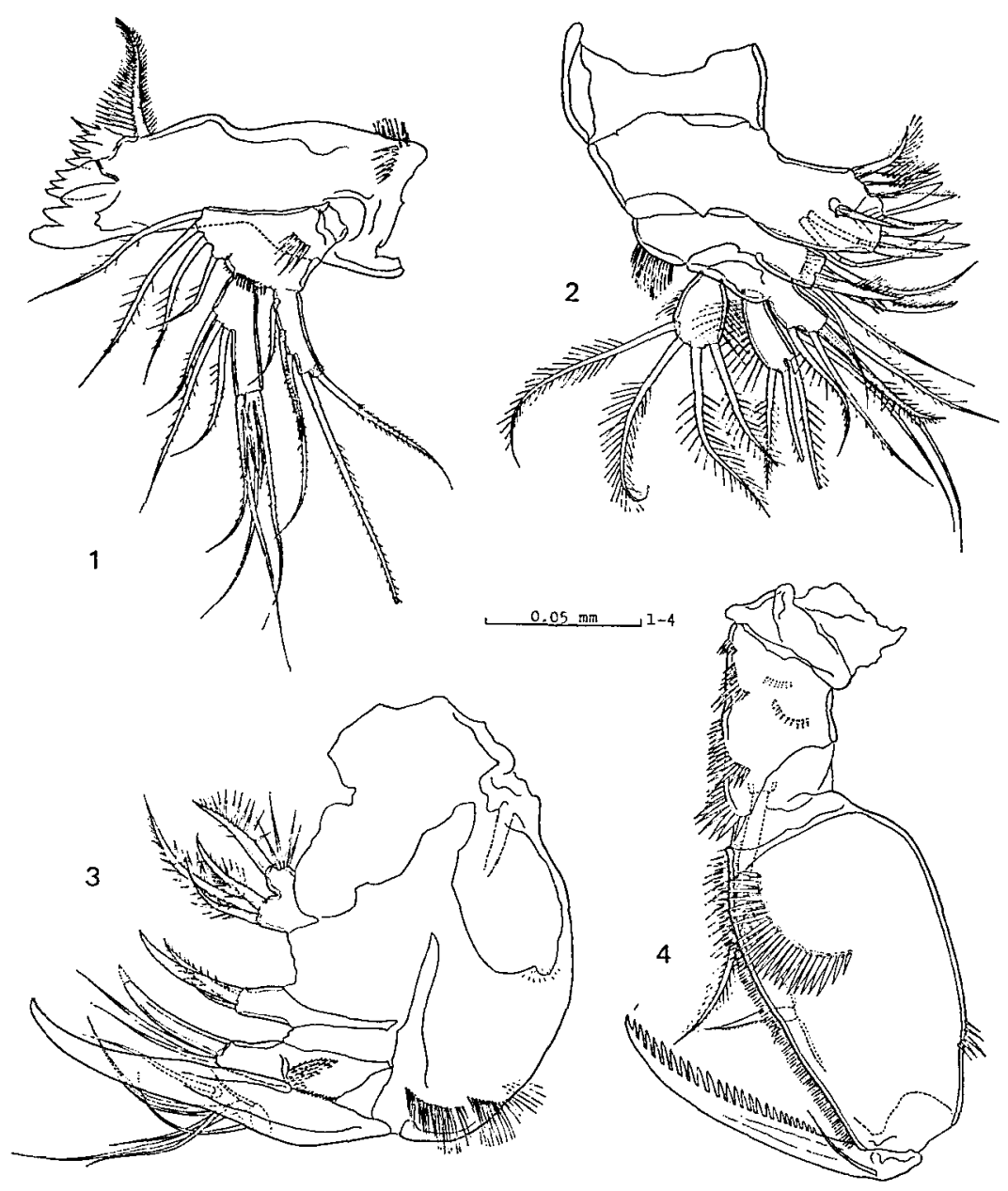

Fig. 42. Pseudotachidius horikohsii n. sp. Female (holotype): 1. mandible; 2. maxillula; 3. maxilla; 4. maxillipede.

apically. Maxillula (Fig. 42-2). Arthrite of precoxa armed with two, medially geniculate, parallel setae on anterior face, six claws, one setula, and three spinulose short setae along cutting edge, and one spinulose short seta on posterior face. Coxa with fine spinules along outer edge; inner process reaching the middle of arthrite of precoxa, with a transverse row of spinules on subapical anterior face, armed with two spinulose spines and two setae apically, and one slender seta on subapical ventral edge. Inner process of basis extending beyond coxal inner process, armed with one spinulose spine and three setae apically, and two juxtaposed setae on subapical ventral edge. Exopodite represented by a segment of an almost oval outline, fringed with spinules, armed apically with four well-developed setae which are bilaterally fringed with fine spinules. Endopodite represented by a segment which is slimmer than exopodite segment, fringed with long spinules along 
its outer edge, armed with three spinulose setae apically or subapically. M a xilla (Fig. 42-3). Syncoxa with rows of fine and long spinules subapically, furnished with three endites; first endite clearly bilobated, armed with one spinulose spine on dorsal lobe together with a few long spinules, three spinulose stout setae on ventral lobe; second endite widely separated from first endite, subcylindrical, armed apically with one bare claw, one spinulose spine and one small seta; third endite close to the preceding endite, subcylindrical, armed apically with one bare claw and two slender setae; very short spinules scattered on lateral face near base of third endite. Basis forming a strong claw, armed with a seta. Endopodite consisting of two very small segments, armed with two slender setae on the first, five setae on the second. Maxillipede (Fig. 42-4). Coxa short. Basis cylindrical, twice as long as thick, with several arched rows of spinules, armed with one strong spinulose seta subapically. First endopodite segment twice as long as its greatest width, somewhat swelling, not concaved through inner edge, with an arched row of closely set prominent spinules on its proximal half near inner edge, a few spinules on subapical outer edge, numerous short spinules along whole of inner edge, and armed with one short seta near the middle of inner edge. Second endopodite segment forming a dorsally pectinate strong claw accompanied with a slender seta near its base.

L e g 1 (Fig. 43-1). Intercoxal plate wide, with no hairs or spinules. Coxa much wider than long, with a few spinular rows near outer edge, a very short spinules on anterior face along distal extremity, a pore at a distal inner portion of anterior face. Basis triangular, with a pore on anterior face close to dorsal extremity above exopodite; outer spine close to coxa, thick, with spinules on its apical half; inner spine arising from about the middle of inner edge, thick, about half as long as first endopodite segment, furnished with spinules; spinules fringing around apex; a transverse short row of fine long spinules occurring near the center of anterior face; a transverse row of short spinules attached onto anterior face near base of inner spine; a few spinules on inner edge near base. Exopodite three-segmented; first segment as long as apical two segments combined, furnished with spinules along outer edge, many fine hairs along inner edge, a small pore on anterior face near outer distal angle, armed with one finely spinulose outer spine; second segment almost as long as wide, armed with one spinulose outer spine and one plumose inner seta which is longer than three exopodite segments combined; third segment as long as second segment, with a small pore on anterior face near base of first (dorsalmost) outer spine, armed with three spinulose outer spines, one plumose, rather short seta apically, and one seta, which arises from subapical inner edge, is longer than the previous seta and bears hairs inwards and spinules outwards. Endopodite attached onto distal inner edge of basis, two-segmented; first segment almost as long as three exopodite segments combined, 3.3 times as long as its greatest width, with a prominent pore on anterior face, spinules on and near outer edge, many hairs along inner edge from its base to inner seta, two almost longitudinal rows of spinules on posterior face, and armed with one thick plumose inner seta which arises 


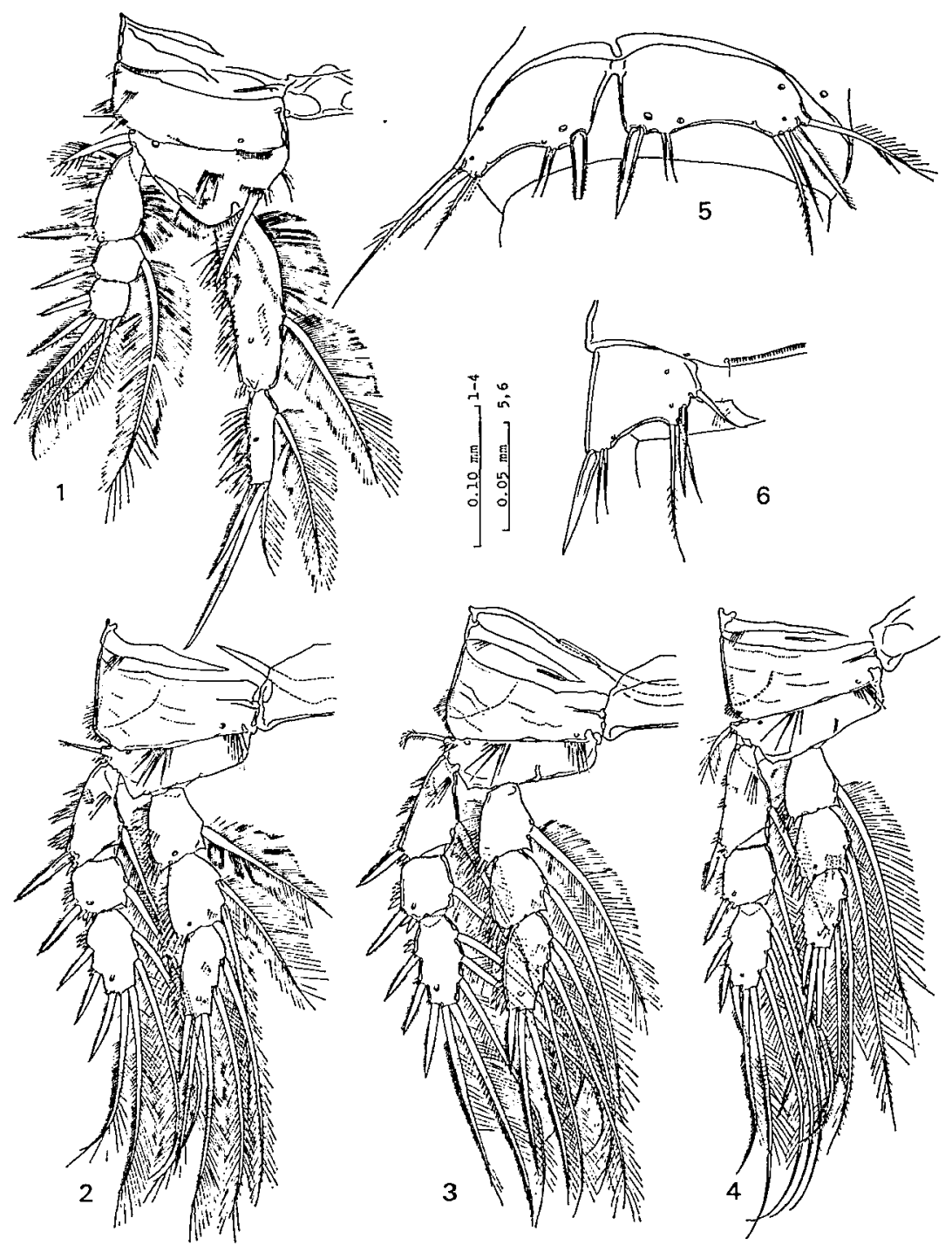

Fig. 43. Pseudotachidius horikoshii n. sp. Female (holotype): 1. leg 1; 2. $\operatorname{leg} 2 ; 3$. leg $3 ; 4$. $\operatorname{leg} 4 ; 5$, a pair of leg 5 in situ; 6 . lateral view of left leg 5 in silu.

from a point at about two-thirds the length of inner edge from the base and is furnished with short spinules along its distal half; second segment small, half as long as first segment, equally subdivided into two parts by an indistinct constriction, furnished with spinules on outer edge, armed with two spines which are spinulose outwards and one short hairy seta apically, and one long plumose seta which arises from the middle of inner edge of proximal part and is furnished with short spinules on its distal half. L e g 2 (Fig. 43-2). Intercoxal plate wider than long, with 
no spinule. Coxa wider than long, with spinules along outer edge, several transverse rows of minute spinules on anterior face, a transverse row of long spinules along distal extremity of anterior face near inner edge, a prominent pore near inner distal angle of anterior face. Basis short, forming an apically pointed projection between exopodite and endopodite, with a pore on anterior face near proximal extremity above exopodite, a transverse row of long spinules along proximal extremity of anterior face, armed with one short seta which arises from a short process and is furnished with a few hairs apically. Both rami three-segmented, subequal in length. Exopodite: first segment with groups of spinules on outer edge, an oblique row of a few short spinules on posterior face near outer edge, an oblique row of a few long spinules on anterior face near inner edge, a serrate hyaline membrane on inner apical edge, armed with one spinulose outer spine and one plumose inner seta; second segment about half as long as first segment, with a prominent pore on anterior face near outer distal angle, a serrate hyaline membrane on inner distal edge, armed with one spinulose outer spine and one plumose inner seta; third segment about 1.5 times as long as second segment, with a pore on anterior face near outer apical angle, armed with three spinulose outer spines which are subequal in length and spaced equally from each other, two long apical setae which are spinulose outwards and hairy inwards, and two plumose inner setae. Endopodite: first two segments subequal in length, pointed at both outer and inner distal angles, with a pore on each subapical anterior face; first segment armed with one plumose inner seta; second segment armed with two plumose inner setae; third segment a little slimmer and longer than second segment, with a pore on subapical anterior face, armed with one spinulose outer spine subapically, two terminal setae which are spinulose outwards and hairy inwards, and two plumose inner setae; all segments fringed with spinules along each outer edge. L e g 3 (Fig. 43-3). Intercoxal plate, coxa, and basis as in leg 2. Exopodite: third segment armed with three inner setae, otherwise as in leg 2. Endopodite: second segment armed with one inner setae, otherwise as in leg 2. L e g 4 (Fig. 43-4). Intercoxal plate, coxa, basis, and exopodite as in leg 3. Endopodite: third segment armed with two inner setae, otherwise as in leg 3. L e g 5 (Figs. 43-5, 43-6). Both legs fused with each other proximally. Each leg represented by a low and wide plate with two prominent pores near inner distal edge, a small pore at exopodite region, and a pore near proximal outer edge, armed with one hairy seta which arises from a short process at outer proximal edge, one stout spine and two closely set setulae on distal edge near inner angle, one spine and two setae on exopodite region.

Remarks. The shape of the leg 5 of the present new species clearly shows that this species belongs to the 'similis' group within the genus Pseudotachidius in the sense of Montagna (1980). The new species, however, differs from any congeneric species, in the peculiar shape of the first endopodite segment of leg 1 which is much elongated. 
The specific name is in hornor of Dr. M. Horikoshi of the Ocean Research Institute, Tokyo University.

\section{Pseudotachidius minutus n. sp.}

(Figs. 44-47)

Material. An adult female dissected was designated as the holotype. Type-locality: Southeast off Mindanao, the Pacific Ocean. The specimen was collected with Murano's net (6-II-1979).

Female (holotype). Body (Figs. 44-1, 44-2) slim, $1.2 \mathrm{~mm}$ long, colorless and semitransparent. Cephalothorax $0.25 \mathrm{~mm}$ wide, a little longer than succeeding three free thoracic somites combined, forming a prominent rostrum armed with a pair of well-developed sensory hairs frontally (Fig. 44-3); integument fringed with three hyaline membranes (two lateral and one posterior membranes) which are very thin (Fig. 44-4); labrum (Fig. 44-5) armed with numerous stout spinules on apical edge; paragnaths (Fig. 44-6) armed with short spinules on each inner edge of widely spaced lobes. Each pleurotergite of first, second, and third free thoracic somites fringed with a well-developed hyaline membrane. Genital double-somite (Figs. $44-7,44-8,44-9)$ subdivided dorsally by a transverse suture accompanied with numerous minute spinules; a circumambient row of minute spinules occurring along posterior hyaline membrane; genital area complex (Fig. 44-8), furnished with a pair of rudimentary leg 6 , each of which is represented by a small protuberance with three setulae. Antepenultimate somite with a circumambient row of minute spinules along posterior hyaline membrane. Penultimate somite with a row of minute spinules on posterior face along posterior hyaline membrane. Anal somite short, posteriorly bipartite; anal operculum scarcely protruded, with many hairs (? arising beneath the operculum). Furcal ramus about twice as long as wide, armed with a short seta on dorsal outer face, one basally geniculate hairy seta on dorsal inner face, one hairy seta on subapical outer face, one short hairy seta on inner apical end; outer one of principal terminal setae bearing hairlike spinules outwards.

Antennule (Fig. 45-1) seven-segmented, armed with spinulose setae; first segment thick and short; fourth segment very short, somewhat extending anterodistally, terminating in an aesthetasc together with bare slender setae; sixth segment with a small aesthetasc posteriorly. An t e n n a (Fig. 45-1). Coxa bare. Allobasis about three times as long as thick, with a transverse suture (see remarks) on inner face, armed with one thick spinulose seta which arises from a stepped anterior edge on a point at two-thirds the length from the base. Exopodite threesegmented; three segments combined as long as allobasis; first segment three times as long as second segment, with a group (? transverse row) of long spinules on posterior face, a transverse row of many minute spinules on inner face, armed with two setae anteriorly; second segment short, armed with one seta anteriorly; third segment four times as long as second segment, with prominent spinules near apex, 


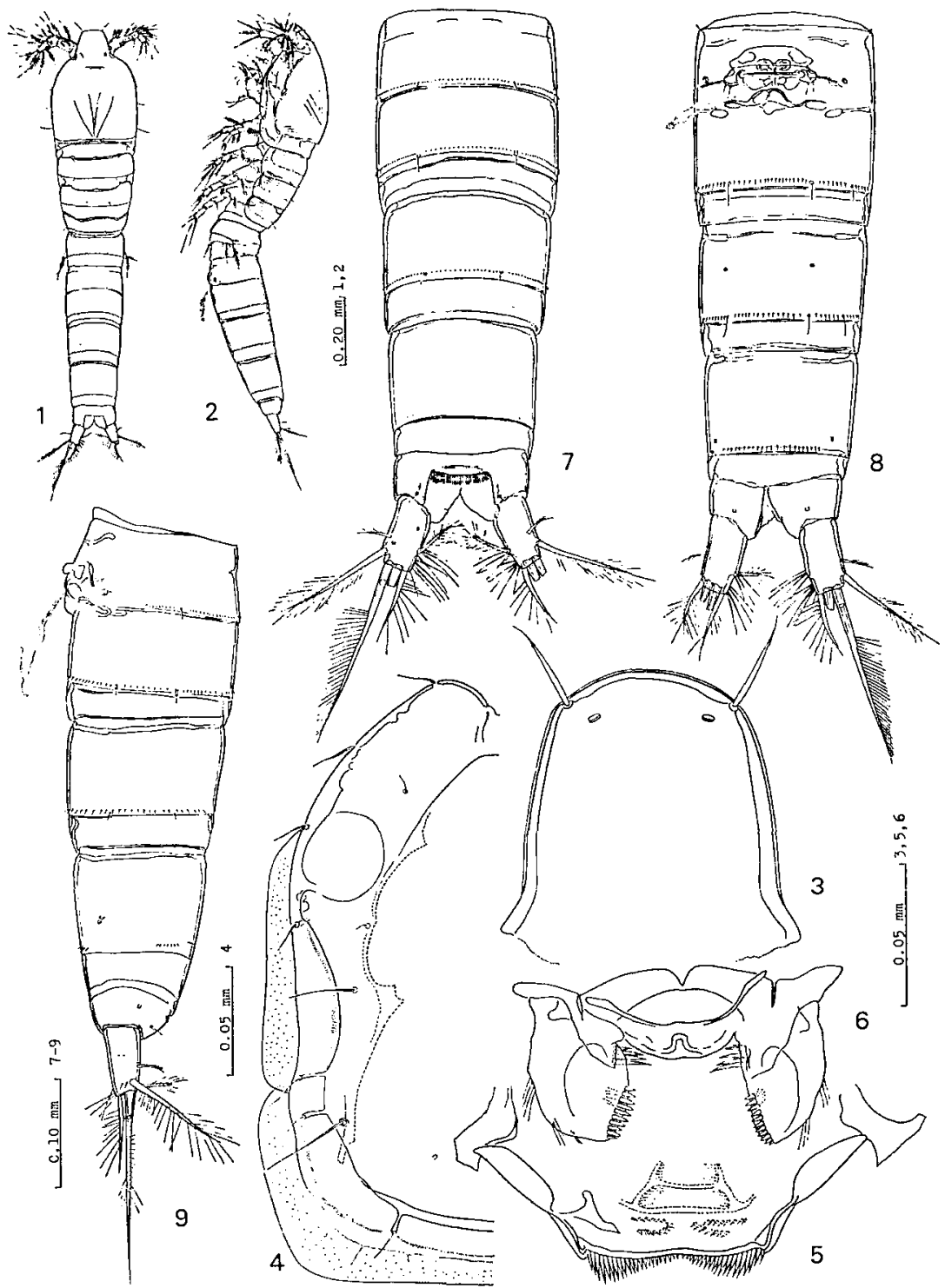

Fig. 44. Pseudotachidius minutus n. sp. Female (holotype): 1. habitus, dorsal; 2. habitus, lateral; 3. rostrum; 4. cephalothoracic integument; 5. labrum; 6. paragnaths; 7. abdomen, dorsal; 8. abdomen, ventral; 9. abdomen, lateral.

armed with one anterior spine on a point at a proximal third the length, and two setae apically; all setae thick and markedly spinulose. Endopodite segment as long as three exopodite segments combined, with a transverse row of prominent spinules on anterior inner face at a proximal third the length from the base, armed with four setae, two of which are thick and spinulose, on anterior and inner face at about the middle of the length, six setae apically, two of which are thick and spinulose. 


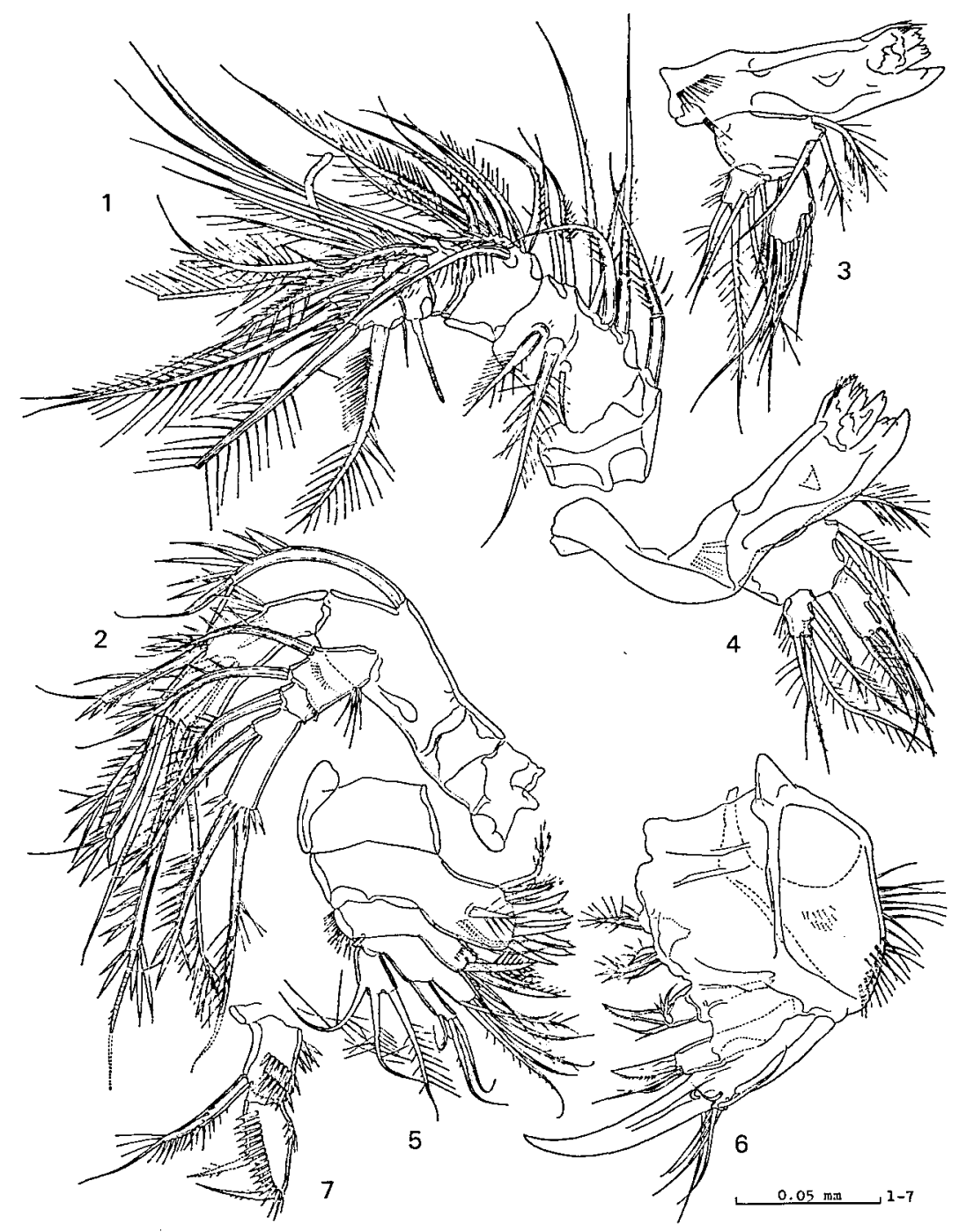

Fig. 45. Pseudotachidius minutus n. sp. Female (holotype): 1. antennule; 2. antenna; 3. mandible; 4. mandible; 5. maxillula; 6. maxilla; 7. maxillipede.

Mandible (Figs. 45-3, 45-4). Precoxa well sclerotized, with a row of fine spinules proximally; pars incisiva tridentate. Coxa-basis widening distally, armed with three spinulose setae apically, Exopodite represented by a small segment armed with three spinulose setae apically. Exopodite represented by a small segment armed with three inner setae, two of which are juxtaposed, and two apical and subapical setae. Endopodite segment longer than exopodite segment, armed with two juxtaposed setae on about the middle of inner edge, five setae apically. Maxillula (Fig. 45-5). Arthrite of precoxa armed with two slender parallel setae anteriorly, one short spinulose seta posteriorly, 10 spines and setae on cutting 
edge. Coxa fringed with spinules on outer edge; inner process armed subapically and apically with one spinulose spine, three spinulose thick setae, and two slender setae. Inner process of basis armed apically with six setae which bear spinules sparsely. Exopodite represented by a segment attached onto outer angle of basis, armed with three setae which bear long spinules. Endopodite represented by a slender segment armed with three setae. $M$ axilla (Fig. 45-6). Syncoxa as long as wide, with many long spinules on and near outer edge, furnished with four endites which are almost equally spaced; first endite represented by a small protuberance with one spinulose short seta; second endite represented by three short setae which are closely placed; third endite represented by a short process armed with one spinulose spine and two setae; fourth endite represented by a cylindrical process armed with one spinulose spine and two setae; fourth endite represented by a cylindrical process with one thick spinulose spine and two slender setae. Basis forming a very strong claw accompanied with three bare setae proximally, one of which is located near the base of endopodite. Endopodite represented by a small protuberance with four bare setae apically, one bare seta subapically. M a xillipede (Fig. 45-7) small. Coxa very short. Basis about twice as long as wide, with prominent spinular rows, armed with one thick spinulose seta on inner distal angle. First endopodite segment as long as coxa, tapering apically, with spinules on outer edge, a longitudinal row of prominent spinules along inner edge, armed with one seta (missing) on about the middle of inner edge. Second endopodite segment represented by a spine which bears a few short spinules.

L e g 1 (Fig. 46-1). Intercoxal plate short, with hairs on almost flat free edge. Coxa markedly extending outwards, about 1.5 times as wide as basis, with two oblique rows of long spinules on anterior face near outer edge, a row of long spinules on posterior face along outer edge; numerous minute spinules on anterior face along distal extremity of inner quarter. Basis clearly stepped at outer distal part, furnished with long hairs on inner edge; a prominent pore occurring above exopodite anteriorly; outer spine thick, bearing spinules on its apical half; inner spine arising from distal edge near outer angle, bearing spinules on its apical half; prominent spinules attached onto anterior face near each base of outer and inner spines and along distal edge between exopodite and endopodite. Both rami three-segmented. Exopodite arising from a stepped edge of basis; first segment widening apically, as long as apical two segments combined, fringed with hairs inwards, armed with one outer spine subapically; second segment as long as wide, armed with one outer spine subapically and one plumose inner seta subapically; third segment as long as second segment, armed with three outer spines, two apical setae which bear spinules outwards and hairs inwards; all outer spines of each segment bearing spinules bilaterally; each segment furnished with spatulate spinules on outer edge and along outer distal angle. Endopodite: three segments combined shorter than three exopodite segments combined; first segment thick, twice as wide as apical segments, as long as two apical segments combined, furnished with an oblique row of spatulate spinules on outer edge, a row of spatulate spinules along outer distal angle, 
armed with one plumose seta on a point at two-thirds the length of inner edge from the base; a prominent pore occurring on anterior face near outer distal angle; second and third segments subequal in length; second segment with an oblique row of spatulate spinules on anterior face near outer distal angle, armed with one plumose inner seta subapically; third segment with spatulate spinules along outer edge, armed with one spine on a subapical stepped edge, two apical setae, the outer thick and spinulose outwards and hairy inwards, the inner slender and bilaterally hairy.

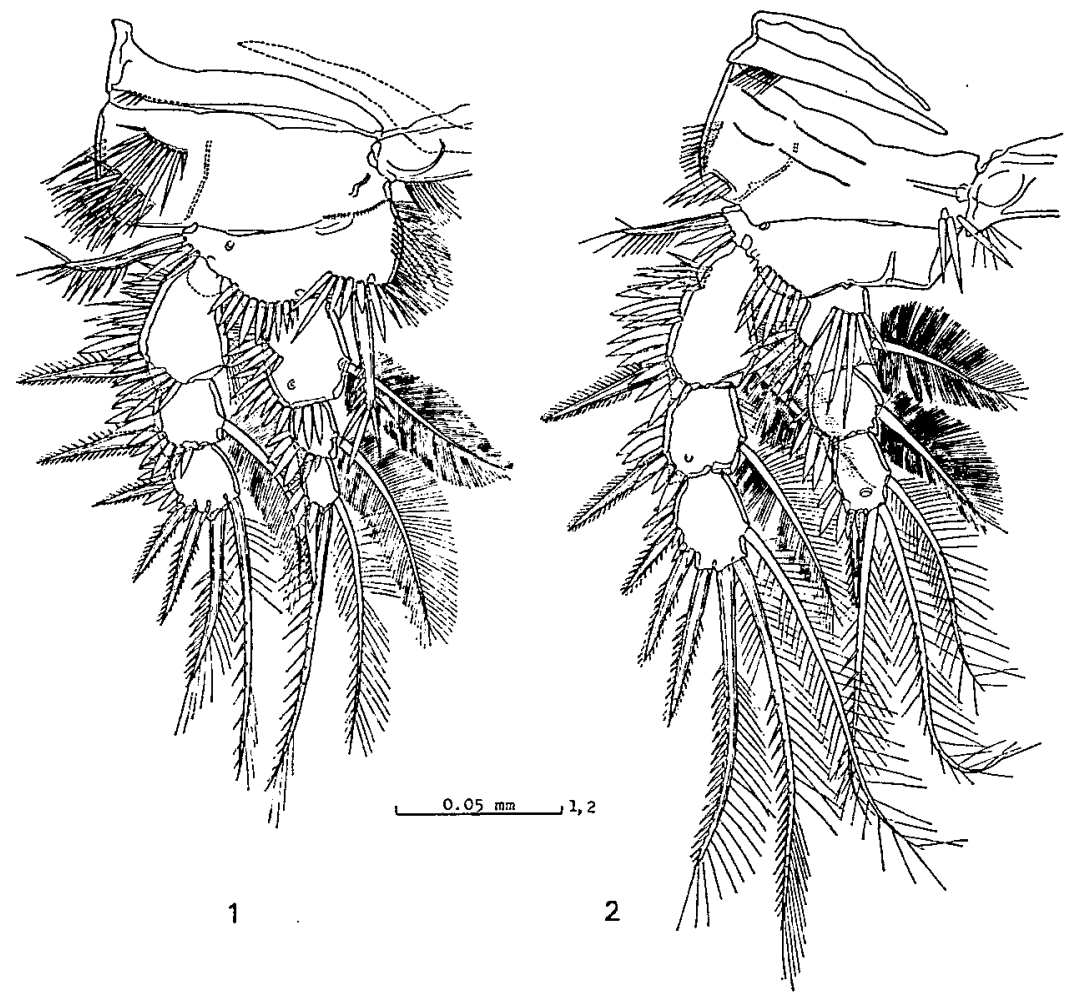

Fig. 46. Pseudotachidius minutus n. sp. Female (holotype): 1. leg 1; 2. leg 2.

L e g 2 (Fig. 46-2). Intercoxal plate scarcely concaved at free edge with several hairs bilaterally. Coxa wide, armed anteriorly with transverse row of closely set spinules near outer distal edge; a row of fine spinules attached onto posterior face along outer edge. Basis rounded between exopodite and endopodite, armed with one outer spine which bears fine spinules on its apical half; a prominent pore occurring anteriorly above exopodite; an oblique row of closely set spatulate spinules occurring on anterior face between rami; inner edge bare. Both rami threesegmented. Exopodite longer than endopodite; first segment a little shorter than apical two segments combined, furnished with hairs inwards, a serrate membrane on inner half of distal end, many spatulate spinules arranged in several oblique rows on and near outer edge, armed with one outer spine and one plumose inner seta; 
second segment with a few hairs on inner edge, a pore on anterior face near outer distal angle, spatulate spinules on outer edge, a serrate membrane on inner half of distal end, armed with one outer spine and one plumose inner seta; third segment with spatulate spinules on outer edge, armed with three outer spines, two apical setae which are spinulose outwards and hairy inwards, and one hairy inner seta subapically. Endopodite widely separated from inner distal angle of basis; first segment a little bigger than apical two segments, pointed at outer and inner distal

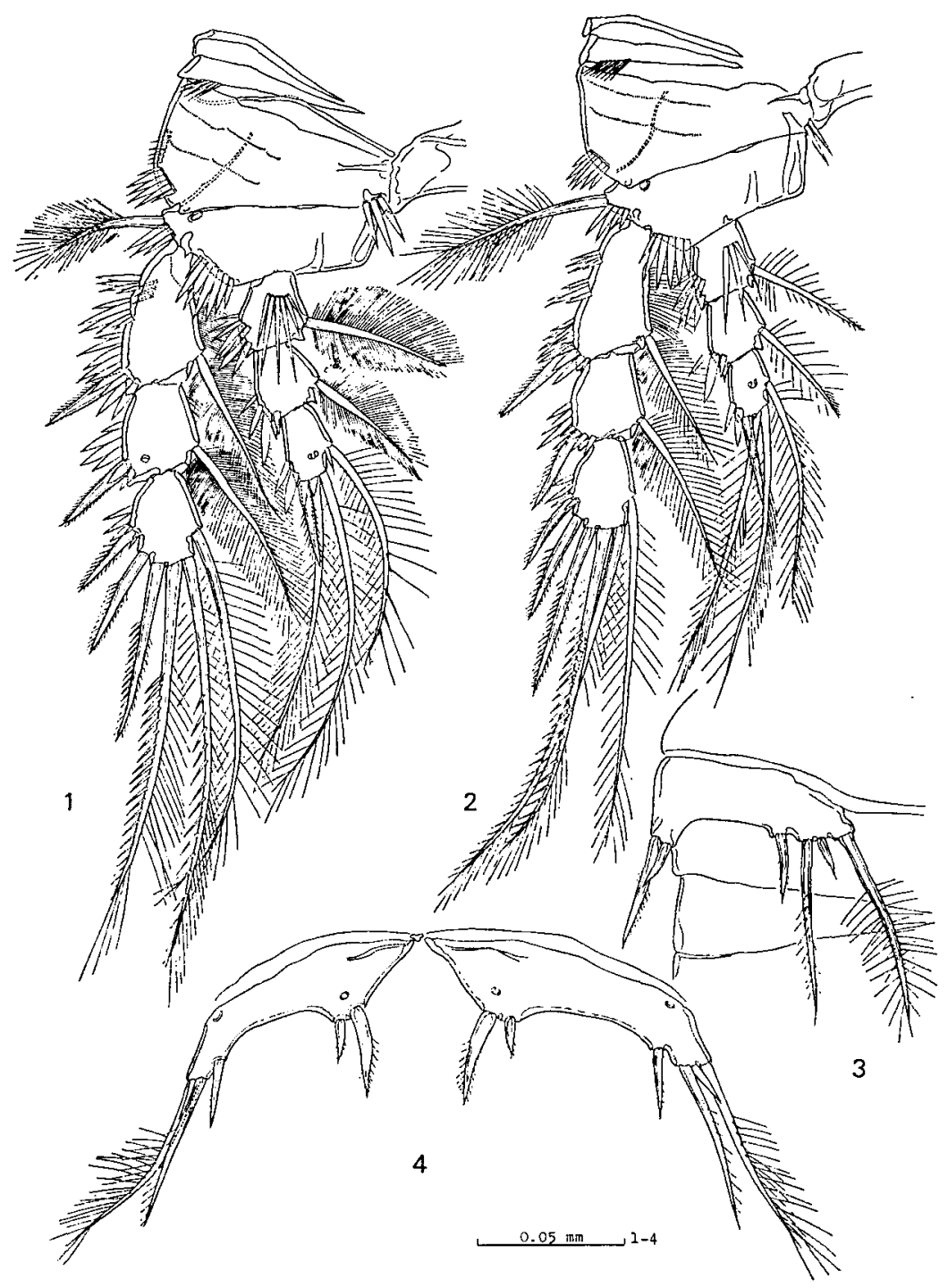

Fig. 47. Pseudotachidius minutus n. sp. Female (holotype): 1. $\operatorname{leg} 3 ; 2 . \operatorname{leg} 4$; 3. lateral viwe of left leg 5 in situ; 4. a pair of leg 5 in situ. 
angles, with an arched row of very much elongate spinules on anterior face, spatulate spinules on and near outer edge, armed with one plumose inner seta subapically; second segment pointed at outer and inner distal angles, with spatulate spinules on outer edge, armed with one plumose inner seta which bears a few spinules anteriorly; third segment with a prominent pore on anterior face subapically, with spatulate spinules on anterior edge, armed with one spinulose outer spine subapically, two apical setae which are spinulose outwards and hairy inwards, and one inner seta subapically, which bears hairs bilaterally and spinules anteriorly. Leg 3 (Fig. 47-1). Intercoxal plate bare. Basis armed with one thick outer seta which bears numerous hairs arising roughly. Three endopodite segments combined a little shorter than first two exopodite segments combined. Segmentation and other principal armatures as in leg 2. L e g 4 (Fig. 47-2). Second exopodite segment with no pore on its anterior face. Three endopodite segments combined distinctly shorter than first two exopodite segments combined. Each inner seta of first two endopodite segments not plumose but bearing hairs sparsely and several short spinules. Other principal structure as in leg 3. L e g 5 (Figs. 47-3, 47-4) represented by a wide plate armed with two spinulose short setae on somewhat protruded inner distal angle (representing inner expansion of baseoendopodite), one thick hairy seta on outer extremity. Exopodite represented by three setae, of which the middle is long, attached onto distal edge near outer extremity.

Remarks. The present new species resembles Pseudotachidius similis Scott, 1902, Ps. vikingus Drzycimski, 1968, Ps. abyssalis Becker, 1974, and Ps. horikoshii mihi, in the general shape of the female leg 5 , which has no separate exopodite segment. The new species, however, is easily discernible from the latters because it bears two setae on the inner expansion of baseoendopodite of the female leg 5, whilst the latters bear three setae on the counterpart.

The new species is remarkable in the unique characteristic that the cephalothorax is fringed with three separate hyaline membranes. The antennal allobasis of the new species is subdivided into two parts by a transverse suture (see Fig. 45-2), and the same characteristic is certainly present in the right antenna unillustrated. If the suture represented a demarcation between fused segments, the segment described as the 'allobasis' would be a fused segment composed of the allobasis and the coxa; furthermore, the segment described as the 'coxa' would be regarded as the precoxa.

The specific name of the new species alludes its body size that is smaller than the other two sympatric congeners previously described in this paper.

\section{Malacopsyllus hirsutus n. sp.}

(Figs. 48-54)

Material. Two adult females and one adult male were dissected. One of the females was designated as the holotype, the other female and the male as paratypes. Type-locality: Southeast off Mindanao, the Pacific Ocean. The specimens were collected with Murano's net (6-II-1979). 
Female (holotype). Body (Figs. 48-1, 48-2) subcylindrical, about $1 \mathrm{~mm}$ long, colorless and semitransparent, furnished with very long hairs on all somites except for penultimate somite. Cephalothorax as long as wide, not forming rostral projection, rather concaved frontally (see Fig. 48-4), furnished with many papillae, each of which terminates in a long hair (lost in some), especially on dorsal surface and along ventral margin and posterior edge of integument; a ringed membranous ridge occurring posterior to cephalothoracic integument (see Figs. 48-3 and 48-4);

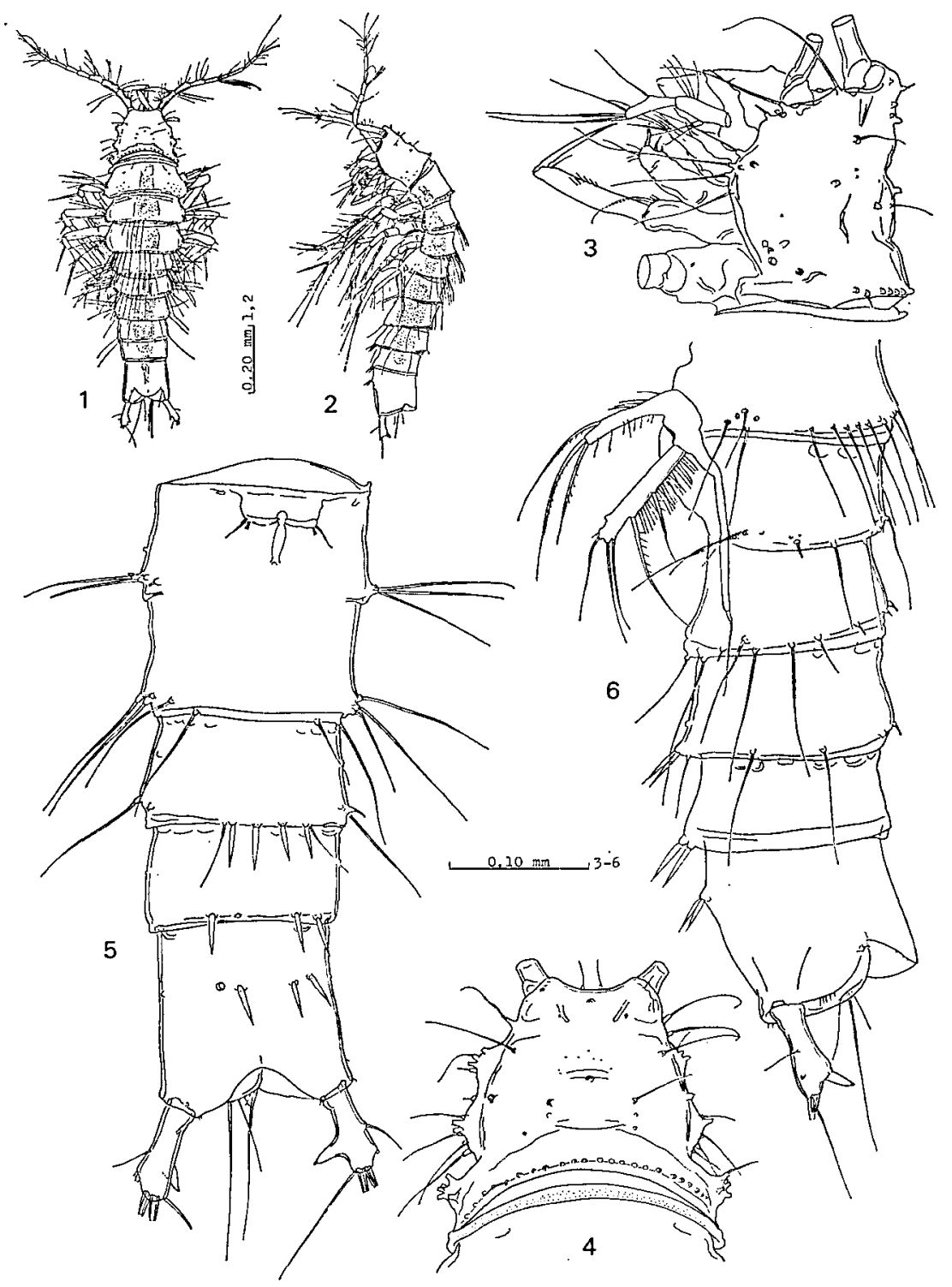

Fig. 48. Malacopsyllus hirsutus n. sp. Female (holotype): 1. habitus, dorsal; 2. habitus, lateral; 3. cephalothorax, lateral; 4. cephalothorax, dorsal; 5. abdomen; 6. leg 5 and abdomen, lateral. 
a pair of glands (?) occurring frontally, each extending a duct (?) toward antennule (cf. Figs. 52-2 and 52-3); labrum (Fig. 48-2) short, forming a membranous rim ventrally. Pleurotergite of thoracic somites not clearly defined laterally, furnished with hair-bearing papillae along posterior edge and indistinct lateral edges. Abdomen (Figs. 48-5, 48-6, 49-1) scarcely tapering posteriorly. Genital doublesomite subdivided dorsally and laterally by a transverse suture with hair-bearing papillae; genital area small, with a pair of fine setulae; hair-bearing papillae occurring along posterior end dorsally and laterally. Antepenultimate somite furnished with hair-bearing papillae along posterior end dorsally and ventrally, and four prominent spinules placed between two hairs ventrally. Penultimate somite with no hair-bearing papillae, furnished ventrally with four spinules (one of them lost). Anal somite as long as the preceding two somites combined, furnished with four prominent spinules (one of them lost) arranged transversely on ventral face; anal operculum well developed, semicircular; a fine long hair attached onto each dorsal edge near anal operculum; a few very long hairs attached onto both sides of anus. Furcal rami divergent, widely separated from each other, half as long as anal somite, about three times as long as its proximal width, forming a horny projection (which probably terminates in a setula, because a vestige of a broken setula remains) on inner subapical face, furnished with a setula on the middle of outer face and two vestiges of probably lost setulae on subapical lateral face; principal terminal setae present (broken); one slender seta attached onto inner apical end. Anten$\mathrm{n}$ u le (Fig. 49-3) consisting of eight slender segments; first segment longest, with many fine long spinules on a swelling at the middle of anterior face; second and third segments armed anteriorly with slender setae which bear very short spinules sparsely; fourth segment armed apically with an aesthetasc together with two bare setae; fifth segment with a bare seta subapically; sixth segment as long as apical two segments combined, with a bare setula on the middle of anterior face; seventh segment with fine bare setae anteriorly and posteriorly; eighth segment with fine bare setae apically and posteriorly, and a fine aesthetasc apically. Ante n n a (Fig. 49-4). Coxa bare. Basis longer than coxa, with spinules on subapical anterior face and near proximal end. Exopodite represented by a small cylindrical segment, which is shorter than basis, terminating in a seta which bears several fine spinules. First endopodite segment longer than coxa and basis combined, somewhat thickening apically, with spinules around the middle of anterior face. Second endopodite segment longer than the preceding segment with a few spinules on proximal half of anterior face, armed with two spines on about the middle of anterior face, five slender geniculate spines of different lengths apically, of which the longest is proximally bifurcated. M a n dible (Fig. 49-5). Precoxa rather weak, with short spinules proximally; pars incisiva four-dentate; at least four prominent spinules attached onto cutting edge; a spinulose fine setula arising from dorsal edge. Coxa-basis almost vertically arising from precoxa, about 3.5 times as long as basal width, with long hairs. Exopodite represented by a rudimentary segment with 


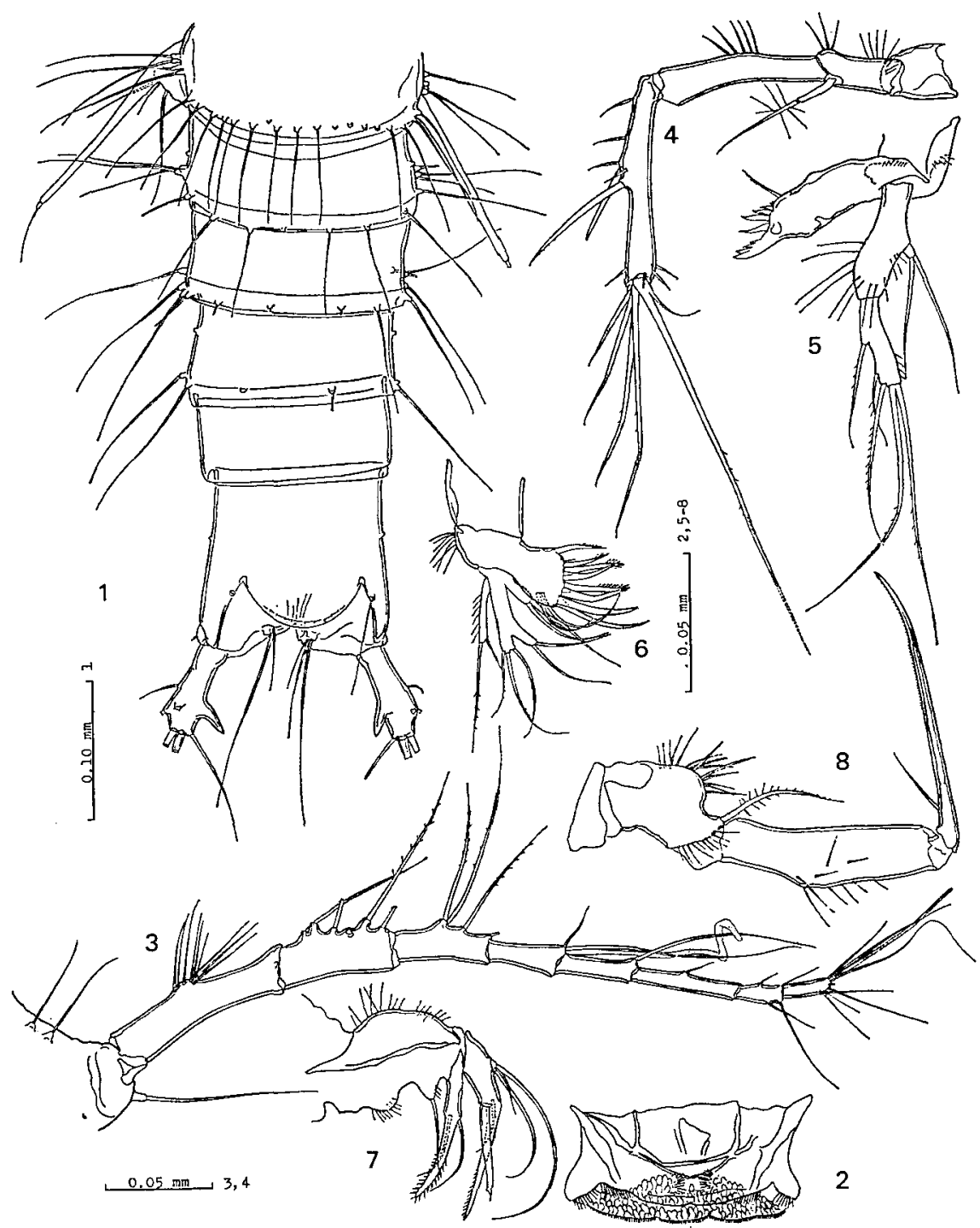

Fig. 49. Malacopsyllus hirsutus n. sp. Female (holotype): 1. leg 5 and abdomen, dorsal; 2. labrum; 3. antennule; 4. antenna; 5 . mandible; 6. maxillula; 7. maxilla; 8. maxillipede.

two bare setae apically. Endopodite represented by a well-developed segment arising from the apex of coxa-basis, armed with a seta near the middle of inner edge, two setae on subapical inner edge, and two juxtaposed setae apically; all setae with short spinules sparsely. Maxillula (Fig. 49-6). Precoxa furnished with hairs along outer edge; arthrite widening inwards, armed with two fine parallel setae on anterior face near ventral edge, eight spines or setae and a setula on inner edge. Coxal inner process small and cylindrical, terminating in two slender 
setae. Basis extending almost vertically, and bipartite apically, armed with two apical setae on inner part and three setae on outer part. Endopodite represented by a narrow segment with hairs along outer edge, terminating in two fine setae. Exopodite wanting. Maxilla (Fig. 49-7). Syncoxa bearing fine spinules on outer edge and on a proximal swelling at inner edge, furnished with two endites; first endite represented by a small projection terminating in a slender seta; second endite represented by a cylindrical process apically forming a bilaterally spinulose claw which is accompanied with a slender seta and a spine. Endopodite represented by a rudimentary segment with two long setae and one setula. M a xillipede (Fig. 49-8). Coxa short, bare. Basis extremely sinuate along inner edge with long spinules, armed with a spinulose seta on apical inner edge; an oblique row of spinules on distal anterior face. First endopodite segment about 1.7 times as long as basis, furnished with fine spinules scattered on and near outer edge. Second endopodite segment represented by a short slender spine which is longer than the preceding segment, accompanied with a fine seta near proximal inner edge, short spinules along distal half of inner edge.

L e g 1 (Fig. 50-1). Intercoxal plate very low and wide. Coxa tapering apically, with hairlike spinules on outer edge and anterior face. Basis markedly widening toward apical and extending outwards, armed with one spinulose stout seta which is as long as exopodite segments combined and arises from outer distal angle, one seta arising from a short process on subapical inner edge. Both rami two-segmented, very slender. Exopodite: first segment three times as long as its median width, armed with one long outer spine subapically, hairlike spinules along inner edge; second segment about 1.5 times as long as first segment, armed with four outer spines, two geniculate slender spines apically, and one slender inner seta on a point at a proximal third the length. Endopodite longer than exopodite; first segment a little shorter than two exopodite segments combined, armed with one inner seta on a point at two-thirds the length from the base; second segment longer than first segment, with widely spaced spinules along outer edge, armed with one simple spine, one medially geniculate long spine, and one small seta apically, and a small inner seta on a point at a proximal third the length. L e g 2 (Fig. 502). Intercoxal plate low and wide. Coxa with hairlike spinules on outer edge, a few short spinules on inner edge. Basis much longer than coxa, markedly extending outwards with one outer seta (broken) on subapical edge. Both rami twosegmented. Exopodite broken; proximal segment composed of two fused segments which are separated by an indistinct suture, armed with two outer spines and one inner seta (broken) on subapical edge; distal segment longer than proximal segment, armed with three, widely spaced, outer spines, one long spine and one seta apically, and two hairy inner setae. Endopodite: first segment short, armed with one hairy inner seta; second segment about seven times as long as first segment, armed with one slender outer spine subapically, two hairy setae apically, and two hairy inner setae which are widely spaced; each outer edge fringed with hairlike spinules. Leg 3 (Fig. 50-3). Segmentation and armature as in leg 2. Leg 4 


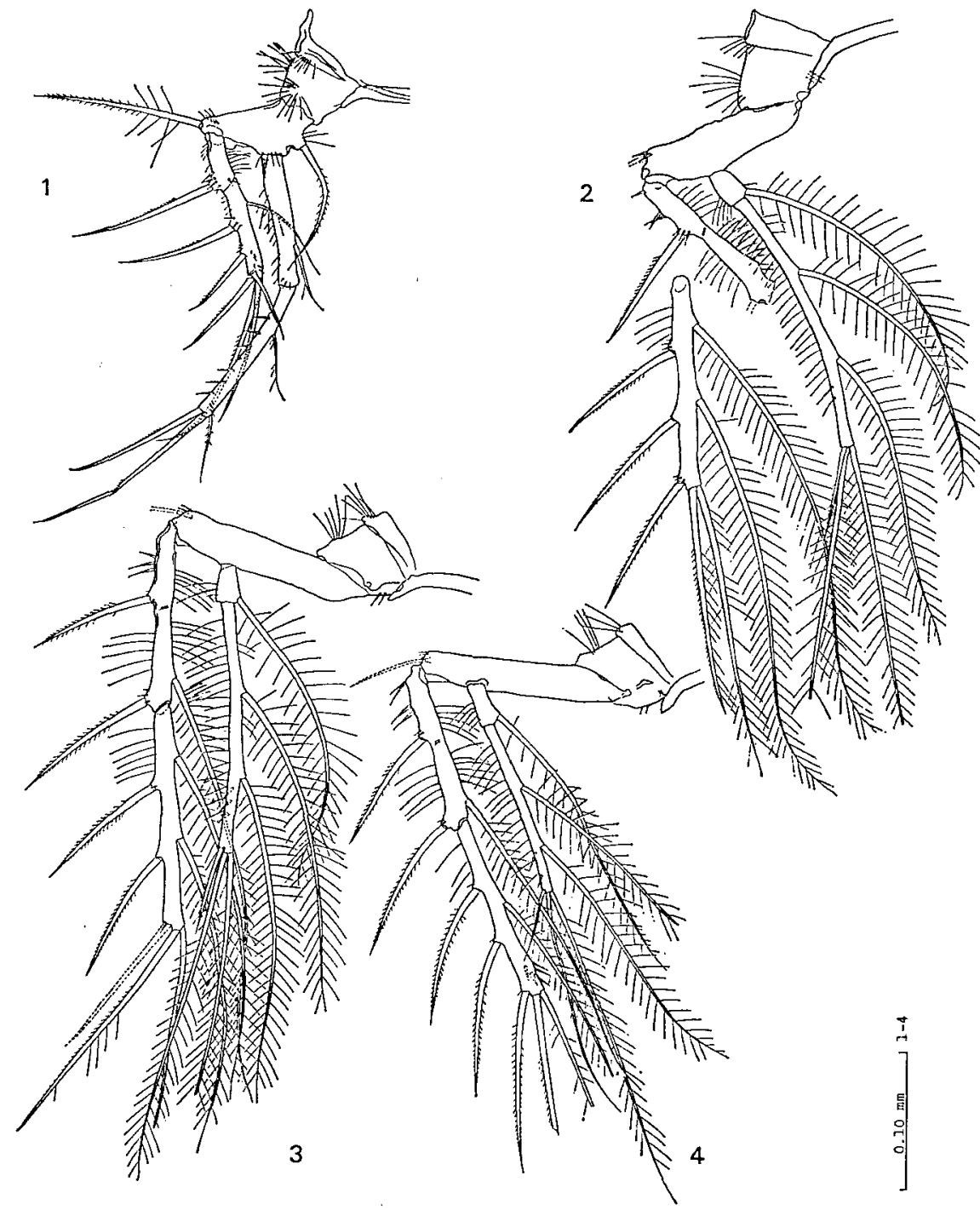

Fig. 50. Malacopsyllus hirsutus n. sp. Female (holotype): 1. leg 1; $2 . \operatorname{leg} 2$ (exopodite broken); $3 . \operatorname{leg} 3 ; 4 . \operatorname{leg} 4$.

(Fig. 50-4). Intercoxal plate, coxa, and basis as in leg 3. Exopodite and endopodite smaller than those of leg 3. Distal exopodite segment differing from that of leg 3, armed with one inner seta almost medially and a group of several spinules on subapical inner edge. L e g 5 (Fig. 51-1). Baseoendopodite forming a prominent inner expansion which extends vertically, reaches about the middle of exopodite segment, and bears one inner and two apical long setae with hairs and short spinules; outer seta arising from an extremely elongated cylindrical process; long hairs occurring on inner edge and along outer edge of inner expansion. Exopodite represented by a narrow segment about 6.5 times as long as its median width, 
armed with a setula, which arises from a papillary projection on subapical inner edge, and five setae in all along outer edge and around its apex; long hairs attached onto outer edge.

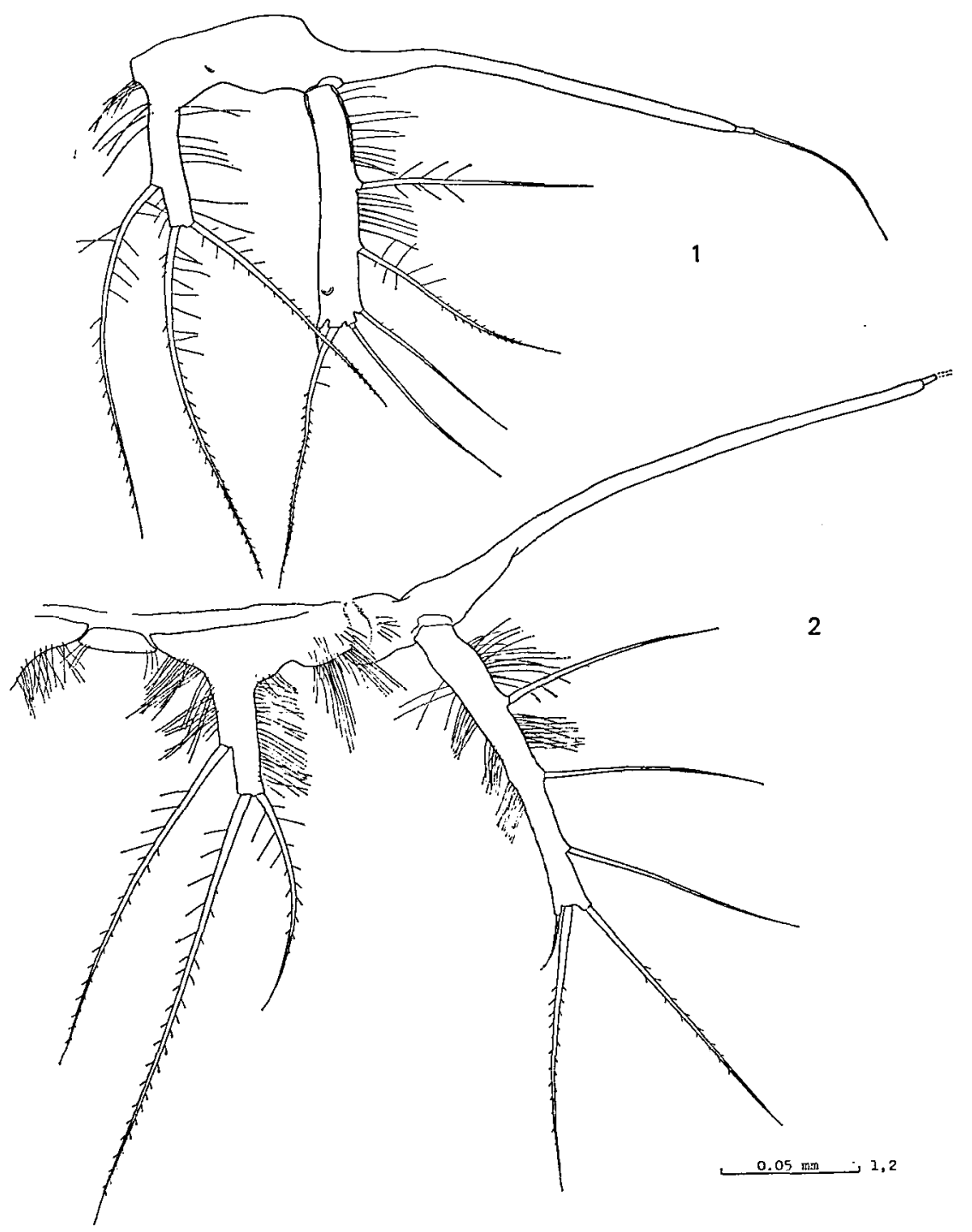

Fig. 51. Malacopsyllus hirsutus n. sp. Female (holotype): 1. leg 5 (holotype); 2. leg 5 (paratype).

Notes on the paratypic female. Body $1.02 \mathrm{~mm}$ long. L e g 5 (Fig. 51-2). Baseoendopodite with many long hairs on inner edge and outer edge of inner expansion of baseoendopodite and on free edge between inner expansion and exopodite. Exopodite about 9.5 times as long as its median width, with hairs along inner edge and outer edge, armed with one setula which arises from a papillary projection at 
inner distal angle, one seta on distal edge, one seta arising from a papillary projection at outer distal angle, and three inner setae which are widely spaced. No particular structure differing from the holotype was detected in principal characters.

Male (allotype). Body (Fig. 52-1) $0.91 \mathrm{~mm}$ long. A pair of glands (?) clearly present within cephalothorax (Figs. 52-2, 52-3). Dorsal and posterior hairs of cephalothoracic and thoracic somites well preserved as shown in figures. Abdomen (Figs. 53-1, 53-2, 53-3) furnished with prominent spinules ventrally. A n t e n$\mathrm{n}$ u le (Fig. 54-1) haplocer, consisting of eight slender segments. Fifth segment armed with short setae on anterior face. A $\mathrm{n}$ te $\mathrm{n} n$ a and or a 1 a p p e n d a ges

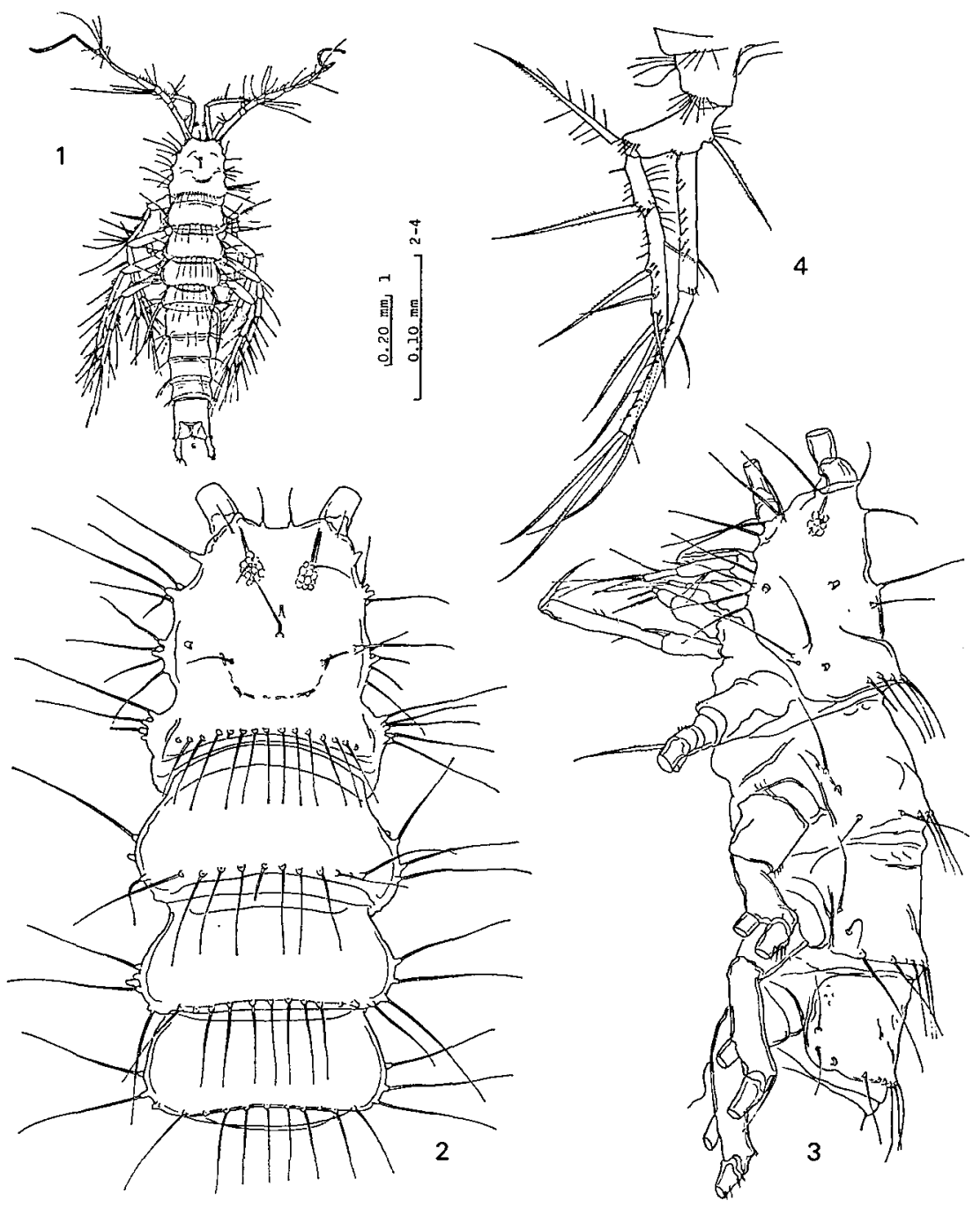

Fig. 52. Malacopsyllus hirsutus n. sp. Male (allotype): 1. habitus, dorsal; 2. fore body, dorsal; 3. fore body, lateral; 4. leg 1 . 


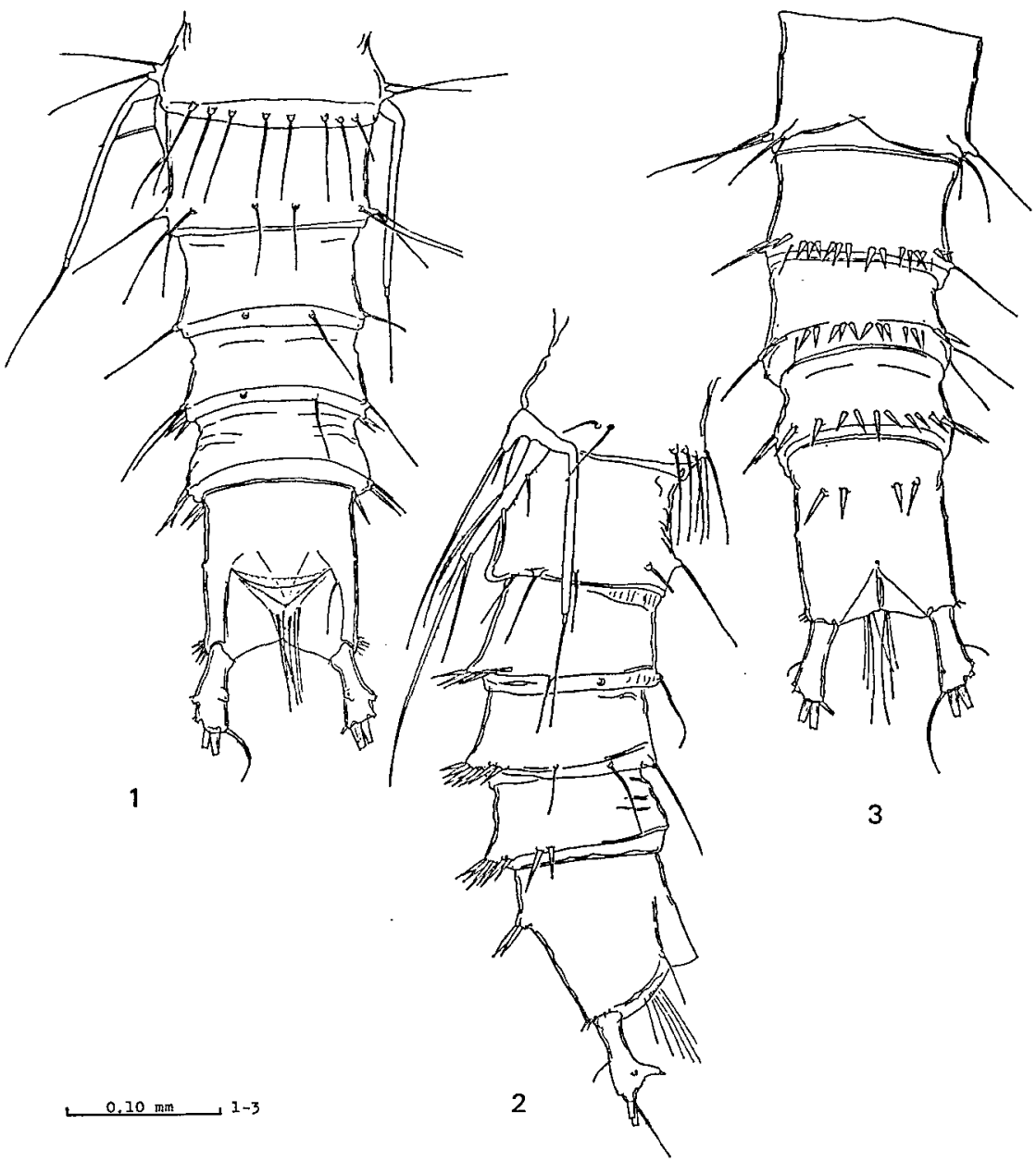

Fig. 53. Malacopsyllus hirsutus n. sp. Male (allotype): 1. leg 5 and abdomen, dorsal; 2. leg 5 and abdomen, lateral; 3. abdomen, ventral.

principally as in the holotype.

Leg 1 (Fig. 52-4), leg 2 (Fig. 54-2), leg 3, and leg 4 principally as in the holotype. L e g 5 (Fig. 54-3). Both baseoendopodites confluent with each other; each inner expansion represented by a short process terminating in long seta which is accompanied with a dwarfed setula (right leg) or a short seta (left leg) near its outer base; each outer seta arising from a very long cylindrical process. Exopodite represented by a narrow segment armed with six setae in all. Right exopodite armed with three outer setae which are widely spaced, one terminal seta, and one fine seta on subapical inner edge and one rudimentary seta near the middle of inner edge. Left exopodite armed with three outer setae which are widely spaced, one terminal seta, and one small (not very fine) seta on subapical inner edge and one long seta near the middle of inner edge. L e g 6 (Fig. 53-3) represented by a low 


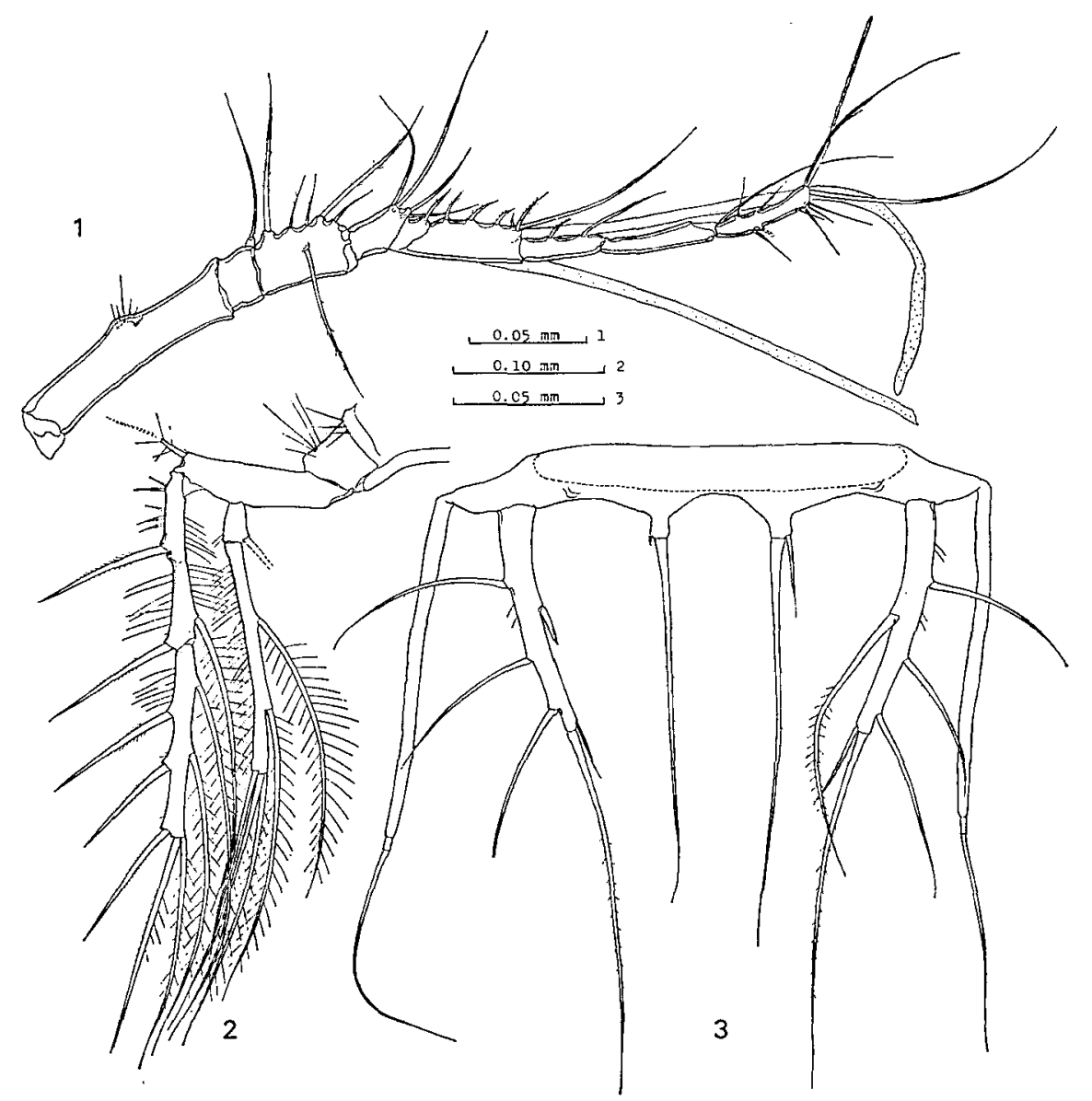

Fig. 54. Malacopsyllus hirsutus n. sp. Male (allotype): 1. antennule; 2. leg 2; 3. leg 5 .

plate forming outwards a small process armed with two small setae.

Remarks. The present new species resembles Malacopsyllus hades Becker, 1974, which was reported from the Peru Trench at a depth of $6300 \mathrm{~m}$, in the general appearance of the body with long hairs. The new species, however, clearly differs from the latter and other congeneric species in the segmentation of each exopodite of the first four legs and of the endopodite of leg 1 because these rami are composed of two segments in the new species and of three segments in the latters. A similar reductive characteristic is found in Anoplosoma sordidum Sars, 1911, whose exopodites of leg 2 and leg 4 are composed of two segments (see a footnote in Lang, 1948, p. 860). In this respect, the new species seems to show an intermediate condition along the course of the reduction from Malacopsyllus toward Anoplosoma which bears extreme reductive characteristics also in the leg 1 and antennular segmentation. Incidentally, the present material shows certain, probably abnormal, structures in 
the leg 5. However, the left part of the fused leg 5 of the male of the new species almost accords with the leg 5 of $M$. hades illustrated by Becker (1974) in the shape and armature.

The specimens of the present new species have a membranous ridge (see Figs. 48-3, 48-4) along the posterior end of cephalothoracic integument. It might be a remnant of the first thoracic somite.

The specific name of the new species alludes the impressive hair-bearing feature of the body.

\section{Parameiropsis magnus n. sp.}

(Figs. 55-59)

Material. An adult female dissected was designated as the holotype. Type-locality: Southeast off Mindanao, the Pacific Ocean. The specimen was collected from the supernatant water of bottom sediment sampled with a spade corer at a depth of $4970 \mathrm{~m}$ (7-II-1979).

Female (holotype). Body (Figs. 55-1, 55-2) including rostrum about $3 \mathrm{~mm}$ long, almost cylindrical; integuments colorless and glossy, very hard. Rostrum (Fig. 55-3) clearly defined at base, bell-shaped, with a pair of short sensory hairs at round apex, under which an apically pointed protuberance is formed. Cephalothoracic integument fringed with a well-developed hyaline membrane, of which each anterolateral portion concaved deeply (see Figs. 55-2, 55-3). A membranous structure, of which posterior edge is gently rounded, inserted beneath posterior hyaline membrane of cephalothorax and seemingly covering over articulation membrane between cephalothorax and first free thoracic somite (? rudimentary pleurotergite of fused first thoracic somite). Labrum (Fig. 55-4) represented by a triangular plate fringed with a hyaline membrane around apex. Paragnaths with long sharp spinules (Fig. 55-5). Fused thoracic somite clearly demarcated from cephalon by a narrow chitinous thickening which extends across the ventral surface of cephalothorax (see Fig. 57-1). Each pleurotergite of first three thoracic somites fringed with a well-developed hyaline membrane laterally and posteriorly. Pleurotergite not defined on fourth thoracic somite with leg 5. Abdomen (Figs. 56-1, 56-2, 56-3) about half as long as total body. Genital double-somite as long as wide, with a transverse chitinous suture on each lateral surface; two pairs of two juxtaposed short spinules on genital area (Fig. 56-3); posterior end fringed with a circumambient hyaline membrane together with short hairs. Antepenultimate and penultimate somites subequal in length, fringed posteriorly with a circumambient hyaline membrane together with short hairs. Anal somite about twice as long as penultimate somite, a little depressed dorsoventrally, tapering posteriorly, furnished with a pair of prominent sensory hairs on dorsal surface, with a flat-edged anal operculum which bears neither spinules nor hairs. Furcal rami separated from each other; each ramus small, longer than wide, armed with two closely set setulae on lateral face near posterior end, a hairy small seta on dorsal face near posterior inner 


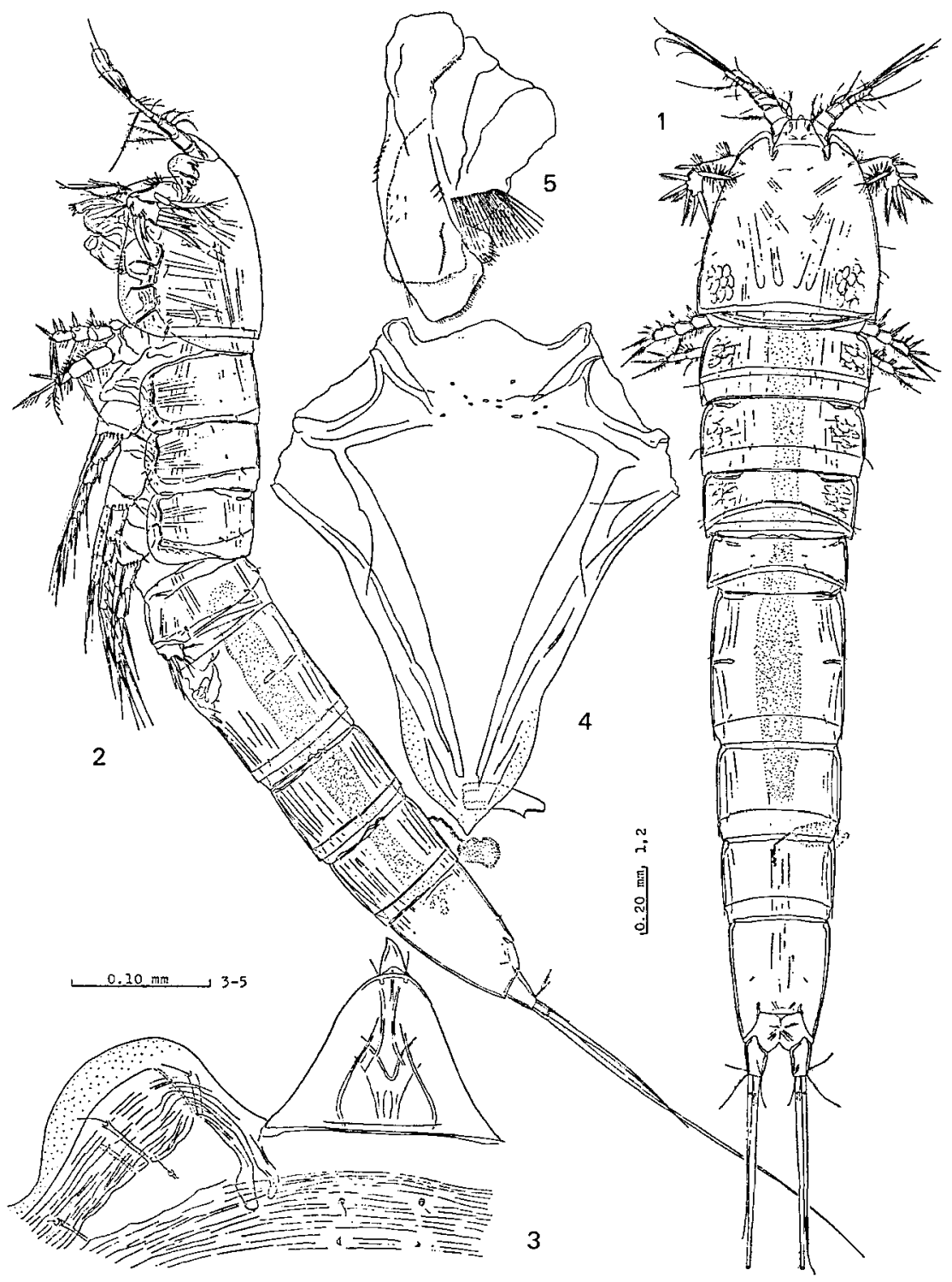

Fig. 55. Parameiropsis magnus n. sp. Female (holotype): 1. habitus, dorsal; 2. habitus. lateral; 3. rostrum and cephalothoracic integument; 4. labrum; 5. paragnaths, lateral.

edge, a slender seta on both lateral sides of principal terminal setae which are well developed.

A n t e n n u le (Fig. 56-4) eight-segmented, gradually tapering toward apical; first segment short, with two oblique rows of spinules on anterior face, bearing a seta with hairs sparsely; second segment longer than first segment, armed with hairy seta anteriorly and dorsally; third segment as long as second segment, bearing 


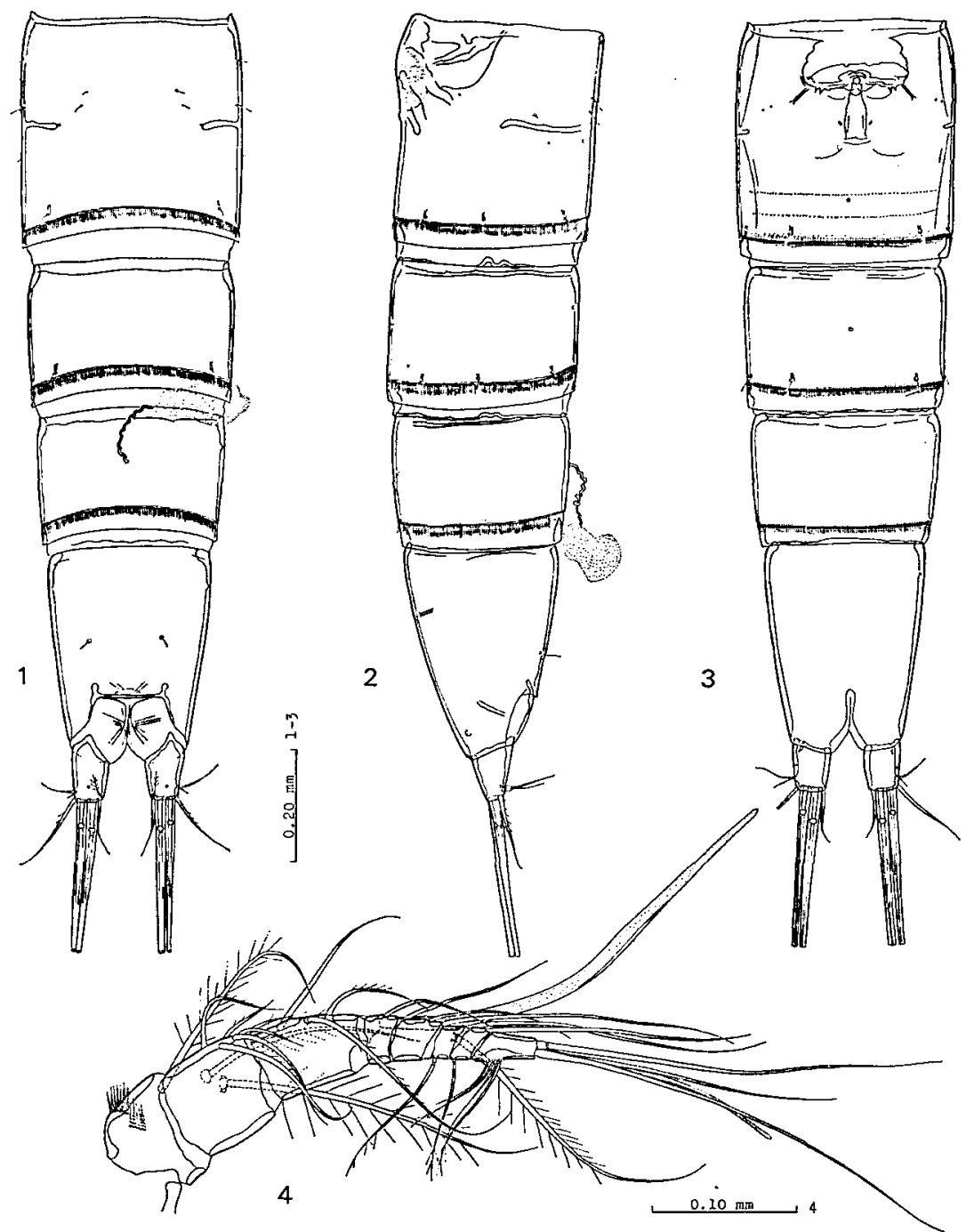

Fig. 56. Parameiropsis magnus n. sp. Female (holotype): 1. abdomen, dorsal; 2. abdomen, lateral; 3. abdomen, ventral; 4. antennule.

setae with short spinules on anterior face, armed with a long aesthetasc apically; fourth and fifth segments with a few slender bare setae anteriorly; sixth and seventh segments with a basally geniculate slender seta posteriorly, long setae anteriorly; eighth segment as long as the preceding two combined, armed with four, basally geniculate, slender setae posteriorly, a narrow aesthetasc together with setae apically. Anten $\mathrm{n}$ a (Fig. 57-2) arising through the concavity of marginal hyaline membrane of cephalothoracic integument, thickly sclerotized, stumpy in appearance. Coxa thick, short, and bare. Allobasis thick, about twice as long as its diameter, separated into two parts by a transverse slit both anteriorly and posteriorly, armed with no seta; long spinules attached onto anterior face near proximal 


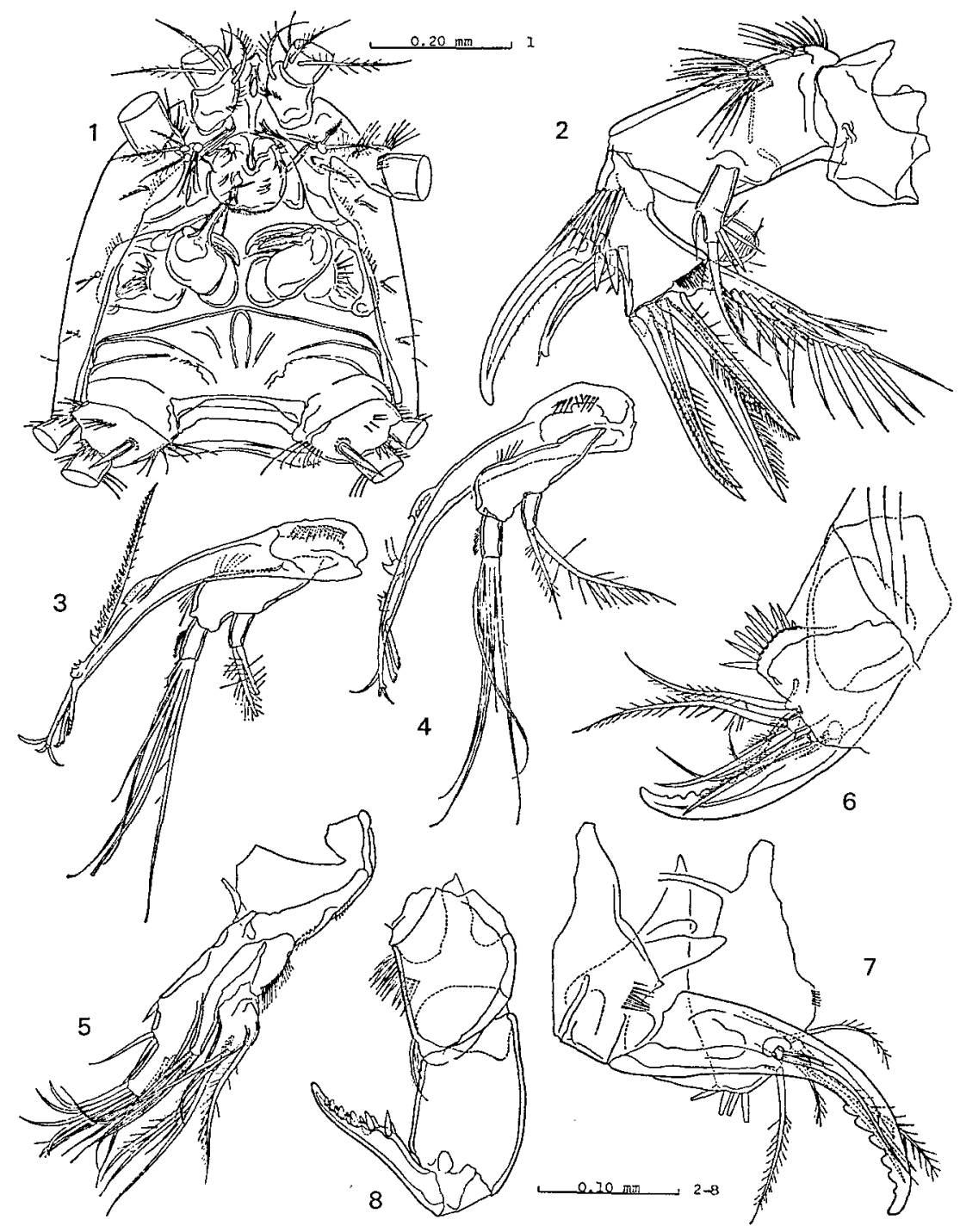

Fig. 57. Parameiropsis magnus n. sp. Female (holotype): 1. ventral view of cephalothorax; 2. antenna; 3. mandible; 4. mandible; 5 . maxillula; 6. maxilla; 7. maxilla; 8. maxillipede.

edge and the slit. Exopodite represented by a subcylindrical segment which tapers apically, armed with one short seta on a point at two-thirds the length of anterior face from the base, several prominent spinules near apex, and one apical seta which is thick and spinulose. Endopodite segment much thickening apically, shorter than allobasis, with a transverse row of long spinules on subproximal anterior face, armed with two very strong arched claws, which are accompanied with three thick spinules near their base, on about the middle of anterior face; apical edge flat, armed 
with four, closely set, spinulose spines which are subequal in length, and one separate spine which is furnished with two longitudinal rows of very prominent spinules and accompanied with a hairy seta; a row of fine spinules along outer apical edge. Mandible (Figs. 57-3, 57-4). Precoxa extremely elongated and tapering toward apical, forming four hooked projections apically, with a row of spinules proximally, armed with two long and two short denticulate spines subapically, and one long stout seta which is furnished with spinular rows arranged longitudinally; pars molaris edged. Coxa-basis elongated, thickening subapically, with very fine hairs along dorsal edge. Exopodite represented by a small cylindrical segment terminating in two hairy setae. Endopodite represented by a cylindrical segment, which is a little bigger than exopodite segment, with short hairs along inner edge, armed with six juxtaposed setae. Maxillula (Fig. 57-5). Each outer edge of precoxa and coxa with fine spinules. Arthrite of precoxa extremely elongated, armed with five slender spines and one seta on apical edge, two closely set setae and one short seta on dorsal edge, two parallel slender setae on anterior face near ventral edge. Inner process of coxa small and cylindrical, armed apically with four slender setae. Inner process of basis scarcely extending beyond coxal inner process, armed with four setae apically, two closely set setae on dorsal edge, a few spinules on anterior face. Endopodite represented by a rudimentary segment terminating in one hairy seta. $\mathrm{Maxilla}$ (Figs. 57-6, 57-7; see also Fig. 57-1). Syncoxa with several fine spinules along outer edge, a vertical row of prominent spinules on posterior face, furnished with three small endites; first endite with one spinulose seta apically; second endite with one slender spine (? stout seta), one hairy setula, and one spinulose seta apically; third endite with one finely spinulose slender spine (? stout seta) apically. Basis forming a strong, much sclerotized, claw which is denticulate dorsally and accompanied with a slender seta on its proximal dorsal edge. Endopodite represented by a very small rudimentary segment terminating in one seta and one setula. $\mathrm{Max}$ allipede (Fig. 57-8). Basis with a longitudinal row of spinules on inner face, two closely set setulae on subapical inner face. First endopodite segment as long as basis, bare. Second endopodite segment represented by a strong claw which is somewhat sinuate and furnished dorsally with apically rounded spinules.

L e g 1 (Fig. 58-1). Intercoxal plate low, bare. Coxa wide, with a few short spinular rows on anterior face. Basis short, narrower than coxa, with long cirri along proximal swelling of inner edge, a row of long spinules near the center of anterior face, prominent spinules on distal edge along each base of exopodite and endopodite; a prominent pore occurring near outer proximal angle of anterior face; outer seta longer than first two exopodite segments combined, with short spinules sparsely; inner spine arising from stepped edge, very strong, a little longer than first endopodite segment, spinulose. Both rami subequal in length, tapering toward apical, three-segmented. Exopodite: first segment about 1.5 times as long as wide, with prominent spinules around outer distal angle, an oblique row of fine spinules on posterior face near inner edge, armed with one outer spine subapically; second 
segment shorter than first segment, with a few prominent spinules around outer distal angle, fine spinules along inner edge, armed with one outer spine on a subapical stepped edge and one hairy inner seta subapically; third segment as long as second segment, with a few fine spinules along inner edge, armed with three outer spines, one spinulose long spine and one stout seta, which is spinulose outwards and hairy inwards, on apical edge; all outer spines of each segment subequal in length,

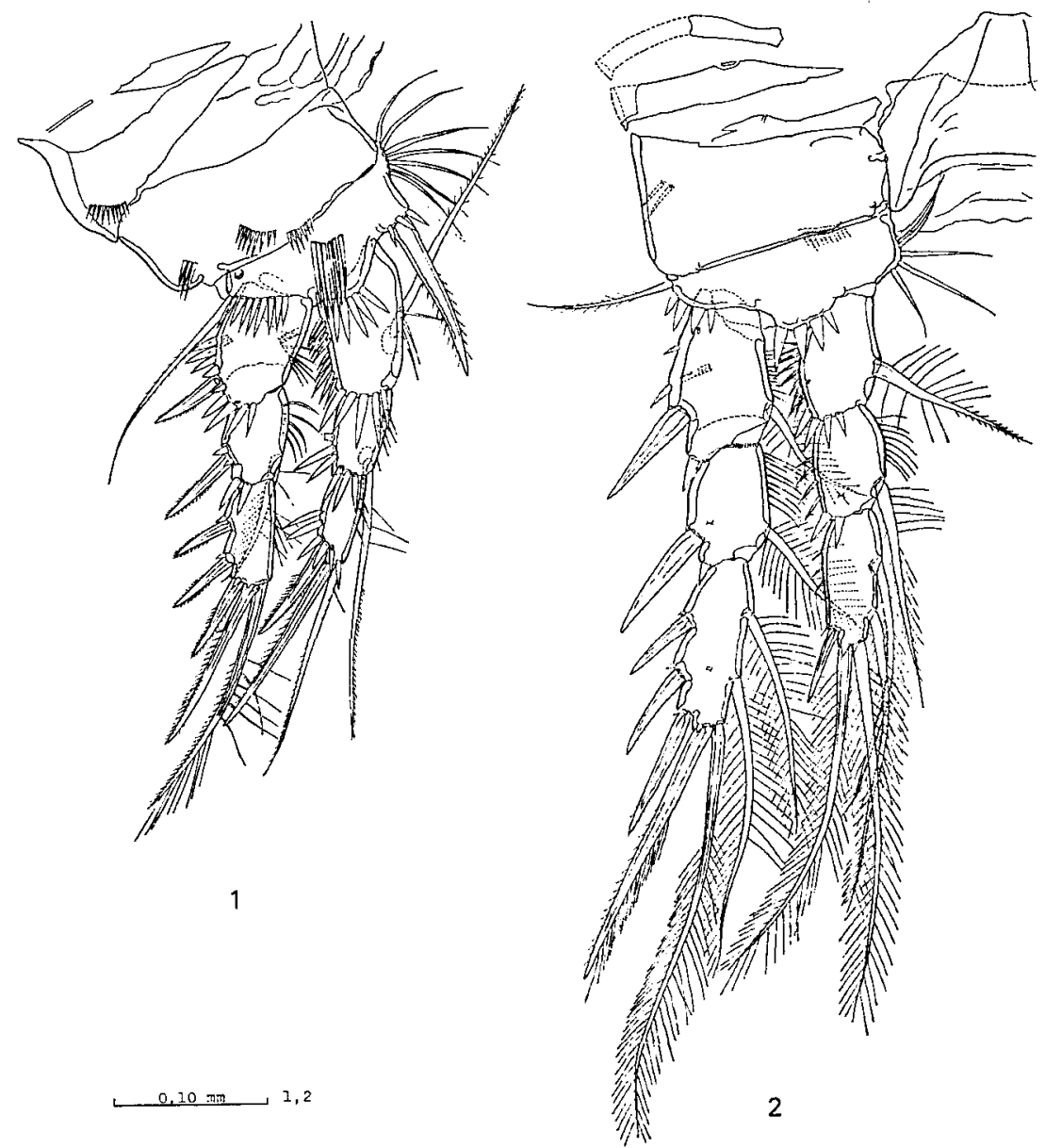

Fig. 58. Parameiropsis magnus n. sp. Female (holotype): 1. $\operatorname{leg} 1 ; 2 . \operatorname{leg} 2$.

finely spinulose. Endopodite: a row of prominent spinules occurring along outer edge of each segment and extending to inner distal angle of each anterior face; a few fine spinules on inner edge of each segment; first segment armed with one long inner seta which is stout, arises from a point just below the middle of inner edge, and is furnished with very short spinules; second segment shorter than first segment, armed with one long inner seta subapically; third segment as long as second segment, armed with one spinulose outer spine subapically, one spinulose elongate spine and one stout spinulose seta apically. Leg 2 (Fig. 58-2). Free edge of 
intercoxal plate widely concaved. Coxa with a pore on anterior face near inner distal angle, two spinules on posterior face near outer edge, a transverse row of short spinules on posterior face near its distal extremity. Basis as wide as coxa, not forming any spinous projection between exopodite and endopodite, with long cirri along inner edge, prominent spinules on outer edge and distal edge between two rami; outer seta as long as first exopodite segment, with short spinules sparsely. Both rami three-segmented. Exopodite longer than endopodite; first segment with a serrate hyaline membrane on inner distal edge, hairs on inner edge, armed with one bare outer spine on a subapical stepped edge and one plumose short inner seta; second segment shorter than first segment, with hairs along inner edge, armed with

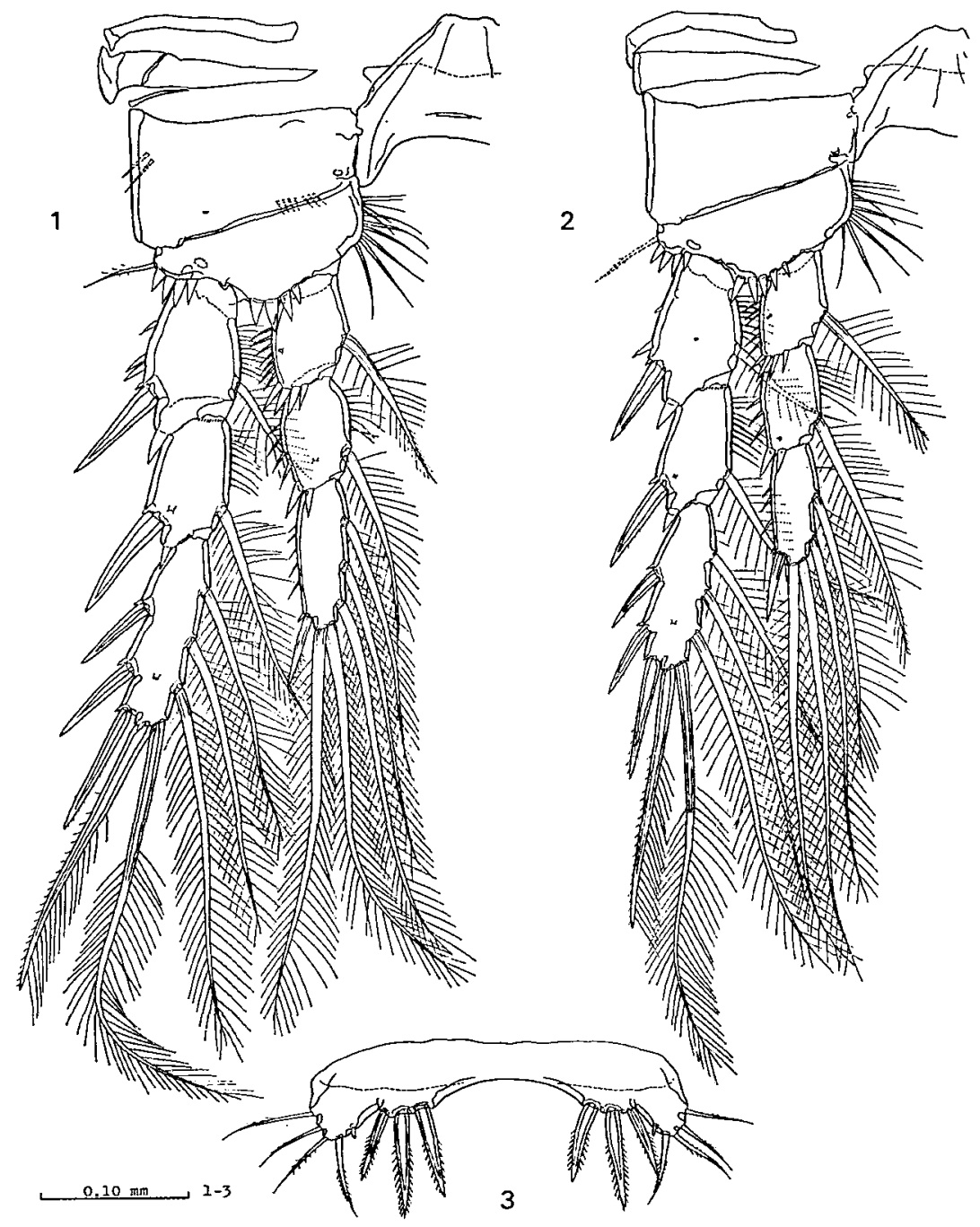

Fig. 59. Parameiropsis magnus n. sp. Female (holotype): 1. leg 3; 2. leg 4; 3. leg 5. 
one bare outer spine on a subapical stepped edge and one short plumose inner seta; third segment longer than second segment, armed with three almost bare outer spines on a stepped outer edge, one long spine, which is spinulose outwards and hairy inwards, and one long plumose seta on apical edge, and two plumose inner setae. Endopodite: first two segments subeuqal in length, with a few prominent spinules on each anterior face around outer distal angle, each armed with one stout inner seta which is plumose and subapically spinulose; third segment reaching distal end of third exopodite segment, 1.2 times as long as second segment, armed with one bare outer spine on a subapical stepped edge, two long plumose setae apically, and two plumose inner setae; outer edge of each segment with fine spinules; hairs attached onto inner edge of second segment. L e g 3 (Fig. 59-1). Intercoxal plate, coxa, and basis almost as in leg 2. Outer seta of basis short. Third exopodite segment armed with three plumose inner setae; otherwise as in leg 2. Third endopodite segment 1.4 times as long as second endopodite segment, armed with three inner setae; otherwise as in leg 2. L e g 4 (Fig. 59-2). Intercoxal plate, coxa, and basis narrower than those of leg 2. Coxa with no spinule. Third endopodite segment not reaching the middle of third exopodite segment, 1.2 times as long as second endopodite segment, armed with two inner setae; otherwise as in leg 3. L e g 5 (Fig. 59-3). Both legs represented by a low and wide common plate. Both inner expansions of baseoendopodite widely separated by a concaved bare rim; each armed with three spinulose spines. Each outer part forming a lobe with four small setae marginally and a short tubule (not a broken seta) on a midway of its inner edge.

Remarks. The genus Parameiropsis has so far contained two species, P. peruanus Becker, 1974, reported from the Peru Trench, and P. rapiens Becker, 1974, reported from the Iberian deep-sea. The present new species resembles $P$. rapiens in having the leg 5 with fused exopodites. The new species, however, differs from the latter in the extremely big size, and the common plate made of fused baseoendopodites of leg 5 and the armature of spines on its inner expansion.

The specific name of this new species alludes the big size.

\section{Abyssameira n. gen.}

This new genus, which belongs to the family Ameiridae, is monotypic, and a preliminary description based upon the male of the type-species is given: Cephalic integument posteriorly accompanied with a rudimentary, but clearly delimited, pleurotergite of fused first thoracic somite; furcal rami not extremely elongate; first segment of antennule not extremely elongate; antennal exopodite consisting of one small segment; exopodite and endopodite of mandible consisting of one segment; maxillula and maxilla degenerative; first four legs with three-segmented exopodite and three-segmented endopodite; endopodite segments of leg 1 subequal in length, not prehensile; each third exopodite segment of leg 2, leg 3, and leg 4 
armed with three outer spines. Characteristics of the new genus and its systematic position will be discussed after the description of the type-species.

The generic name denotes that the type-species is an abyssal dweller and belongs to Ameiridae. The gender is feminine. The new species which is described below is designated as the type-species.

\section{Abyssameira reducta n. sp.}

(Figs. 60-65)

Material Three adult males were dissected, one of them was designated as the holotype, and the others as the paratypes. Type-locality: Southeast off Mindanao, the Pacific Ocean. The specimens were collected with Murano's net (6-II-1979). No female was collected.

Male (holotype). Body (Figs. 60-1, 60-2) $1.2 \mathrm{~mm}$ long, colorless, rather opaque, furnished with numerous short hairs. Cephalon tapering anteriorly, somewhat depressed dorsoventrally; rostrum (Fig. 60-4) small; integument with long hairs marginally, posteriorly fringed with no hyaline membrane but connected with a rudimentary, but clearly delimited, pleurotergite of fused first thoracic somite (Fig. 60-3). Labrum and paragnaths not sclerotized, without particular spinules or hairs (Fig. 62-1). First, second, and third free thoracic somites subequal in width; each pleurotergite with long hairs marginally. Hind body (Figs. 61-1, 61-2, 61-3) subcylindrical, with a well-developed spermatophore inside anterior somites, furnished with spinules (some of them missing) and hairs along posterior edge as shown in figures; an atrophied ribbon-like intestine occurring through several somites (see Fig. 61-3). Anal somite tapering posteriorly, furnished with a transverse row of prominent spinules on ventral face near anterior extremity; anal operculum rounded (Fig. 61-1), with no spinule, furnished with a pair of sensory hairs which are widely separated from each other. Furcal ramus small, as long as wide, armed with one basally geniculate seta which arises dorsally and is membranous, one setula on outer face, two principal terminal setae accompanied with one seta inwards and outwards.

Antennule (Fig. 60-4) haplocer, consisting of 11 segments and annules, longer than cephalothorax; first segment not extremely elongated, with short spinules on anterior (inner) face; some setae bearing short spinules; a long and thick aesthetasc arising from a somewhat swollen segment (? sixth segment); a very slender aesthetasc arising from distal end of apical segment. A n t e n n a (Fig. 60-5). Coxa short, bare. Allobasis with an obscure suture which represents a demarcation between basis and fused endopodite segment, furnished with spinules anteriorly and many scattered short hairs. Exopodite represented by a small segment with a few very long hairs, terminating in one spinulose short seta. Endopodite segment as long as allobasis, with spinules on its proximal half of anterior face and near apex, many scattered hairs, armed with two spaced short setae on about the middle of anterior face; five spinulose setae of different lengths and one fine 


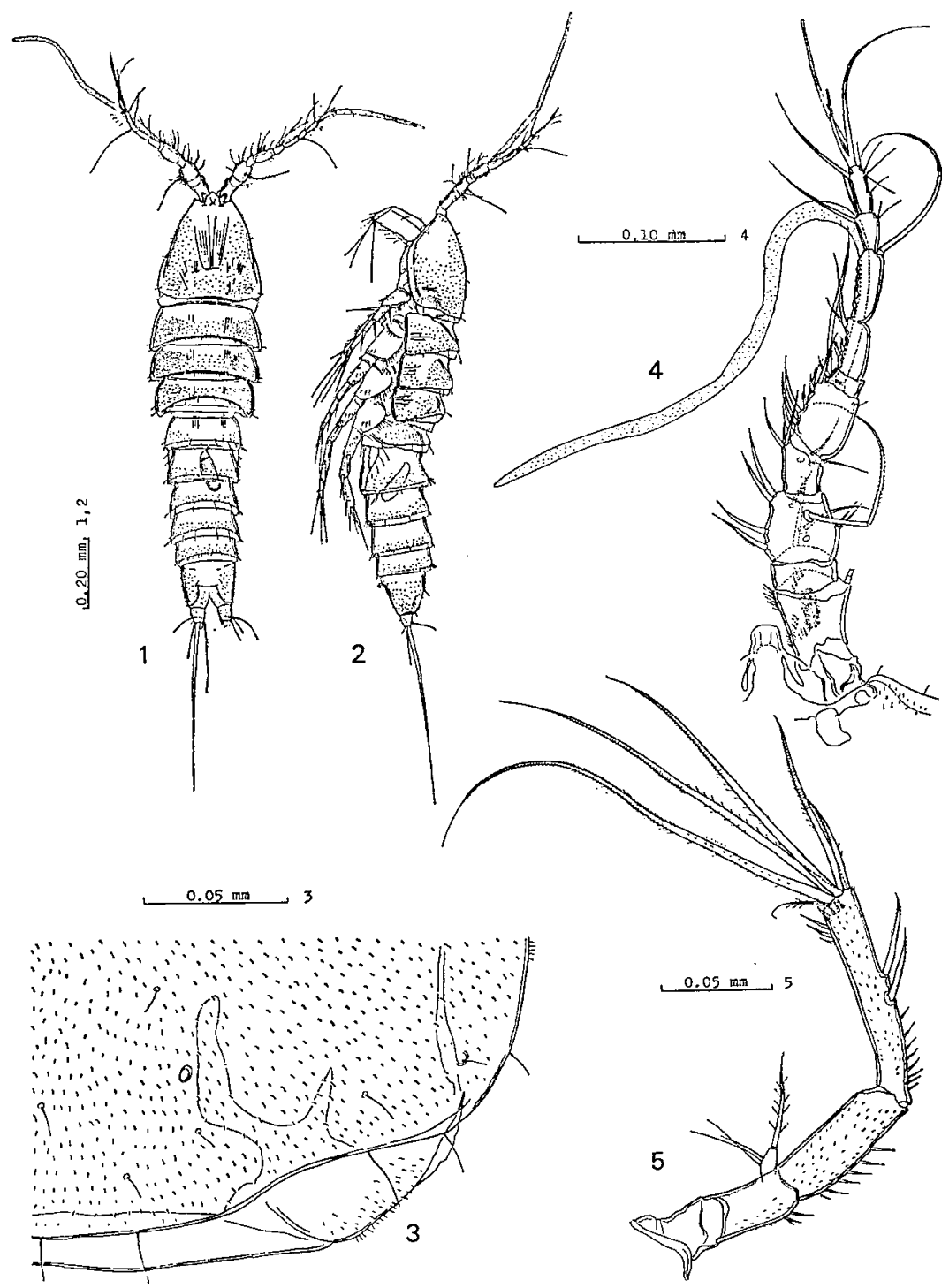

Fig. 60. Abyssameira reducta n. gen., n. sp. Male (holotype): 1. habitus, dorsal; 2. habitus, lateral; 3. cephalic integument and pleurotergite of first thoracic somite; 4. antennule; 5. antenna.

setula arising from distal end. M a n dib le (Fig. 62-2). Precoxa scarcely sclerotized, rather weak. Coxa-basis widening apically, furnished with many scattered spinules, forming a short apical process which bears two setae (one seta missing; see Fig. 62-6). Both rami one-segmented. Exopodite armed with two widely spaced inner setae and two apical setae; all setae bearing hairlike spinules sparsely. Endopodite segment bigger than exopodite segment, armed with one seta on about the middle of inner edge, four juxtaposed setae on subapical inner edge, and two setae apically. Maxillula (Fig. 62-3) atrophied, weak. Although arthrite 

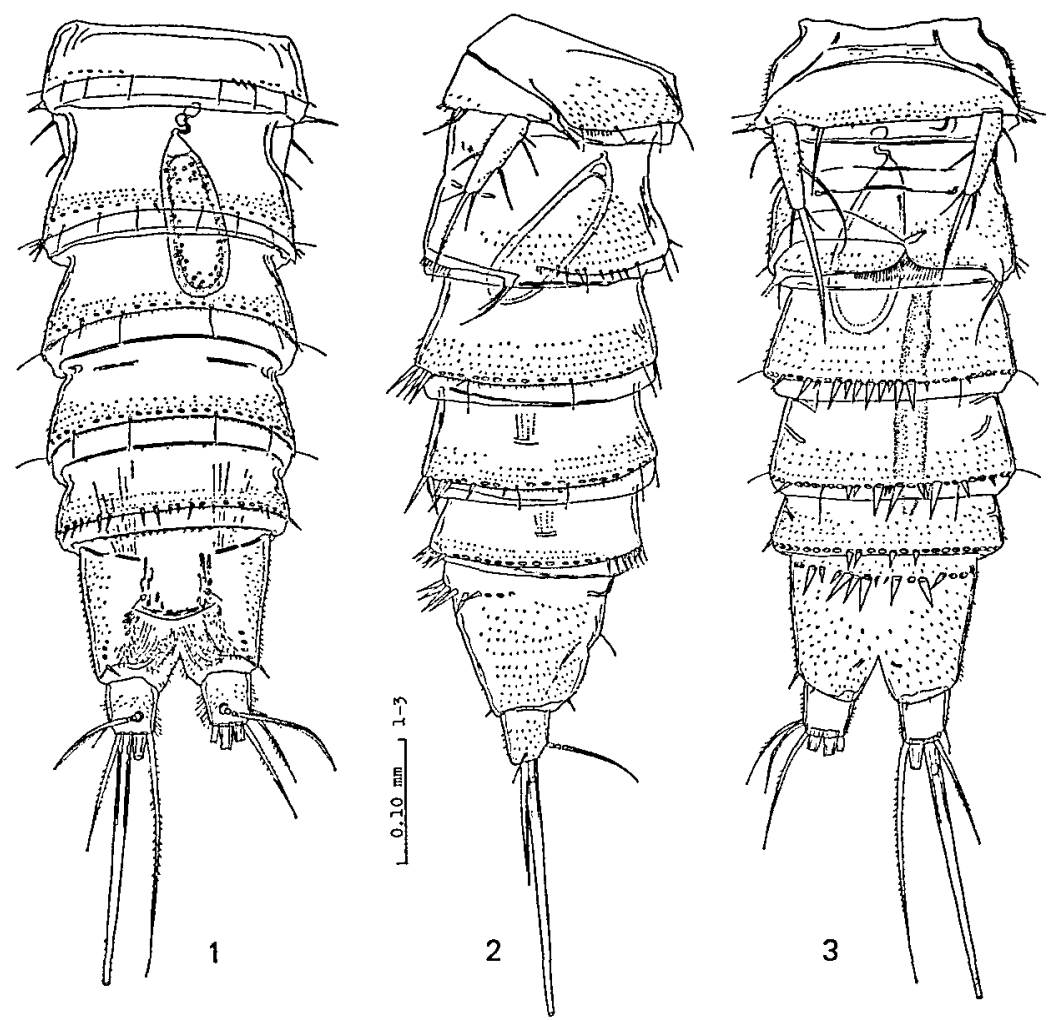

Fig. 61. Abyssameira reducta n. gen., n. sp. Male (holotype): 1. leg 5 and abdomen, dorsal; 2. leg 5 and abdmen, lateral; 3. leg 5 and abdomen, ventral.

of precoxa and a short cylindrical process with two apical setae were detected, detailed structure could not be traced since its contrast was very low. Maxilla (Fig. 62-4) atrophied, very weak. Although several slender setae were detected, detailed structure could not be traced. Maxillipede (Fig. 62-5) not rising from ventral face of cephalothorax but placed horizontally toward anterior (hence, scarcely visible in lateral view: see Fig. 60-2), weak. Coxa short. Basis twice as long as wide, with scattered fine spinules, armed with one seta on subapical inner edge. First endopodite segment about 1.5 times as long as basis, tapering apically, with spinules on inner edge. Second endopodite segment forming a sinuate elongate spine (not rigid) accompanied with one seta.

L e g 1 (Fig. 63-1). Intercoxal plate very low and wide. Coxa as long as wide, with spinules on outer edge and anterior face. Basis with spinules on inner edge and rounded edge between exopodite and endopodite, armed with one outer spine and one inner spine. Both rami three-segmented. Exopodite segments subequal in length, with spinules on each outer edge, hairs on each inner edge; first segment tapering proximally, armed with one outer spine; second segment armed with one outer spine and one hairy inner seta subapically; third segment armed 


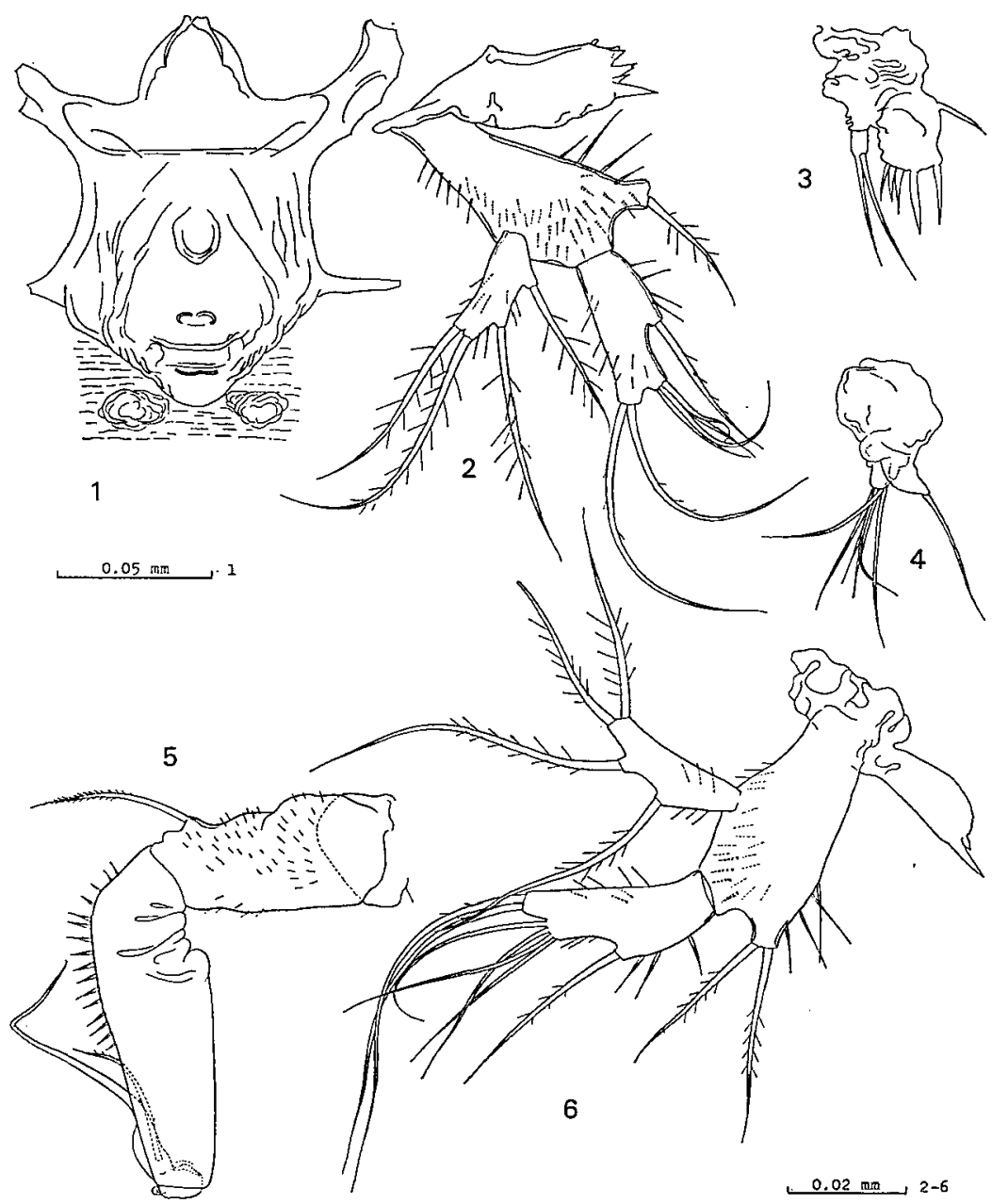

Fig. 62. Abyssameira reducta n. gen., n. sp. Male. Holotype: 1. ventral view of labrum and paragnaths in situ; 2 . mandible; 3 . maxillula (not precisely traced); 4. maxilla (not precisely traced); 5. maxillipede. Paratype: 6. mandible.

with three outer spines, the first (proximal) two widely spaced, two setae apically and subapically, which are finely spinulose outwards and hairy inwards; all outer spines furnished with minute spinules. Three endopodite segments combined as long as three exopodite segments combined; segments subequal in length; first segment with spinules on anterior face along distal edge, armed with one inner seta almost medially; second segment slimmer than first segment, armed with one inner seta subapically; third segment slimmer than second segment, armed with one finely spinulose outer spine on a stepped subapical edge, two apical setae, the outer bearing fine spinules outwards; all setae bearing hairs sparsely; each segment with spinules on each outer edge; apical two segments with hairs on each inner edge. L e g 2 (Fig. 63-2). Intercoxal plate low and wide, moderately arched, with several 


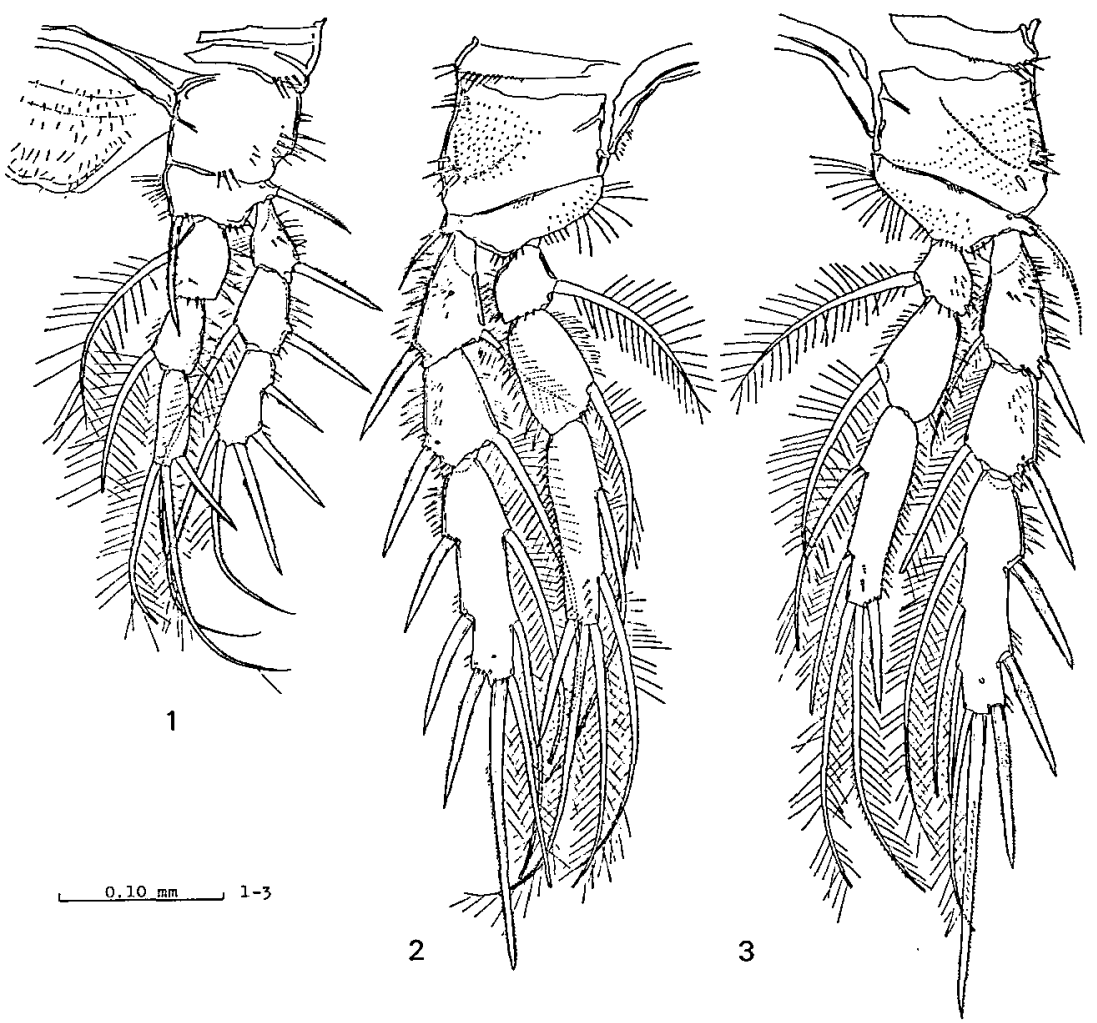

Fig. 63. Abyssameira reducta n. gen., n. sp. Male (holotype): 1. leg 1; 2. $\operatorname{leg} 2 ; 3 . \operatorname{leg} 3$.

short hairs on free edge near each lateral end. Coxa with short scattered hairs on anterior face, spinules on anterior and posterior faces along outer edge. Demarcation between coxa and basis inclining. Basis forming no spinous projection between exopodite and endopodite, furnished with short scattered spinules on anterior face, hairs on inner distal edge, armed with one short outer seta which bears short spinules. Both rami three-segmented. Exopodite: first two segments subequal in length, widening apically, with fine scattered spinules on each posterior face, hairs on each inner edge, each armed with one outer spine and one inner seta; third segment about as long as first two segments combined, armed with three outer spines, two inner setae, and one outer terminal spine and one inner terminal seta; all spines bearing very fine spinules marginally and posteriorly; all setae bearing hairs bilaterally; all segments with spinules on each outer edge. Endopodite shorter than exopodite; first segment short, as long as wide, armed with one inner seta subapically; second segment about twice as long as first segment, a little widening subapically, armed with one inner seta subapically; third segment as long as first two segments combined, armed with one outer spine subapically, two terminal setae, and two widely spaced inner setae; all inner setae bearing hairs; outer terminal seta bearing spinules together with hairs; all segment with spinules on each 

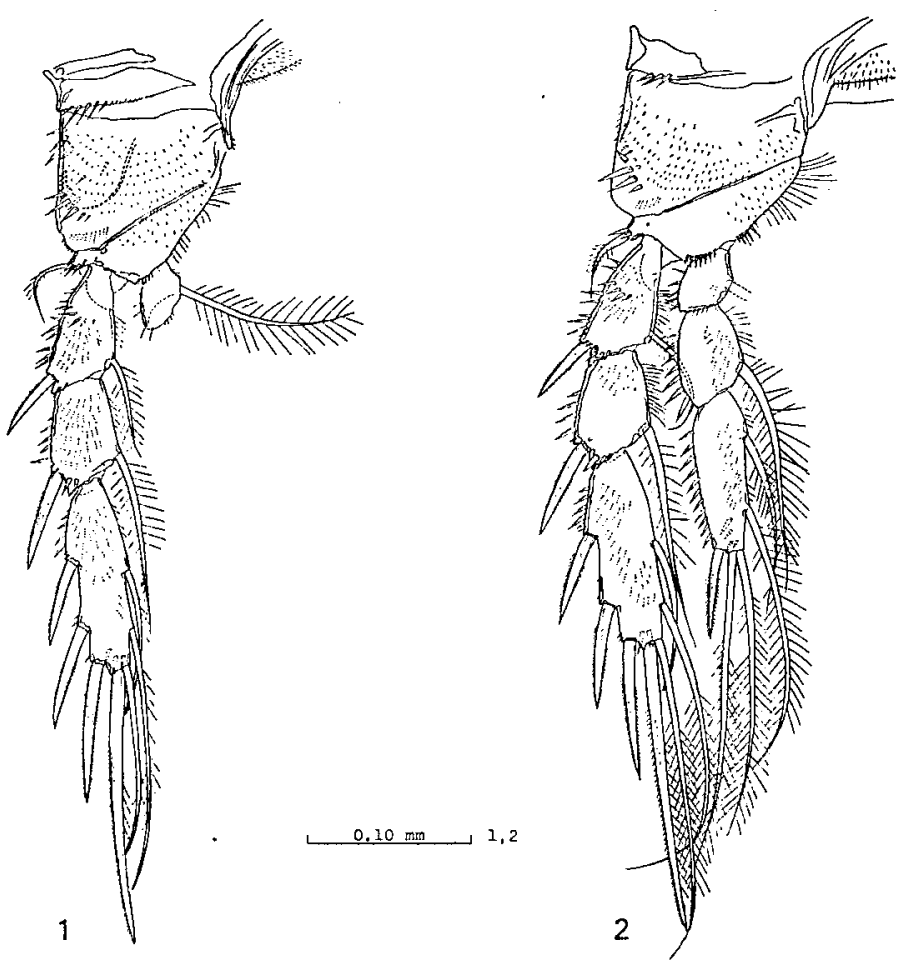

Fig. 64. Abyssameira reducta n. gen., n. sp. Male. Holotype: 1. leg 4 (endopodite broken). Paratype: 2. leg 4.

outer edge. L e g 3 (Fig. 63-3). Third exopodite segment armed with three inner setae. Other principal armature and segmentation as in leg 2. L e g 4 (Fig. 641). Coxa, basis, and exopodite almost as in leg 2, with numerous scattered spinules posteriorly. Endopodite was broken (also in the left leg), and the apical two segments were missing: first segment short, armed with one innerseta. L e g 5 (Figs. 65-1, 65-2). Both baseoendopodites represented by a broad common plate (broken during dissection: see Fig. 65-3); a seta arising from a cylindrical process on each outer extremity; two closely set setae on distal edge near each exopodite. Right exopodite (Fig. 65-1) consisting of one elongate segment, about four times as long as its basal width, tapering apically, armed with three widely spaced outer setae, the distalmost located subapically, one spinulose terminal seta, which is stout and longer than this segment, one small seta on subapical inner edge, and one long seta on about the middle of inner edge; a short seta-like structure, which is very transparent, attached onto anterior face near base of first outer seta. The left exopodite differs from the right exopodite in the following characteristics: terminal seta as long as this segment; first inner seta not particularly elongate. L e g 6 (Fig. 61-3). Left leg fused with body, right leg represented by a wide plate clearly demarcated from body. Two setulae arising from a small process at each outer extremity. 


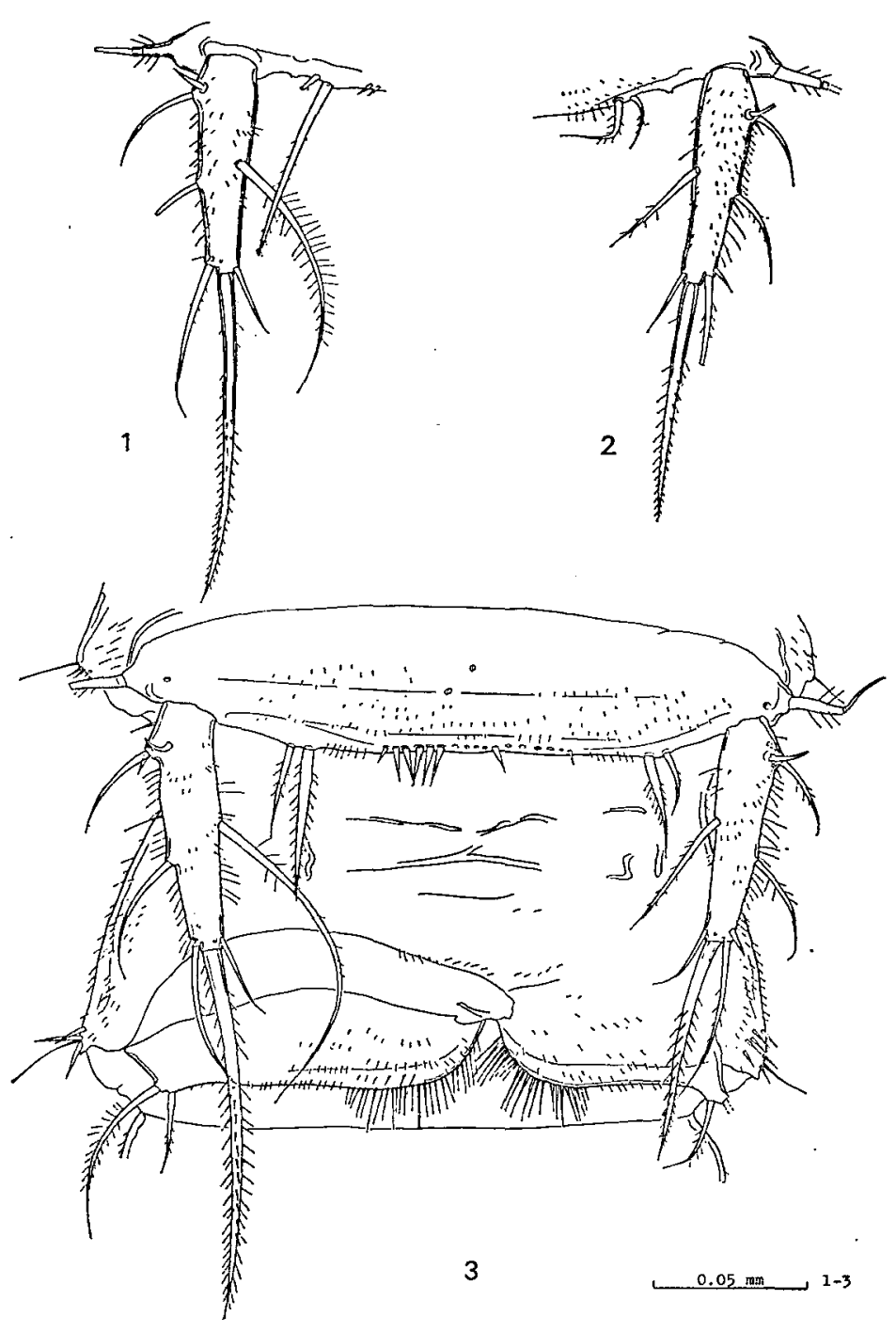

Fig. 65. Abyssameira reducta n. gen., n. sp. Male. Holotype: 1. leg 5; 2. leg 5. Paratype: $3 . \operatorname{leg} 5$ and leg 6 in situ.

Notes on the paratypes and variability. The paratypic males are about $1.4 \mathrm{~mm}$ long, have a well-developed spermatophore inside abdomen. The paratypes accord with the holotype in the asymmetrical nature of the leg 5 and leg 6 (see Fig. 65-3). These specimens show that the principal armature of the endopodite of leg 4 accords with that of the leg 3 as well as leg 2 (see Fig. 64-2).

Remarks. According to Lang's keys to the genera of Ameiridae (Lang, 1948, p. 785, and 1965, p. 339), the present new genus runs to the genus Ameiropsis. The new genus, however, is clearly discernible from Ameiropsis because its endopodite of the leg 1 is composed of three segments which are subequal in length, whilst the 
counterpart of the latter is rather prehensile, and is composed of an elongate proximal segment and two short apical segments. The general shape of the leg 1 is similar rather to those of Pseudameira and certain species of Sarsameira (for example, S. sarsi Lang, 1948).

One of the most remarkable characteristics of the males of the present new species would be the degenerative nature in the oral appendages as well as digestive tract (The specific name alludes this nature.). It would not seem to me that they can eat. In fact, I obtained some other specimens which are not yet dissected, and found that they were all the male. This species might be commensal or parasitic, and it is highly probable that only the adult male can swim freely for reproduction without feeding activity. This probability must be ascertained by further studies.

\section{REFERENCES}

Papers which were not directly consulted but cited from Lang's monograph (1948) are not listed below.

Becker, K.-H. 1974. Eidonomie und Taxonomie abyssaler Harpacticoidea (Crustacea, Copepoda).

Teil I. Cerviniidae-Ameiridae. "Meteor" Forsch.-Ergebn., D, 18: 1-28.

Brotzkaja, V.A. (Brodskaja, V.A.) 1963. A survey of the family Cerviniidae (Crustacea, Copepoda). Zool. Zhurn., 42: 1785-1807. (In Russian.)

Coull, B.C. 1973. Meiobenthic Harpacticoida (Crustacea, Copopoda) from the deep sea off North

Carolina II. The family Cerviniidae Sars, Lang. Trans. Amer. micros. Soc., 92: 198-208.

Drzycimski, I. 1968. Drei neue Harpacticoida aus West-norwegen. Sarsia, 36: 55-64.

Itô, T. 1982. Harpacticoid copepods from the Pacific abyssal off Mindanao. I. Cerviniidae. J. Fac.

Sci. Hokkaido Univ., Ser. VI, 23: 63-127.

Lang, K. 1936. Die Während der schwedischen Expedition nach Spitzbergen 1898 und nach Grönland 1899 eingesammelten Harpacticiden. Kungl. sv. vet. Akad. Handl., Tredje Ser., 15 (4): $1-55$.

— 1 1948. Monographie der Harpacticiden. 1682 pp. Hakan ohlssons Boktryckeri. Lund.

1965. Copepoda Harpacticoidea from the Californian Pacific coast. Kungl. sv. vet. Akad. Handl., Fjarde Ser., 10 (2): 1-560, pls. 1-6.

Montagna, P.A. 1979. Cervinia langi n. sp. and Pseudocervinia magna (Copepoda: Harpacticoida) from the Beaufort Sea (Alaska, USA). Trans. Amer. micros. Soc., 98: 77-88.

- 1980. Two new bathyal species of Pseudotachidius (Copepoda: Harpacticoida) from the Beaufort Sea (Alaska, U.S.A.). J. nat. Hist., 14: 567-578.

- 1981. A new species and a new genus of Cerviniidae (Copepoda: Harpacticoida) from the Beaufort Sea, with a revision of the familv. Proc. biol. Soc. Wash., 93: 1204-1219.

Por, F.D. 1964. A study of the Levantine and Pontic Harpacticoida (Crustacea, Copepoda). Zool. Verhandel., 64: 1-128.

1967. Level bottom Harpacticoida (Crustacea, Copepoda) from Elat (Red Sea), part I. Israel J. Zool., 16: 101-165.

- 1969. Deep-sea Cerviniidae (Copepoda: Harpacticoida) from the Western Indian Ocean, collected with R/V Anton Bruun in 1964. Smiths. Contr. Zool., 29: 1-60.

Sars, G.O. 1903-1911. Copepoda Harpacticoida. An account of Crustacea of Norway. Vol. V. Bergen Mus. Bergen.

Scott, T. 1901. Notes on gatherings of Crustacea, collected for the most part by the fishery steamer "Ga:land" and the steam trawler "St. Andrew" of Aberdeen, and examined during the year 1900. 19th Ann. Rep. fish. Board Scotland, Pt. III: 235-280, pls. 17-18. 
Smirnov, S. 1946. New species of Copepoda-Harpacticoida from the northern Arctic Ocean. Trud. Dreif. Eksped. Glavs. Ledok. Parak. "G. Sedov", 1930-40, 3: 231-263. (In Russian with English summary.)

Soyer, J. 1970. Contribution a l'étude des Copépodes Harpacticoldes de Mediterranée occidentale. 1.-Cerviniidae Sars, Lang. Vie Milieu, B, 20: 367-386. 